\title{
The international dimension of a fragile EMU
}

\section{Demosthenes Ioannou $^{a}$, Maria Sole Pagliari ${ }^{\mathrm{b}}$ and Livio Stracca ${ }^{a}$}

\author{
December 2020, WP 795
}

\begin{abstract}
This paper quantifies the economic influence that shocks to EMU cohesion, which in turn reflect the incomplete nature of the monetary union, have on the rest of the world, by disentangling euro area stress shocks and global risk aversion shocks on the basis of a combination of sign, magnitude and narrative restrictions in a daily Structural Vector Autoregression (VAR) model with financial variables. We find that the effects of euro area stress shocks are significant not only for the euro area but also for the rest of the world. Notably, an increase in euro area stress entails a slowdown of economic activity in the rest of the world, as well as a fall in imports/exports of both the euro area and the rest of the world. A decrease in euro area stress has somewhat more widespread beneficial effects on both economic performance and global trade activity.
\end{abstract}

Keywords: Economic and Monetary Union, Bayesian SVAR, narrative sign restrictions, panel local projections

JEL classification: C23, C32, F02, F33

We thank Michael Bordo, Roberto De Santis, Massimo Ferrari, Georgios Georgiadis, Jean-Francois Jamet, Arnaud Mehl, Fabio Panetta, seminar participants at the European Central Bank and at the Banque de France, as well as an anonymous referee for useful discussion and comments. We also thank Hannah Engljaehringer for excellent research assistance. All remaining errors are our own.

a European Central Bank, demosthenes.ioannou@ecb.europa.eu, livio.stracca@,ecb.europa.eu.

b Banque de France, maria-sole.pagliari@,banque-france.fr.

Working Papers reflect the opinions of the authors and do not necessarily express the views of the Banque de France and of the European Central Bank. This document is available on publications.banque-france.fr/en 


\section{NON-TECHNICAL SUMMARY}

Since the global financial crisis of 2007-08 and the ensuing crisis in the euro area of 20102012, the "completion" or deepening of the European Economic and Monetary Union (EMU) has been a matter of an extensive and sometimes controversial debate. Already during and soon after that crisis, European Union policy makers announced and then took some significant steps to deepen the EMU ${ }^{c}$. The ECB, for its part and in pursuit of its mandate, also took extraordinary steps during the crisis by implementing some non-standard measures, which have underlined its willingness to act as an appropriate lender of last resort.

Nevertheless, this process of EMU deepening has not been always smooth and remains incomplete. It has implied de facto variations in the degree of EMU cohesion over time. The process was also pursued largely with an inward-looking perspective that mostly neglected, at least explicitly, the external, or international, dimension.

The premise has been that the completion of EMU, apart from making the euro area more resilient to global shocks, will also benefit the global economy. While this is true overall according to our findings, the process of completing EMU has entailed both advances and setbacks, with differentiated effects on advanced economies on the one hand and emerging economies on the other. At the same time, global (risk aversion) shocks as well significantly affect the euro area economy, thus implying the need for more EMU cohesion.

The identification of the various shocks, that is, their origin (euro area or global), the extent to which they are significant and for which part of the global economy, as well as the magnitude of their economic impact, has been a matter of debate in the literature. In this regard, three noteworthy aspects of this paper relate to i) constructing an appropriate, highfrequency measure of EMU cohesion, which we call EASTR (for euro area stress) and which relies on government bond spreads; ii) making use of appropriate (sign, magnitude and narrative) restrictions in a Bayesian structural VAR model to correctly and fully identify the relevant shocks and iii) measuring more precisely, through panel local projections, the macroeconomic impact of shocks in terms of output, trade and inflation. We find that shocks emanating in the euro area have sizeable effects: a one standard deviation increase in euro area stress entails a slowdown of economic activity in the rest of the world, with industrial production dropping by $0.83 \mathrm{pps}$ on average in advanced economies and $0.33 \mathrm{pps}$ in emerging economies over a 12-month horizon. The same shock also entails a significant fall in imports/exports of both the euro area and the rest of the world. By contrast, a release of euro area stress has more long-lasting effects on both economic performance and global trade activity, with an average yearly boost of industrial production by $0.733 \mathrm{pps}$ in advanced economies and 0.453 pps in emerging markets over the first year.

Although our cut-off date for data is August 2019, our findings also speak to the renewed debate over EMU completion following the massive economic shock resulting from the outbreak of the corona virus pandemic. We believe our approach is well suited in delineating specific shocks during this crisis and identifying the magnitude of their impact ${ }^{\mathrm{d}}$

\footnotetext{
${ }^{c}$ For example, in 2012 the decision was taken to create the banking union with single European supervision residing at the ECB, and to advance bank resolution arrangements at the European level through the Single Resolution Mechanism (SRM) and the Single Resolution Fund (SRF). These steps went hand in hand with significant changes in the regulations pertaining to the bail-in of banks' creditors (e.g., the BRRD). Another step consisted of the establishment of regional safety net institutions, such as the European Financial Stabilisation Mechanism (EFSM), the European Financial Stability Facility (EFSF), and finally the European Stability Mechanism (ESM).

dSee the VoxEU column "The international dimension of a fragile EMU" for an application of our approach to the Covid-19 crisis.
} 
Figure: Impulse responses to a one s.d. negative (blue) and positive (red) euro area stress shock
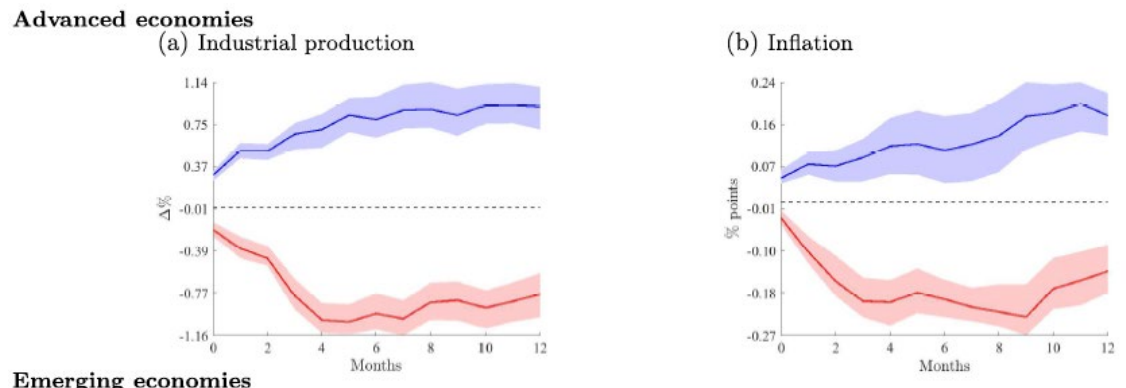

(c) Industrial production

(d) Inflation
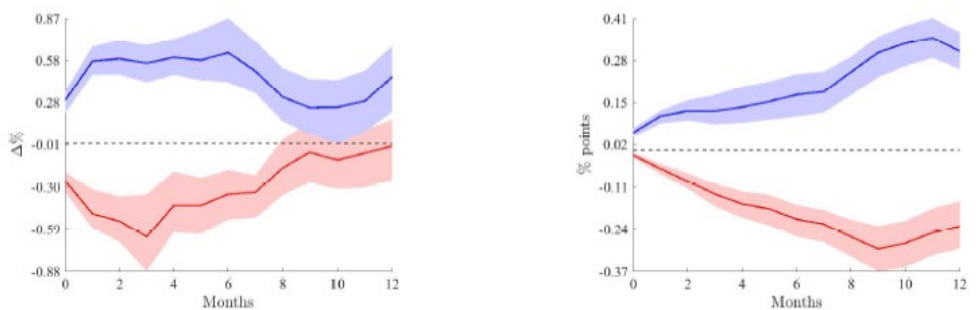

Notes: Inflation is defined as the y-o-y percentage change of the CPI. Shaded areas are $68 \%$ HPD credible sets.

\section{La dimension internationale d'une UEM fragile}

\section{RÉSUMÉ}

Ce document de travail quantifie l'influence économique que les chocs sur la cohésion de l'UEM, qui à leur tour reflètent la nature incomplète de l'union monétaire, ont sur le reste du monde en démêlant les chocs de stress de la zone euro et les chocs mondiaux d'aversion au risque sur la base d'une combinaison de restrictions de signe, d'ampleur et narratives dans un modèle d'autorégression vectorielle structurelle (VAR) quotidien avec des variables financières. Nous constatons que les effets des chocs de stress de la zone euro sont significatifs non seulement pour la zone euro mais aussi pour le reste du monde. En particulier, une augmentation des tensions dans la zone euro entraîne un ralentissement de l'activité économique dans le reste du monde, ainsi qu'une baisse des importations/exportations de la zone euro et du reste du monde. Une diminution du stress dans la zone euro a des effets bénéfiques un peu plus étendus sur les performances économiques et l'activité commerciale mondiale.

Mots-clés : Union économique et monétaire, SVAR bayésien, restrictions des signes narratives, projections locales

Les Documents de travail reflètent les idées personnelles de leurs auteurs et n'expriment pas nécessairement la position de la Banque de France. Ils sont disponibles sur publications.banque-france.fr 


\section{Introduction $^{1}$}

[...in this] world where challenges are global, we've got to be together to be truly sovereign, to be true masters of our destinies, because on our own we would have no way to cope with these global challenges. The evidence is in front of our eyes every day. (Draghi (2019)).

Since the introduction of the euro, twenty years ago, both the global economy and the euro area (EA) economy have changed considerably as has the interaction between the two. On the one hand, the European Union (EU) has become not only the largest global trading block, handling $17.3 \%$ of world trade ${ }^{2}$, but also a monetary union, whose currency has rapidly become the second most important in the international monetary system (see ECB IRE 2020). On the other hand, the international economy has experienced some dramatic changes, mainly driven by globalization and the rise of the so-called emerging market economies ${ }^{3}$. Moreover, these trends have been accompanied by a continued increase in financial integration, which has only slightly slowed down after the Great Financial Crisis (GFC), and a greater global correlation between real and financial macro-variables (see Ca' Zorzi et al. (2019)).

In light of these facts, the rich and controversial debate on EMU deepening ${ }^{4}$ needs to take into account how such a process affects and is affected by rising global economic change and integration. Notably, the debate needs to consider the international impact that an increase in the depth of European integration and an improvement in its quality (henceforth "EMU cohesion") would likely exert on the rest of the world. From a policy perspective, this analysis can help clarify the potential effects stemming from progress, or alternatively, a slowdown in the enhancement of EMU functioning, the latter being defined by the further development of micro- and macroeconomic policy tools, as well as institutions, presented in the Four Presidents' Report (2012) and Five Presidents' Report (2015) $)^{5}$. Such an investigation becomes even more pressing in light of the risks stemming from the recent rise in protectionism and a potential reversal in the multilateral development of the international economic order ${ }^{6}$.

However, providing an answer to this research question is not an easy task in that, beyond the

\footnotetext{
${ }^{1} \mathrm{~A}$ previous version of this paper has been released with the title "The international dimension of an incomplete EMU" on the ECB Working Paper Series (N. 2459, https://www.ecb.europa.eu/pub/pdf/scpwps/ecb. wp2459 1530e6d2d9.en.pdf).

${ }^{2}$ Excluding intra-EU trade, as reported by EC DG Trade 2019.

${ }^{3}$ According to IMF WEO 2019, the ratio between the world GDP share of advanced economies and that of emerging markets will be $36 / 63$ by 2024 .

${ }^{4}$ See Pisani-Ferry and Zettelmeyer (2019) for a collection of policy-oriented articles by academic observers.

${ }^{5}$ The two reports postulate that the completion of EMU should rely on four unions developed in parallel: financial (including banking and capital markets union (CMU)), fiscal, economic and political.

${ }^{6}$ As pointed out in Corsetti (2015): "The future of the Eurozone (EZ) therefore rests on developing an institutional framework that can credibly deliver stability at the EZ level."
} 
incomplete nature of EMU, the two processes of European and international integration have been deeply intertwined, with the direction of causality often running both ways and, hence, being difficult to identify. Against this backdrop, and given the complexity of the process, this paper contributes to the ongoing debate by focusing on the effects that stress shocks in the EMU, arising from the degree of its completion, might exert on the rest of the world (RoW). In this sense, we refer here to the "international dimension of an incomplete EMU" 7 . While this international dimension is only one of many as regards EMU deepening, ${ }^{8}$ an investigation of the channel of EMU shock transmission to the global economy can help inform the current policy discussions.

Conceptually, our paper builds on two main streams of research: i) the strand of literature aiming at quantifying the cross-border transmission of macroeconomic shocks ${ }^{9}$ and, in particular, of monetary policy shocks ${ }^{10}$; ii) the papers focusing on crises periods to evaluate the international spillovers of the euro area crisis. Among the latter, Stracca (2015) shows that the global repercussions of the euro area crisis have mainly impacted the financial sector via a fall in equity returns, which has been more pronounced for countries with higher trade exposure to the euro area and a currency pegged to the euro, as well as for non-EA members of the $\mathrm{EU}^{11}$. In a similar vein, Aizenman et al. (2012) show that the effects of the euro area crisis in emerging economies are generally smaller than the responses to the global financial crisis. On the other hand, Ahmad et al. (2013) find that the transmission of shocks from the peripheral euro area economies to the emerging markets can feature either contagion (e.g. in the case of the BRICS) or interdependence (e.g. for Indonesia and South Korea) ${ }^{12}$. With a somewhat different focus, Claessens et al. (2011) analyse the behavior of firm-level stock returns of EU and non-EU companies and find that the effects of euro area crisis events ultimately depend on a series of country and firm-level characteristics.

Differently from these contributions, our empirical strategy firstly aims at quantifying the changes in the cohesion of the euro area economy as a whole, both in crisis and non-crisis periods. Specifically, we construct a Structural Vector Autoregressive model with euro area and global financial variables where shocks to EMU cohesion ("euro area stress shocks") are disentangled from "external" shocks, i.e. shocks originating outside of the euro area, by means

\footnotetext{
${ }^{7}$ This aspect can be put in perspective against the Four Presidents' Report and the Five Presidents' Report, as the two reports remain largely silent on the international dimension of EMU completion apart from a call for the consolidation of the euro area's external representation.

${ }^{8}$ In this regard, in Section 2.1 below we link our EMU stress variable also to a synthetic index of EMU institutional deepening, the EURII.

${ }^{9}$ See Dungey et al. (2011) and Forbes (2012) for a survey.

${ }^{10}$ See, among others, Forbes et al. (2017)) and Chen et al. (2017).

${ }^{11}$ Allegret et al. (2017) provide similar results using a Smooth Transition Regression (STR) framework.

${ }^{12}$ Similarly, Bird et al. (2017) disentangle between contagion and safe-haven effects, when evaluating the spillovers of the euro area sovereign debt crisis onto the non-EA neighbours.
} 
of sign, magnitude and narrative restrictions. This approach, which is novel in the literature studying the effects of the euro area crisis, successfully teases out shocks that originate inside the euro area from global risk aversion shocks, in spite of the fact that they are qualitatively very similar.

In a second step, we produce an assessment of the broader macroeconomic implications that these types of shocks can have. Notably, we show that euro area stress shocks negatively impact the economic activity of the RoW and entail a temporary slowdown in global trade whose magnitude can become substantial if no corrective action is undertaken. To the best of our knowledge, a quantification of EA cohesion spillovers on to extra-EA economies is an original contribution to the existing research ${ }^{13}$.

The remainder of the paper is structured as follows: Section 2 introduces the methodology that we use to isolate "euro area stress shocks" and presents the main results; Section 3 quantifies the effects that these shocks have on the RoW from a macroeconomic perspective; Section 4 concludes.

\section{Methodology}

Our empirical approach consists of two main building blocks: i) we estimate a daily SVAR, with sign, magnitude and narrative restrictions, in order to tease out euro area stress shocks (Section 2.2 ) ; ii) we assess the effects that such shocks have on a set of macroeconomic variables for the RoW by means of panel local projections (Section 3). Before proceeding to i), however, we first construct a quantitative measure of EMU cohesion to be used to identify euro area stress shocks (Section 2.1).

\subsection{The proxy for euro area financial cohesion (EASTR)}

The proxy for EMU cohesion (EASTR henceforth) is given by the average 10-year government bond spread between Italy and Spain on the one hand and Germany on the other. This definition essentially relates the degree of cohesion among the euro area Member States to the stress of their sovereign bond markets relative to the benchmark (Germany) ${ }^{14}$. The choice of average sovereign spreads as stress indicators for euro area cohesion is supported by a series of stylized facts and empirical evidence provided by the relevant literature. While a non-zero bond yield spread may be seen as normal in a monetary union in the presence of country-specific

\footnotetext{
${ }^{13}$ Most of the related literature, indeed, mainly focuses on the macroeconomic repercussions that the euro area crisis had on its Member States. In this regard, see Neri and Ropele (2015)

${ }^{14}$ The measure excludes countries that had temporarily lost market access during the financial crisis to control for idiosyncratic movements in sovereign spreads.
} 
macroeconomic conditions and policies, large and abrupt fluctuations of bond spreads may be interpreted as a demand for higher risk premia on the part of market participants because of uncertainty arising from the incomplete nature of EMU. Such premia vis-à-vis the benchmark sovereign exhibiting safe haven status during peak stress moments, i.e. the German Bund, are not necessarily linked to the macroeconomic fundamentals of individual euro area Member States.

In this regard, Attinasi et al. (2009) show that the increase in euro area sovereign spreads over the period 2008-2009 was due to a reassessment on the part of investors of sovereign risk following the announcements of several bank rescue packages which initiated the bank-sovereign nexus. Di Cesare et al. (2012) find that the high levels of sovereign yields over the period 2011-2012 in several euro area countries were mainly due to an increase in the perceived risk of a break-up of the euro area, rather than to macroeconomic and fiscal developments ${ }^{15}$. Similarly, De Grauwe and Ji (2013) show that a significant part of the surge in the spreads of the peripheral euro area economies during 2010-2011 was not linked to the deterioration of the underlying fundamentals, but it was rather determined by strong negative self-fulfilling market sentiments as of the end of 2010 linked to "the fragility of the Eurozone". Afonso et al. (2018) find that the OMT announcement in August 2012 marked a regime shift in the pricing of sovereign bonds in the euro area, whereby the link between sovereign spreads and fundamentals has grown weaker, while spreads and re-denomination risk have become relatively higher compared to the pre-crisis period ${ }^{16}$. Born et al. (2020) get to fairly similar conclusions when assessing the transmission of spread shocks to a set of macroeconomic fundamentals both in advanced and emerging economies. However, they also provide evidence of a stronger link between the volatility of sovereign spreads and macroeconomic shocks in advanced economies after 2008. Finally, Bahaj (2020) deploys a narrative identification strategy based on a set of foreign events during the euro crisis to show that Eurozone sovereign spreads were driven not only by the domestic economic conditions.

On the other hand, some contributions seem to point in a different direction. Krishnamurthy et al. (2017), for instance, show that the ECB's SMP and OMT led to a fall in the sovereign bond yields of Italy, Spain and Portugal which was only partially due to redenomination risk, though focusing on shorter-term yields ${ }^{17}$. The structural relationship between government debt maturity and default vs. redenomination risk is extensively discussed in Bocola and Dovis (2019),

\footnotetext{
${ }^{15}$ De Santis (2012) also shows that a "regional risk factor" is one of the main drivers of the generalized increase in euro area sovereign spreads in 2008-2011.

${ }^{16}$ In this regard, see also von Hagen et al. (2011), Afonso et al. (2014, 2015) and Manganelli and Wolswijk (2014).

${ }^{17}$ This does not seem to have been the case for most recent programmes like the Pandemic Emergency Purchase Programme (PEPP) launched in March 2020.
} 
where it is found that, in the presence of higher roll-over (redenomination) risks, government might find it optimal to issue longer-term debt, whereas the contrary holds true in case of a worsening of fundamentals leading to an increase in default risk. Even if the authors show that most of the movements in Italian spreads between 2011 and 2012 were due to a deterioration of fiscal fundamentals, the results are highly influenced by the initial assumptions and the model is not able to account for a large share of movements in spreads at the height of the sovereign debt crisis. Moreover, in line with some of the above mentioned contributions, as of mid-2012 movements in the spreads of both Italy and Spain have been accompanied by a steady increase in the average debt maturity, which seems to suggest that redenomination risk has played an increasingly relevant role ever since (Figure 1).

Figure 1: Average debt maturity and 10-year spread against Germany for Italy and Spain

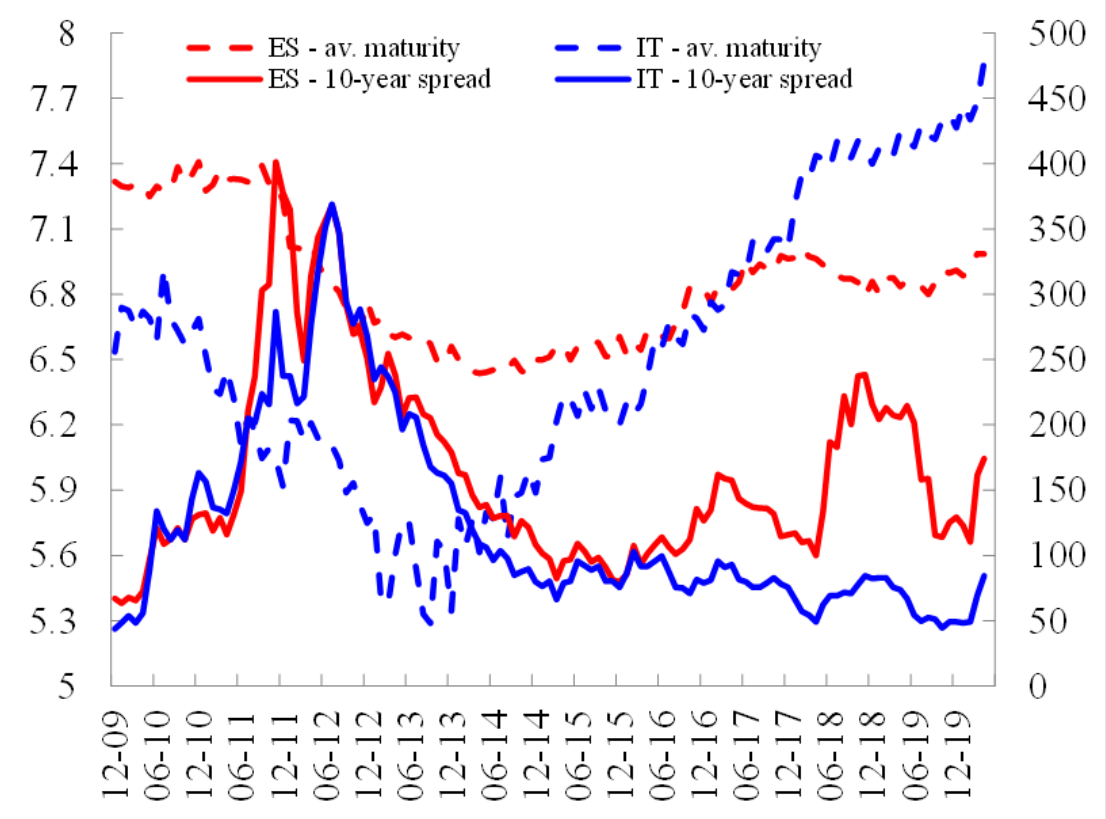

Notes: Debt duration is expressed in years and is plotted on the left-hand scale, while 10-year spreads against the German Bund are plotted on the right-hand scale and indexed with $2010=100$.

Sources: ECB, Haver Analytics and authors' calculations.

Besides the support provided by a part of the existing literature, the EASTR measure is also found to be highly correlated with other commonly-used indicators of within-euro area stress, e.g. the sum of (absolute) TARGET2 balances (Figure 2a) and 5-year CDS premia (Figure 2b), with an estimated correlation coefficient swinging over time between 0.66 (peripheral) and 0.76 (core) for the former and ranging from 0.42 (core bank CDS premia) to 0.89 (peripheral bank CDS premia) for the latter ${ }^{18}$. Moreover, there is also a high degree of co-movement with the redenomination risk measure of De Santis (2019), which is based on 3-year quanto CDS spreads

\footnotetext{
${ }^{18}$ On the relationship between TARGET2 balances and macroeconomic adjustments in the euro area, see Fagan and McNelis (2014). On the use of CDS premia on sovereign and bank bonds as proxy for the sovereign-bank nexus, see De Bruyckere et al. (2013), Angelini et al. (2014), Acharya et al. (2014).
} 
Figure 2: Comparison between EASTR and other indicators.

(a) EASTR vs TARGET2 balances

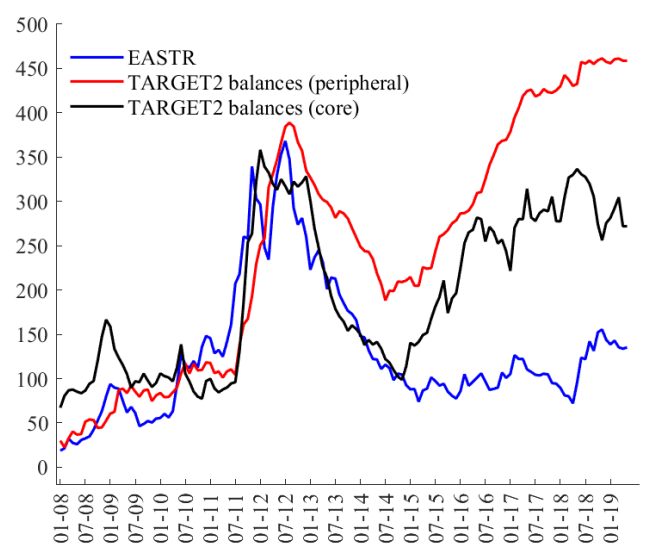

(c) EASTR vs Redenomination Risk

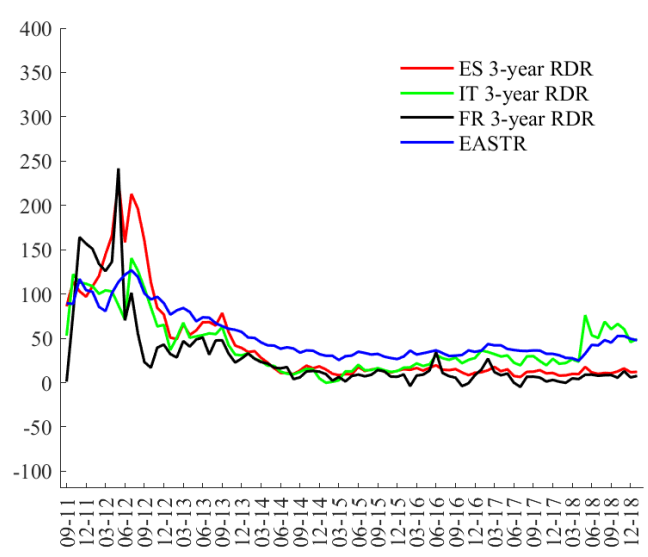

(b) EASTR vs 5-year CDS premia

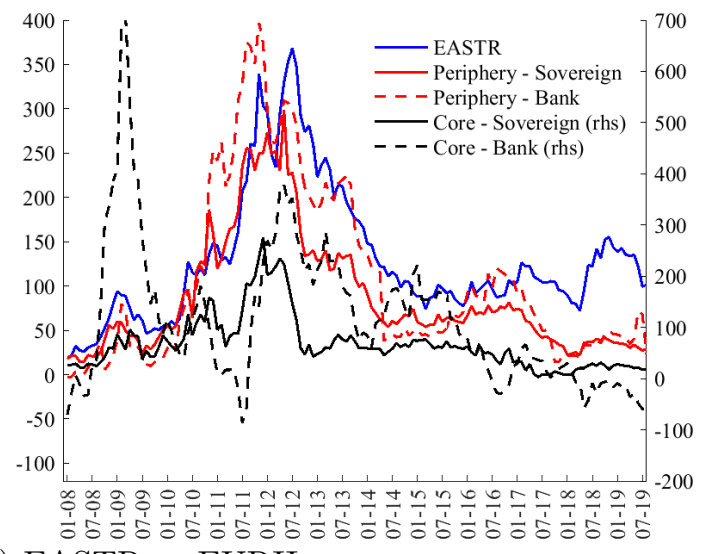

(d) EASTR vs EURII

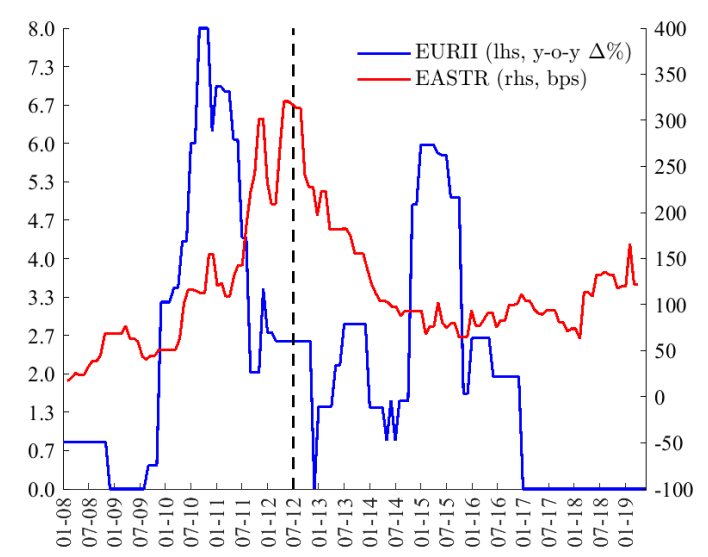

Notes: CDS premia are defined as the 5yr euro-denominated CDS spreads vis-à-vis Germany; redenomination risk is computed using 3-year CDS premia; TARGET2 balances are computed as the sum of absolute values; in Figures $2 \mathrm{a}$ and 2b, EASTR, CDS premia and TARGET2 balances are indexed with $2010=100$; in Figure 2c series are indexed with $2011=100$; in Figure 2d, EURII index is in annual percentage change and the dashed vertical line corresponds to the London speech.

Sources: ECB, Datastream, De Santis (2019) and authors' calculations.

vis-à-vis Germany (Figure 2c) ${ }^{19}$.

The evolution of the EASTR measure is also consistent with the institutional response of the euro area authorities to the financial and the euro area debt crises, as quantified by the European Institutional Integration Index (EURII) which measures the steps of institutional and policy deepening along a comprehensive set of dimensions ${ }^{20}$. Figure $2 \mathrm{~d}$ shows that periods of tension to EMU cohesion corresponding to increases in the EASTR variable (financial crisis of 2007-2009, euro area debt crisis of 2010-12) are followed by increases in the EURII index capturing the implementation of EMU deepening measures such as the establishment of the European Stability Mechanism (ESM) or the setup of the Banking Union through the creation of European banking supervision and resolution (2013-2016). Given all this, the EASTR measure can be interpreted as a high frequency quantitative measure of the completeness (and ultimately viability) of the euro area. It is in this sense, then, that "EMU cohesion" measured by the EASTR proxy needs 
to be interpreted in this paper.

\subsection{The SVAR model}

The first step of our empirical exercise consists of disentangling between shocks to the deepening and cohesion of the euro area coming from inside the euro area itself on the one hand, and external shocks influencing in particular global financing conditions and risk aversion. One can think of singular events during the euro area sovereign debt crisis period 2010-2012 as an example of the former, and peak events during the global financial crisis such as the Lehman Brothers bankruptcy as an instance of the latter. With this aim, we estimate a daily Structural Vector Autoregression model (SVAR) of the following form:

$$
A_{0} Y_{t}=\mathbf{c}+A_{1} Y_{t-1}+\cdots+A_{p} Y_{t-p}+\varepsilon_{t}
$$

where $\varepsilon_{t}$ is a vector of structural shocks which are assumed to be Gaussian with mean zero and variance $I_{N}$, conditional on past information and the initial conditions $\left(Y_{0}, \ldots, Y_{-p}\right)^{21}$. The vector $Y_{t}$ includes seven financial variables, both euro area-based and global: our EASTR measure, the Chicago Board Options Exchange (CBOE) Volatility Index (VIX), the world equity price index excluding the euro area ("RoW equity"), the equity price index for the euro area ("EA equity"), the nominal effective exchange rate of the euro (€NEER), the US 10-year benchmark government bond yield and the spread of JP Morgan's Emerging Market Bond Index Plus (EMBI+) ${ }^{22}$. Data cover the period from January 1999 to August 2019.

We aim at identifying two types of shocks within the SVAR, namely: i) a within-euro area (EA) stress shock influencing the market perception about the long term viability of the monetary union and ii) a more standard global risk shock. Teasing out the two shocks is challenging because within-euro area stress shocks can become global risk shocks for the rest of the world (Stracca (2015)). Following Antolín-Díaz and Rubio-Ramírez (2018), the identification strategy is based on a combination of sign, magnitude and narrative restrictions. The underlying intuition is that global shocks entail generalized fluctuations in the spreads across different regions, which

\footnotetext{
${ }^{19}$ We would like to thank Roberto De Santis for providing the estimated measure of redenomination risk for Spain, Italy and France.

${ }^{20}$ Notably, the EURII includes the following sub-components: Free Trade Area and Customs Union, Supranational institutions and decision-making, Financial Markets Union, Coordination of monetary and exchange rate policies, Democratic legitimacy and accountability, Internal Market, Economic Union, Fiscal Union and Monetary Union (see Dorrucci et al. (2015)).

${ }^{21}$ In what follows, $p$ is set equal to 2 , as indicated by the posterior marginal likelihood. This specification, though parsimonious, is well-suited to capture most of the relevant dynamics, as also indicated by the robustness checks in Section C.3 below.

${ }^{22}$ The VIX, the equity price indexes and the $€$ NEER are included in log terms, while all the variables are demeaned and standardized. An increase in the €NEER means an appreciation of the euro against the main trading partners' currencies. See Appendix A for data sources.
} 
should then move in a similar manner (both direction and magnitude-wise). Therefore, events of positive (negative) global risk aversion shocks on the one hand are partially identified by imposing the restrictions below:

i) there must be an increase (decrease) in the VIX;

ii) the EA stress variable and the EMBI+ spread must both increase (decrease);

iii) the EMBI+ spread must react more than the EA stress variable (magnitude restriction);

iv) the US 10-year government bond yield must decrease (increase).

On the other hand, positive (negative) EA stress shocks are identified as follows:

i) there must be a increase (decrease) in the EA stress variable;

ii) the EA stress variable must react more than the EMBI+ spread (magnitude restriction);

iii) the euro nominal effective exchange rate must depreciate (appreciate).

Table 1 compares the daily changes in the variables of interest around some well-known global and euro area events over the period 2010-2017. The preliminary evidence seems to support the proposed identification scheme.

\subsubsection{Event study}

In order to check that the changes in Table 1 are significant and, hence, that the restrictions to be imposed on the daily SVAR are supported by the data, we perform an event study around those events.

Table 1: Daily changes around selected events

\begin{tabular}{|c|c|c|c|c|c|c|c|c|}
\hline & Date & EA stress & $€ N E E R$ & VIX & EMBI & EA eq. & RoW eq. & US10Y \\
\hline \multicolumn{9}{|l|}{ Global events } \\
\hline Lehman Brothers default & $16 / 09 / 2008$ & 0.65 & -0.46 & 4.06 & 10.67 & -69.66 & -4.19 & -0.02 \\
\hline Taper tantrum & $22 / 05 / 2013$ & 9.60 & -0.01 & 0.18 & 11.67 & -58.23 & -2.88 & -0.02 \\
\hline Chinese stock market bubble burst $^{1}$ & Jun-Aug 2015 & -3.45 & 0.30 & -5.75 & -23.67 & 64.760 & 1.320 & 0.108 \\
\hline \multicolumn{9}{|l|}{ EA events } \\
\hline Greece requests for programme & $23 / 04 / 2010$ & 11.30 & -0.16 & 0.67 & -0.67 & 28.93 & 0.81 & 0.00 \\
\hline Ireland requests for programme & $22 / 11 / 2010$ & 14.50 & -0.56 & 1.86 & 7.00 & -72.06 & -0.30 & -0.03 \\
\hline Spain and Cyprus request for programme & $27 / 06 / 2012$ & 10.95 & -0.27 & 0.25 & 4.00 & -7.99 & 0.15 & -0.04 \\
\hline London speech ${ }^{+}$ & $26 / 07 / 2012$ & -35.05 & 0.16 & -0.75 & -16.33 & 50.18 & 2.05 & 0.11 \\
\hline Greek bailout referendum & $06 / 07 / 2015$ & 3.50 & -0.39 & -0.65 & 4.33 & -71.01 & 3.54 & -0.03 \\
\hline $\mathrm{EG}^{*}$ agrees on Greek third programme & $09 / 07 / 2015$ & -24.30 & 0.66 & -3.02 & -11.33 & 108.78 & -0.05 & 0.08 \\
\hline Brexit referendum & $23 / 06 / 2016$ & 24.65 & -0.63 & 7.98 & 18.00 & -261.77 & -6.07 & -0.19 \\
\hline Sintra speech ${ }^{+}$ & $27 / 06 / 2017$ & -2.35 & 0.77 & -0.97 & 2.00 & -2.62 & -0.05 & 0.02 \\
\hline
\end{tabular}

Notably, we assess the significance of daily changes in the endogenous variables by running the following regression:

$$
\Delta x_{t}=\alpha_{x}+\text { Event }_{t} \beta_{x}+\mathbf{D}_{t} \gamma_{x}+\varepsilon_{x, t},
$$


where $\Delta x_{t}=\left\{\Delta E A S T R_{t}, \Delta E U R N E E R_{t}, \Delta V I X_{t}, \Delta E M B I_{t}, \Delta E A E Q_{t}, \Delta R o W E Q_{t}\right.$, $\left.\Delta U S 10 y r_{t}\right\}$ and Event $_{t}$ is a $1 \times M$ vector of dummy variables that refer to the events in Table 1 . Such dummies are set equal to 1 on the date of the event they are linked to and 0 otherwise. In addition, we include a $1 \times(K+P)$ matrix of control variables, $\mathbf{D}_{t}$, that is partitioned as:

$$
\mathbf{D}_{t}=\left[\mathbf{R}_{t} \mid \mathbf{P}_{t}\right]
$$

where $\mathbf{R}_{t}$ is a $1 \times K$ matrix of dummy variables that are equal to 1 on the date of the release of European macroeconomic data and 0 otherwise, while $\mathbf{P}_{t}$ is a $1 \times P$ matrix including dummy variables that equal 1 on the dates of release of US macroeconomic data, and 0 otherwise. In our setting, we consider 6 macroeconomic releases for the euro area and the US: Consumer Price Index Estimate, Actual Consumer Price Index, Real Gross Domestic Product, Unemployment Rate, Industrial Production and Consumer Confidence Index. The inclusion of these regressors helps us control for possible omitted variable bias, as these events might trigger significant movements in the dependent variables at daily frequency ${ }^{23}$.

The parameter of interest in Equation (2.2) is the $1 \times M$ vector $\beta_{x}$, whose $i$-th element represents the difference between the change in variable $x$ on event day $i$, with $i=1, \ldots, M$, and the average daily change of $x$ on other dates, excluding the events and the release days of other macroeconomic data either in the euro area or US. Therefore, if the $i$-th element of $\hat{\beta}_{x}$ is statistically significant, then event $i$ has a significant effect on $x$. In addition, we check for the joint significance of the elements of $\beta_{x}$ by performing a Wald test with null $H_{0}: \sum_{i=1}^{M} \hat{\beta}_{i, x}=0$. This indicates whether the whole set of events in Event $t$ has a cumulative significant impact on $x$.

Regression results, reported in Table 2, show that changes around the majority of events are highly significant across all the endogenous variables. Moreover, they provide a clear indication on the restrictions to impose on the matrix of contemporaneous relations $\left(A_{0}\right)$ as explained below.

\subsubsection{Baseline identification}

Based on the estimates in Table 2, Table 3 reports the baseline restrictions for $A_{0}{ }^{24}$. It is worth noticing how the magnitude restrictions on the EMBI+ spread are pivotal to pin the shocks

\footnotetext{
${ }^{23}$ This approach draws from the rich literature using event studies to assess the effects of conventional and unconventional monetary policies (see, among others, Altavilla et al. (2016), Altavilla and Giannone (2017), Lloyd (2017)).

${ }^{24}$ The number of restrictions imposed is more than what would be required to identify the two shocks. However, part of the literature has underlined the importance of implementing all the theoretically plausible restrictions to pin down the shocks of interest (see, among others, Baumeister and Benati (2013)).
} 
Table 2: Significance of daily changes around global and European events

\begin{tabular}{|c|c|c|c|c|c|c|c|}
\hline & EA stress & €NEER & VIX & EMBI & EA eq. & RoW eq. & 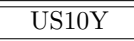 \\
\hline \multicolumn{8}{|l|}{ Global events } \\
\hline Lehman Brothers default & $\begin{array}{c}0.13 \\
(0.15)\end{array}$ & $\begin{array}{c}-1.282^{* * *} \\
(0.00)\end{array}$ & $\begin{array}{c}\mathbf{2 . 9 7 1} \text { *** } \\
(0.00)\end{array}$ & $\begin{array}{c}1.246^{* * *} \\
(0.00)\end{array}$ & $\begin{array}{c}-1.470^{* * *} \\
(0.00)\end{array}$ & $\begin{array}{c}-\mathbf{2 . 5 3 7} * * * \\
(0.00)\end{array}$ & $\begin{array}{c}-\mathbf{0 . 2 7 3} * * * \\
(0.01)\end{array}$ \\
\hline Taper tantrum & $\begin{array}{c}1.257^{* * *} \\
(0.00)\end{array}$ & $\begin{array}{c}-\mathbf{0 . 0 5 7} * * * \\
(0.00)\end{array}$ & $\begin{array}{c}\mathbf{0 . 1 6 2} \text { *** } \\
(0.00)\end{array}$ & $\begin{array}{c}1.336^{* * *} \\
(0.00)\end{array}$ & $\begin{array}{c}-\mathbf{1 . 3 2 8} \\
(0.00)\end{array}$ & $\begin{array}{c}-\mathbf{1 . 7 6 4} * * * \\
(0.00)\end{array}$ & $\begin{array}{c}-\mathbf{0 . 4 0 6} \mathbf{6}^{* * *} \\
(0.00)\end{array}$ \\
\hline Chinese stock market bubble burst & $\begin{array}{c}-\mathbf{0 . 4 6 0} * * * \\
(0.00)\end{array}$ & $\begin{array}{c}\mathbf{0 . 6 9 2} * * * \\
(0.00)\end{array}$ & $\begin{array}{c}-4.083^{* * *} \\
(0.00)\end{array}$ & $\begin{array}{c}-\mathbf{2 . 6 8 4 ^ { * * * }} \\
(0.00)\end{array}$ & $\begin{array}{c}1.492^{* * *} \\
(0.00)\end{array}$ & $\begin{array}{c}\mathbf{0 . 7 4 3} \text { *** } \\
(0.00)\end{array}$ & $\begin{array}{c}1.871 * * * \\
(0.00)\end{array}$ \\
\hline \multicolumn{8}{|l|}{ EA events } \\
\hline Greece requests for programme & $\begin{array}{c}1.480^{* * *} \\
(0.00)\end{array}$ & $\begin{array}{c}-\mathbf{0 . 4 2 6} \\
(0.00)\end{array}$ & $\begin{array}{c}\mathbf{0 . 5 2 0}^{* * *} \\
(0.00)\end{array}$ & $\begin{array}{c}\mathbf{0 . 4 7 2}^{* * *} \\
(0.00)\end{array}$ & $\begin{array}{c}\mathbf{0 . 6 6 4} * * * \\
(0.00)\end{array}$ & $\begin{array}{c}-\mathbf{0 . 0 6 1} * * * \\
(0.00)\end{array}$ & $\begin{array}{c}-\mathbf{0 . 0 7 0} * * * \\
(0.00)\end{array}$ \\
\hline Ireland requests for programme & $\begin{array}{c}1.900 * * * \\
(0.00)\end{array}$ & $\begin{array}{c}-1.443 * * * \\
(0.00)\end{array}$ & $\begin{array}{c}\mathbf{1 . 3 8 4} * * * \\
(0.00)\end{array}$ & $\begin{array}{c}-\mathbf{0 . 2 0 0} \\
\quad(0.00)\end{array}$ & $\begin{array}{c}-\mathbf{1 . 6 4 6} \text { **** } \\
(0.00)\end{array}$ & $\begin{array}{c}-\mathbf{0 . 4 9 6} * * * \\
(0.00)\end{array}$ & $\begin{array}{c}\mathbf{0 . 8 0 5} * * * \\
(0.00)\end{array}$ \\
\hline Spain and Cyprus request for programme & $\begin{array}{c}1.434^{* * *} \\
(0.00)\end{array}$ & $\begin{array}{c}-\mathbf{0 . 7 0 7 * * *} \\
(0.00)\end{array}$ & $\begin{array}{c}\mathbf{0 . 2 1 5} \\
\quad(0.00)\end{array}$ & $\begin{array}{c}\mathbf{0 . 0 7 2} \text { *** } \\
(0.00)\end{array}$ & $\begin{array}{c}-\mathbf{0 . 1 8 1} * * * * \\
(0.00)\end{array}$ & $\begin{array}{c}-\mathbf{0 . 7 0 2} * * * \\
(0.00)\end{array}$ & $\begin{array}{c}\mathbf{0 . 4 6 2} \text { *** } \\
(0.00)\end{array}$ \\
\hline London speech & $\begin{array}{c}-4.602 * * * \\
(0.00)\end{array}$ & $\begin{array}{c}\mathbf{0 . 3 8 1} \text { *** } \\
(0.00)\end{array}$ & $\begin{array}{c}-\mathbf{0 . 5 1 1} * * * \\
(0.00)\end{array}$ & $\begin{array}{c}1.223^{*} * * \\
(0.00)\end{array}$ & $\begin{array}{c}1.150^{* * *} \\
(0.00)\end{array}$ & $\begin{array}{c}1.877^{* * *} \\
(0.00)\end{array}$ & $\begin{array}{c}-1.857^{* * *} \\
(0.00)\end{array}$ \\
\hline Greek bailout referendum & $\begin{array}{c}\mathbf{0 . 4 5 7} * * * \\
(0.00)\end{array}$ & $\begin{array}{c}-1.027 * * * \\
(0.00)\end{array}$ & $\begin{array}{c}-\mathbf{0 . 4 3 9} * * * \\
(0.00)\end{array}$ & $\begin{array}{c}\mathbf{2 . 1 2 6} \mathbf{1}^{* * *} \\
(0.00)\end{array}$ & $\begin{array}{c}-1.622 * * * \\
(0.00)\end{array}$ & $\begin{array}{c}-\mathbf{0 . 4 5 8} * * * \\
(0.00)\end{array}$ & $\begin{array}{c}\mathbf{0 . 5 0 0}{ }^{* * *} \\
(0.00)\end{array}$ \\
\hline EG* agrees on Greek third programme & $\begin{array}{c}-\mathbf{3 . 1 9 2} * * * \\
(0.00)\end{array}$ & $\begin{array}{c}\mathbf{1 . 6 6 4} * * * \\
(0.00)\end{array}$ & $\begin{array}{c}-\mathbf{2 . 1 6 0} * * * \\
(0.00)\end{array}$ & $\begin{array}{c}-\mathbf{0 . 0 4 9} * * * \\
(0.00)\end{array}$ & $\begin{array}{c}\mathbf{2 . 4 9 1} * * * \\
(0.00)\end{array}$ & $\begin{array}{c}1.318^{* * *} \\
(0.00)\end{array}$ & $\begin{array}{c}-1.287^{* * *} \\
(0.00)\end{array}$ \\
\hline Brexit referendum & $\begin{array}{c}\mathbf{3 . 2 3 2}^{* * * *} \\
\quad(0.00)\end{array}$ & $\begin{array}{c}-\mathbf{1 . 6 3 7} * * * \\
(0.00)\end{array}$ & $\begin{array}{c}\mathbf{5 . 8 2 9}^{* * * *} \\
(0.00)\end{array}$ & $\begin{array}{c}-\mathbf{3 . 6 9 7} * * * \\
(0.00)\end{array}$ & $\begin{array}{c}-\mathbf{5 . 9 8 6} \\
(0.00)\end{array}$ & $\begin{array}{c}-\mathbf{3 . 2 0 4} * * * \\
(0.00)\end{array}$ & $\begin{array}{c}\mathbf{2 . 0 5 9} \\
(0.00)\end{array}$ \\
\hline Sintra speech & $\begin{array}{c}-\mathbf{0 . 3 1 1} * * * \\
(0.00)\end{array}$ & $\begin{array}{c}1.927 * * * \\
(0.00)\end{array}$ & $\begin{array}{c}-\mathbf{0 . 6 7 1} * * * \\
(0.00)\end{array}$ & $\begin{array}{c}-\mathbf{0 . 0 4 9} * * * \\
(0.00)\end{array}$ & $\begin{array}{c}-\mathbf{0 . 0 5 8} * * * \\
(0.00)\end{array}$ & $\begin{array}{c}\mathbf{0 . 3 9 8} * * * \\
(0.00)\end{array}$ & $\begin{array}{c}\mathbf{0 . 2 3 4} * * * \\
(0.00)\end{array}$ \\
\hline
\end{tabular}

Notes: ${ }^{* * *} p<0.01,{ }^{* *} p<0.05,{ }^{*} p<0.1, p$-values in parentheses. $t$-statistics are computed using Newey and West standard errors. All figures are in standard deviation terms.

For clarifications on the events, see the footnote to Table 1 above.

of interest down. At this stage, it might be questioned whether a simpler framework based on just these restrictions would be sufficient to tease the two shocks out. In Section C.1 below we address this question by setting up a SVAR with just the EASTR variable, the EMBI+ spread and their difference. We then impose simple sign restrictions to identify the euro area stress and global risk aversion shocks. While the structural shocks series are very similar to the ones estimated in our baseline setup, however the IRFs are quite different and they show that the simplified identification scheme is not able to fully disentangle between the two shocks.

Table 3: Baseline sign restrictions

\begin{tabular}{|c|c|c|}
\hline Variables Shocks & EA stress & Global \\
\hline EASTR & $>0$ & $\geq 0$ \\
\hline$€$ NEER & $\leq 0$ & $<$ EA shock \\
\hline VIX & & $>0$ \\
\hline EMBI+ spread & $<$ EASTR & $\geq$ EASTR \\
\hline $\begin{array}{l}\text { EA equity } \\
\text { RoW equity }\end{array}$ & $\begin{array}{c}\quad \leq 0 \\
<\text { EA Equity }\end{array}$ & $\leq 0$ \\
\hline US10Y & & $<0$ \\
\hline
\end{tabular}

In addition, we also impose narrative restrictions corresponding to some identified important events, along the methodology outlined in Antolín-Díaz and Rubio-Ramírez (2018). Complementing the baseline sign and narrative restrictions with additional ones corresponding to a restricted set of events is indeed instrumental to substantially sharpen the identification of the 
shocks of interest, as also shown in Section C.2. Notably, we restrict the sign of the shocks taking place on the dates of five events:

i) Lehman Brothers bankruptcy (15 September 2008): positive global shock;

ii) FED's "Taper tantrum" (22 May 2013): positive global shock;

iii) Request of financial assistance by Spain and Cyprus (27 June 2012): positive euro area shock;

iv) ECB President's London Speech (26 July 2012): negative euro area shock;

v) Approval of the $3^{\text {rd }}$ economic adjustment programme for Greece (9 July 2015): negative euro area shock.

For some of these events, we also complement the sign restrictions on the structural shocks with additional restrictions on the magnitude of the contributions to either the EASTR variable or the VIX. Specifically, the default of Lehman Brothers is considered as a positive global risk aversion shock, which is also the most important contributor to the historical decomposition of the VIX. Similarly, the ECB President's London speech is classified as a negative EA stress shock, which is then the most important contributor to the historical decomposition of the EASTR variable. Table 4 summarizes all the narrative restrictions in the $\mathrm{SVAR}^{25}$.

Table 4: Narrative restrictions

\begin{tabular}{l|l|l|l}
\hline \hline \multicolumn{1}{c|}{ Date } & \multicolumn{1}{|c}{ Event } & \multicolumn{1}{|c}{$\begin{array}{c}\text { Shock } \\
\text { Contribution }\end{array}$} \\
\hline \hline 15-Sep-08 & Lehman Brothers bankruptcy & Global+ $^{*}$ & $\stackrel{+}{\rightarrow} V I X^{* *}$ \\
22-May-13 & FED "Taper tantrum" & Global+ & \\
27-Jun-12 & Spain and Cyprus request for programme & EA+ & \\
26-Jul-12 & London speech & EA- & + \\
09-Jul-15 & Eurogroup agrees on Greek 3 $3^{\text {rd }}$ programme & EA- & \\
\hline \hline
\end{tabular}

Notes: $\quad{ }^{*} z+$ : positive z-shock, $z-$ : negative z-shock;

$\stackrel{* *}{\rightarrow} x$ : most important contributor in historical decomposition of variable $x$. For a formal definition of these types of restrictions, see Section B.4.

\subsection{Results}

Figure 3 displays the Impulse Response Functions (IRFs) for a 10-basis-point increase in the EASTR variable and a 0.63 percentage points (pps) increase in the VIX which, in our framework, correspond to a negative shock to euro area cohesion and a positive shock to global risk aversion. For comparison purposes, we impose a euro area shock that entails the same increase in the

\footnotetext{
${ }^{25}$ The selection of events is done on the basis of an algorithm that considers different combinations from the list reported in Table 1. The final outcome consists of the subset of events, out of 254 different combinations, with the highest number of draws that satisfy the narrative restrictions. Refer to Appendix B for the technical details of the estimation.
} 
VIX as a global risk aversion shock.

Generally speaking, the two shocks lead to different responses across the variables of interest. For instance, a euro area shock has a greater impact on euro area equity prices, the $€$ NEER and the US 10-year yields, while the impact of global risk aversion shocks is more relevant for RoW equity prices as well as the EMBI+ spreads.

Specifically, an increase in the EASTR variable by 10 basis points (bps) affects EA equity prices and the $€$ NEER, which both decrease on impact by 0.87 and 0.34 pps respectively. The same shock also leads to an increase in the US 10-year yield by 6 basis points, while leaving the EMBI+ spread unaffected over a one-month horizon. On the other hand, a global risk aversion shock given by a comparable increase in the VIX $(+0.63 \mathrm{pps})$ entails an immediate drop in the equity prices for both the RoW (-0.42 pps) and the euro area (-0.30 pps). This also leads to a substantial decrease in the US 10-year yield (-3.17 bps) and an increase in the EMBI+ spread $(+2.33 \mathrm{bps})$.

These results suggest that global shocks work their way through equity markets, while euro area stress shocks have more pervasive negative effects through the bond markets, as also confirmed by the estimated differences across IRFs to the two shocks (Figure 4).

\subsubsection{Dynamic multipliers}

The direct comparison of IRFs magnitudes is subject to an important caveat, namely that the functional form as well as the assumptions of our model are ad-hoc and might disregard other important relations across the endogenous variables (e.g., the EMBI+ is by construction a function of the US Treasury yield curve). Therefore, it looks more appropriate to evaluate the reaction of the variables of interest by means of conditional dynamic multipliers, which are computed as the ratio between the cumulative IRFs of two variables against a common shock of interest. Notably, the conditional dynamic multiplier of variable $y$ vis-à-vis variable $z$ is computed as follows:

$$
\Phi_{y z}(k) \equiv\left|\frac{\sum_{k=0}^{K} \frac{\partial y_{t+k}}{\partial \varepsilon_{t}^{x}}}{\sum_{k=0}^{K} \frac{\partial z_{t+k}}{\partial \varepsilon_{t}^{x}}}\right|
$$

where $\sum_{k=0}^{K} \frac{\partial y_{t+k}}{\partial \varepsilon_{t}^{x}}$ is the cumulative IRF of variable $y$ to shock $x$ at horizon $K$. These statistics are particularly useful in this context because they make it possible to study the relations across different variables without requiring any assumption on the form that such relations should take ${ }^{26}$.

Table 5 reports the estimates of Equation (2.3) for the two different shocks, with $y$ and $z$ given

\footnotetext{
${ }^{26}$ See Barnichon and Mesters (2019) and Galí and Gambetti (2019) for additional details.
} 
Figure 3: IRFs - euro area stress (blue) and global risk aversion (red) shocks
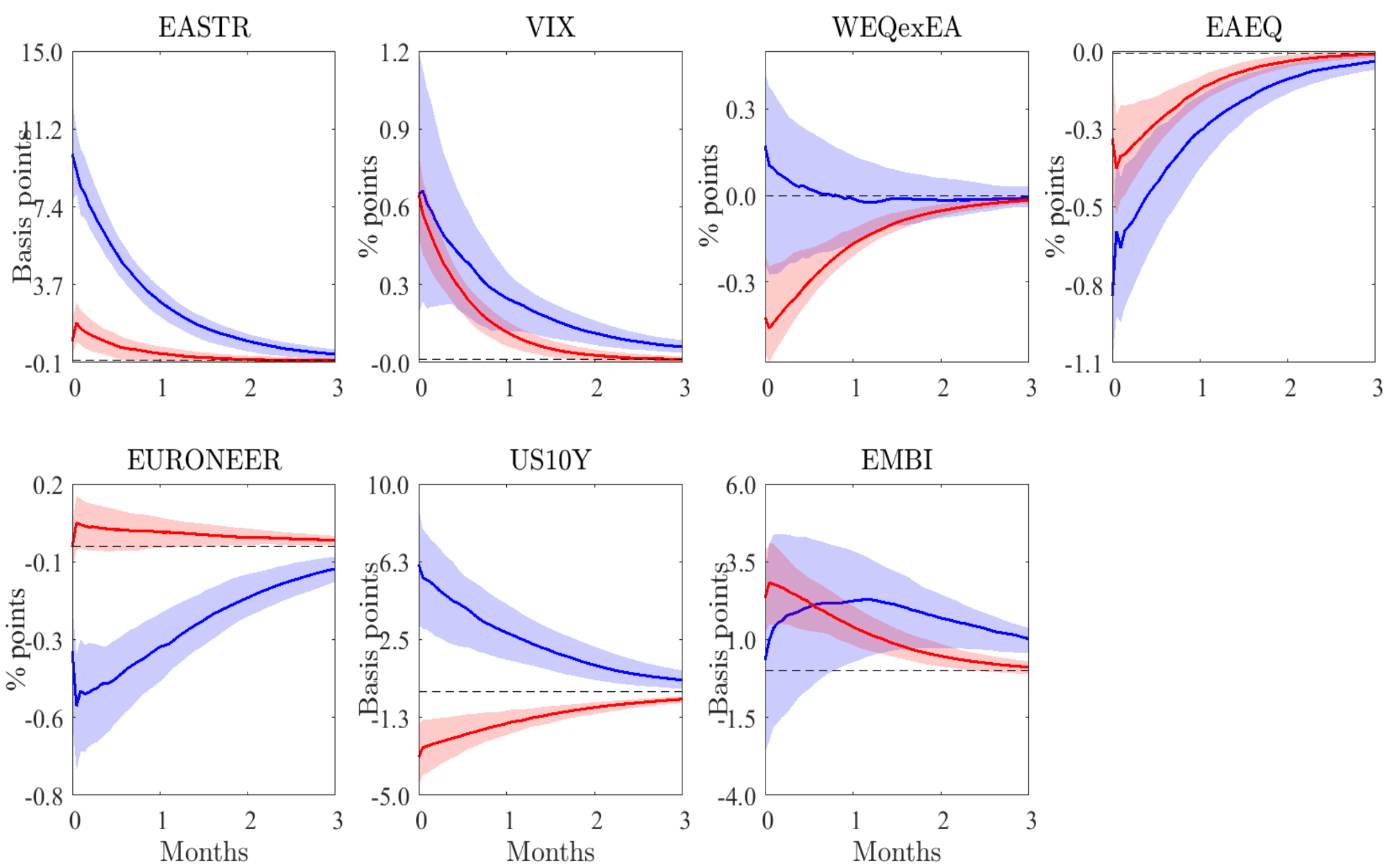

Notes: Shaded areas represent $68 \%$ HPD credible sets.

Source: Authors' calculations. 
Figure 4: Differences between IRFs to euro area stress and global risk shocks.
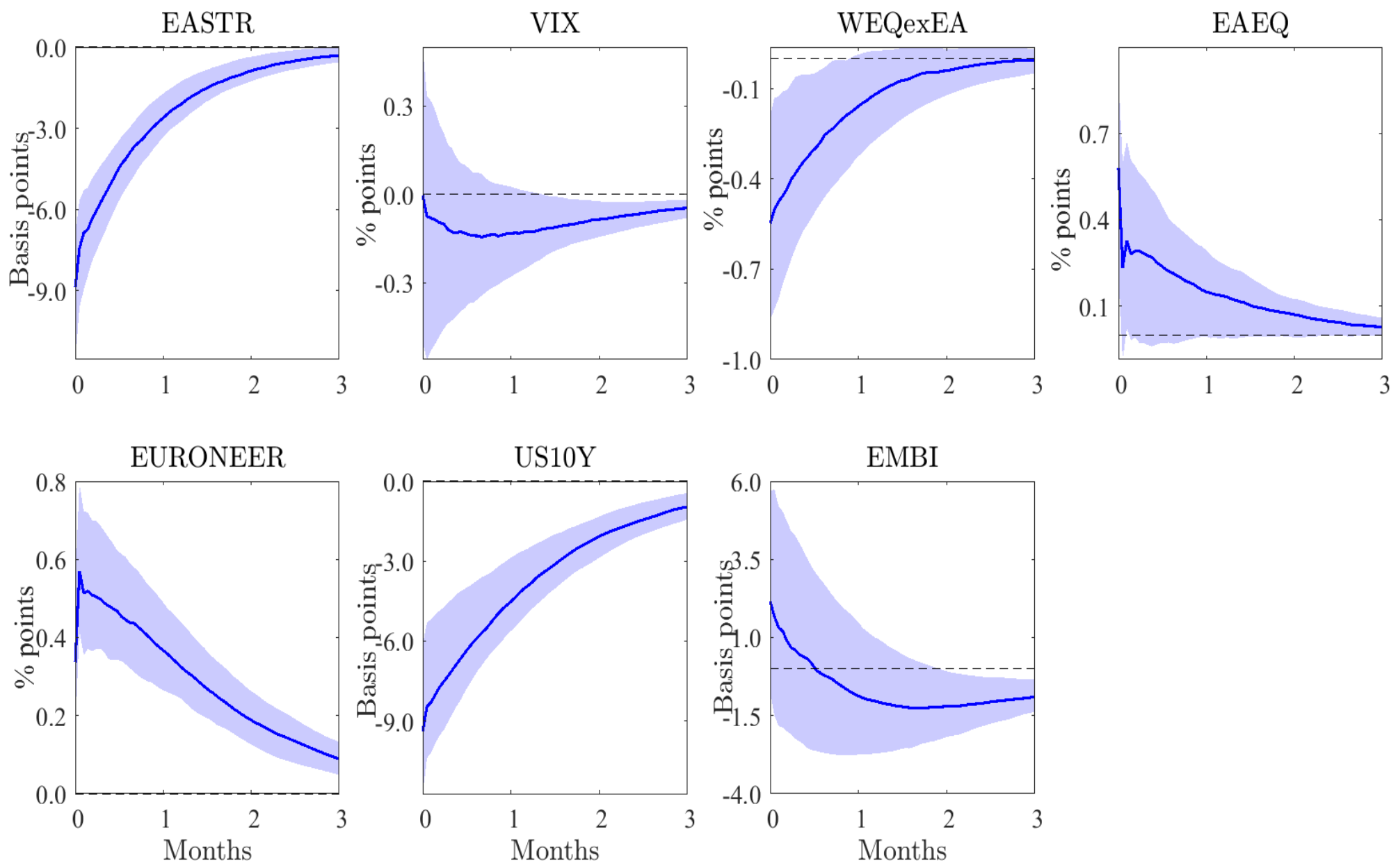

Notes: Charts depict the difference between the responses to global risk aversion shocks and the response to euro area stress shocks. Shaded areas represent $68 \%$ HPD credible sets.

Sources: Authors' calculations. 
Table 5: Maximum dynamic multipliers for EA stress and global risk aversion shocks

\begin{tabular}{lccc}
\hline \hline & 16th percentile & Median & 84th percentile \\
\hline EMBI+/US10Y & & & \\
\hline EA shock & 0.22 & 0.87 & 2.37 \\
Global shock & 0.58 & 1.05 & 2.14 \\
\hline EASTR/EMBI+ & & & \\
\hline EA shock & 2.38 & 4.96 & 14.91 \\
Global shock & 0.32 & 0.56 & 0.88 \\
\hline EA equity/World equity & & \\
\hline EA shock & 1.52 & 3.38 & 15.74 \\
Global shock & 0.55 & 0.89 & 1.29 \\
\hline EASTR/US10Y & & & \\
\hline EA shock & 1.16 & 1.68 & 3.23 \\
Global shock & 0.26 & 0.54 & 0.99 \\
\hline \hline
\end{tabular}

Notes: Multipliers are computed as $\max _{k} \Phi_{y z}(k)$, where $\Phi_{y z}(k)$ is defined in Equation (2.3).

by: i) the EMBI+ spread and the US 10-year government bond yield; ii) the equity price indices for the euro area and the rest of the world; iii) the EASTR and the US 10-year government bond yield; iv) the EASTR and the EMBI+ spread. When comparing the US 10-year yield and the EMBI+, there is no statistically significant difference between the effects of the two shocks in that the confidence bands for the estimated multipliers both include 1. Moving to the pair EASTR variable/US 10-year yield, on the other hand, the median values show that the US yield is more impacted by a global shock than the EASTR variable, while the contrary holds true after a euro area stress shock, with estimates of the dynamic multiplier being significantly above 1. According to the results, EASTR also reacts much more to euro area stress shocks than the EMBI+, while global shocks are more impactful for the latter. Finally, effects of global shocks on world equity prices are not statistically different from the effects on European prices, while the latter react much more than the former in the case of a euro area stress shock.

In line with part of the existing literature, these findings suggest that both euro area and global shocks provoke relevant portfolio re-balancing effects deriving from a shift in the sentiment of investors. However, the nature of such shift appears to be different between the two instances, as euro area stress shocks have generalized negative repercussions on extra-European bond markets as signalled by the increase in the US 10-year yield. Global risk aversion shocks, on the other hand, imply a more typical flight-to-safety reaction as indicated by the decrease in US yields and the increase in EMBI+ spreads. 


\subsubsection{Historical decomposition of shocks}

Additional evidence around the findings discussed so far can be provided by the historical decomposition analysis (Figure 5). Generally speaking, while historical decompositions display higher volatility since the onset of the GFC (2007-2008) and until mid-2012 (London speech), contributions of both global risk aversion and euro area stress shocks have followed a stabler path thereafter, between 2012 and the end of 2017. Moreover, Figure $5 \mathrm{f}$ unveil interesting dynamics for the US 10-year government bond yield, in that the contribution of euro area stress shocks has closely tracked, both level- and volatility-wise, that of global risk aversion shocks until the ECB President's London speech in July 2012 and the ECB's announcement of OMT. For the EMBI+ spread, on the other hand, global risk aversion shocks seems to have been consistently predominant throughout the time span considered (Figure $5 \mathrm{~g}$ ).

In the second half of 2017 , the fall in economic tension in the euro area led to a slight appreciation of the euro (Figure 5e) and a small drop in the EASTR variable (Figure 5a). This trend was, however, more than offset at the beginning of 2018 after the ECB announced the stop of net purchases under the Public Sector Purchase Programme (PSPP). In the first half of 2019, which corresponds to the last part of the sample, global shocks returned to play a major role compared to euro area stress shocks, not only in bond, but also in equity markets (Figure 5d).

\section{The impact of EMU stress shocks}

In this section, we evaluate to what extent euro area stress shocks, as identified in Section 2.2, have affected the euro area economy and the rest of the world.

We consider in particular the impact exerted on a set of monthly macroeconomic indicators for the euro area and a group of Advanced Economies (AEs) as well as Emerging Market Economies $(\mathrm{EMs})^{27}$. With this aim, we first aggregate the daily shocks at the monthly level (Figure 6$)^{28}$ and, then, we quantify the intra-EA and cross-border effects by means of impulse response functions (IRFs) computed with Jordà's local projections approach. This methodology is particularly suitable in this case, given its appealing property of being both more robust to misspecifications and very easily adaptable to non-linear frameworks.

Notably, we set the following panel regression model up:

\footnotetext{
${ }^{27}$ See Appendix A for a complete list of countries.

${ }^{28}$ Following Gertler and Karadi (2015) and Jarociński and Karadi (2020), the aggregation is done by summing up the daily shocks on a monthly basis. As a robustness check, we have also used an aggregation method based on monthly averages. Results, available upon request, are very similar to what shown in the paper.
} 
Figure 5: Historical decomposition - euro area stress (blue) and global risk aversion (red) shocks (a) EASTR

(b) VIX
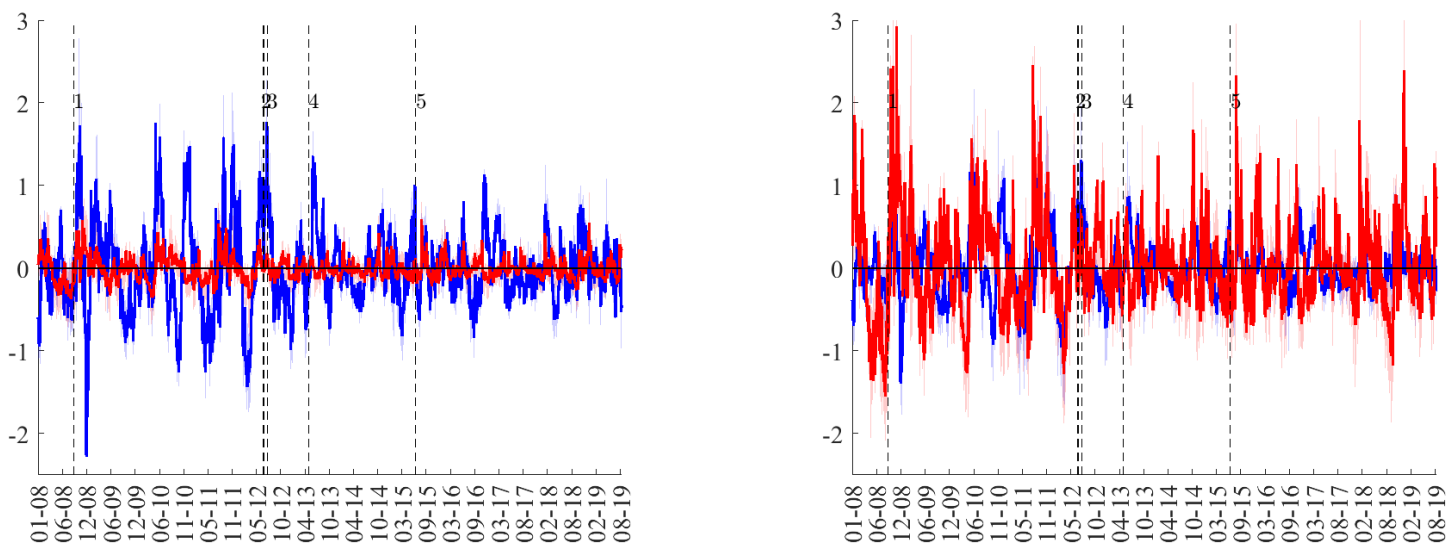

(c) World Equity prices

(d) Euro area equity index
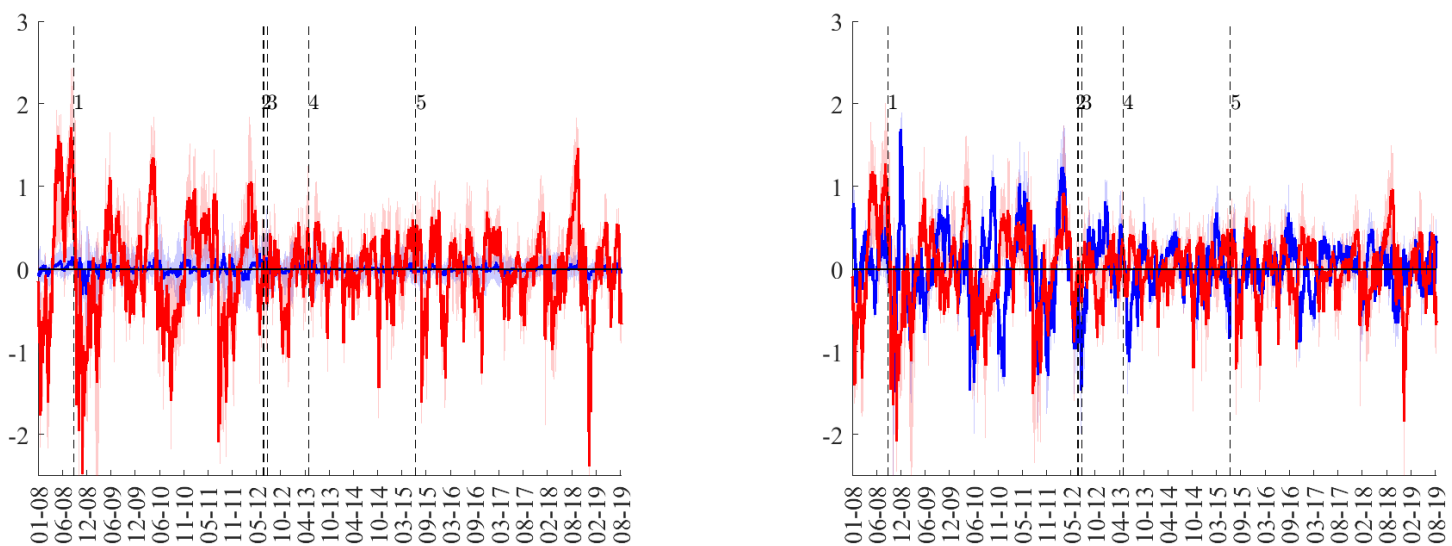

(e) Euro effective exchange rate

(f) US 10-year yield
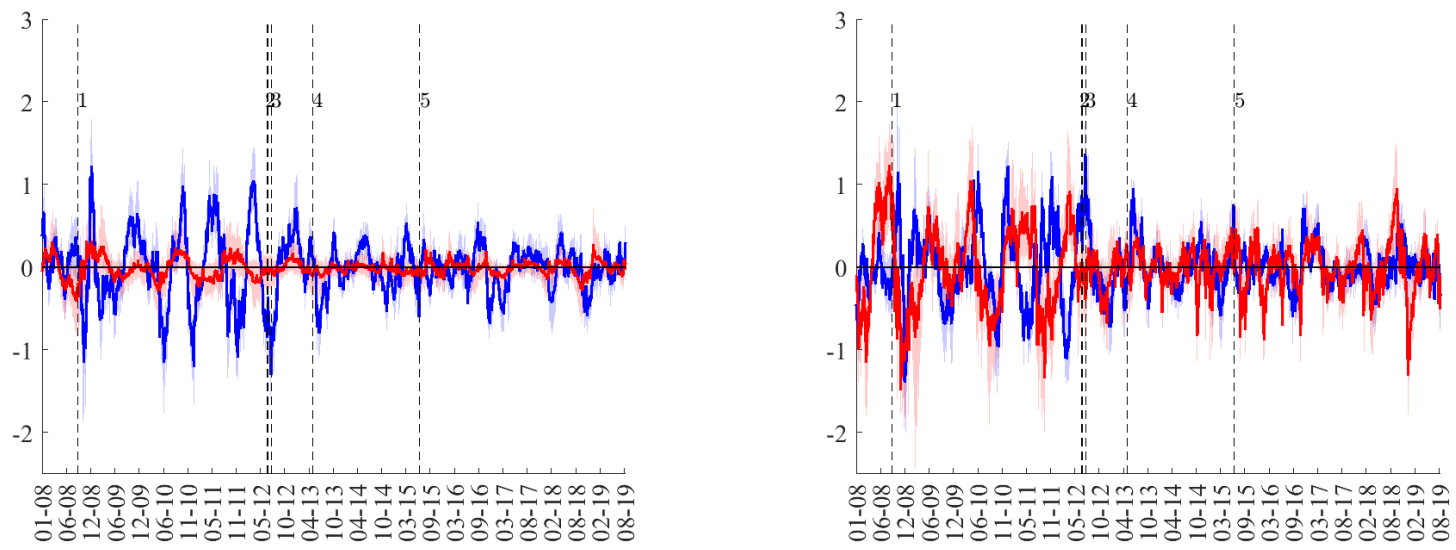

(g) $\mathrm{EMBI}+$ spread

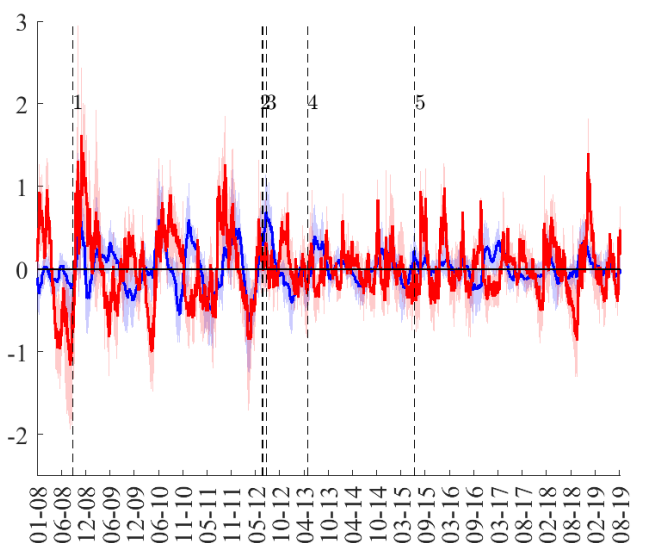

Notes: Shaded areas represent $68 \%$ HPD credible sets. Black dashed lines mark the following relevant events: 1. Lehman Brothers collapse; 2. Spain and Cyprus request for programme; 3. London speech; 4. Fed's "Taper tantrum"; 5. EG agrees on Greek $3^{\text {rd }}$ programme. Source: Authors' calculations. 
Figure 6: Daily shock series.

(a) Euro area stress

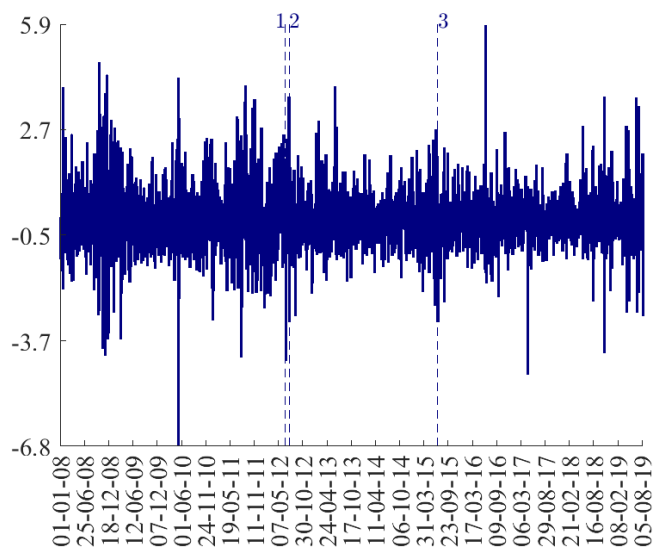

(b) Global risk aversion

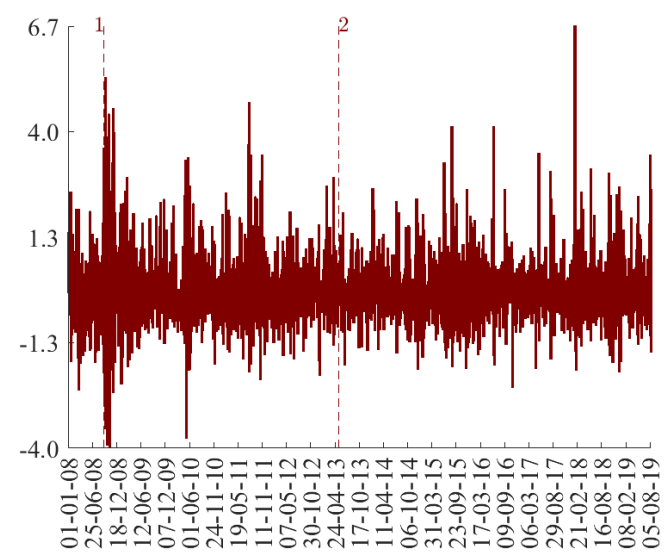

Notes: Blue dashed lines in the left panel mark the following relevant events: 1 . Spain and Cyprus request for programme; 2. London speech; 3. EG agrees on Greek $3^{\text {rd }}$ programme. Red dashed lines in the right panel correspond to the following events: 1. Lehman Brothers collapse; 2. Fed's "Taper tantrum."

Source: Authors' calculations.

$$
x_{i, t+h}=\alpha_{i}+\xi_{h} \varepsilon_{t}^{z}+\sum_{k=1}^{p} \beta_{h} x_{i, t-k}+\gamma \boldsymbol{Z}_{t-1}+\nu_{i, h, t+h}
$$

with $i=1, \ldots, N, t=1, \ldots, T$. The parameter of interest in Equation (3.1) is $\xi_{h}$, which measures the effect that a shock $\left(\varepsilon_{t}^{z}\right)$ at time $t$ has on the variable of interest, $x_{i, t}$, after $h$ months. Moreover, $\boldsymbol{Z}_{t-1}$ is a vector of exogenous regressors containing the (log) USD nominal effective exchange rate and the (log) oil price. In what follows, we estimate Equation (3.1) by alternatively including the aggregated monthly euro area stress and global shocks on the right hand side.

\subsection{Results}

Euro area stress shocks and global risk aversion shocks both exert a significant impact on relevant economic variables of the EA as well as AEs and EMs.

For instance, euro area stress shocks have negative effects on both EA industrial production and inflation, whose magnitude is sometimes comparable to what observed for a global risk aversion shock (Table 6 and Figure $7 \mathrm{a})^{29}$. A positive euro area stress shock indeed drops both EA industrial production and inflation by a maximum of $0.93 \%$ and 2.06 pps respectively (Figure $7 \mathrm{~b}$ ) against a peak reduction of $0.8 \%$ and 2.19 pps after a global shock. Euro area stress shocks can also impact intra-EA trade flows over the medium-term, by decreasing exports and imports by $3.28 \%$ and $3.15 \%$ respectively. Global risk shocks on the other hand entail more marked slowdowns in trade flows over the longer-term (Figures $7 \mathrm{c}$ and $7 \mathrm{~d}$ ), something which

\footnotetext{
${ }^{29}$ These estimates refer to a unit increase in the shock of reference. As the shock series are standardised, this corresponds to a one-standard-deviation increment.
} 
Table 6: Maximum impact of euro area stress and global risk aversion shocks

\begin{tabular}{|c|c|c|c|c|c|c|}
\hline \multirow{2}{*}{ Shock $\quad$ Variable } & \multirow[t]{2}{*}{ IP } & \multirow[t]{2}{*}{ Inflation } & \multicolumn{2}{|c|}{ Exports to } & \multicolumn{2}{|c|}{ Imports from } \\
\hline & & & EA & RoW & EA & RoW \\
\hline \multicolumn{7}{|l|}{ Euro Area } \\
\hline EA & $\begin{array}{r}-0.93 \% \\
(12)^{*}\end{array}$ & $\begin{array}{c}-2.06 \mathrm{pps} \\
(9)\end{array}$ & $\begin{array}{c}-3.28 \% \\
(4)\end{array}$ & & $\begin{array}{c}-3.15 \% \\
(5)\end{array}$ & \\
\hline Global & $\begin{array}{c}-0.8 \% \\
(11)\end{array}$ & $\begin{array}{l}-2.19 \mathrm{pps} \\
(12)\end{array}$ & $\begin{array}{c}-5.31 \% \\
(12)\end{array}$ & & $\begin{array}{c}-4.94 \% \\
(12)\end{array}$ & \\
\hline \multicolumn{7}{|l|}{ Advanced Economies } \\
\hline EA & $\begin{array}{c}-1.02 \% \\
(4)\end{array}$ & $\begin{array}{c}-0.23 \mathrm{pps} \\
(9)\end{array}$ & $\begin{array}{c}-2.79 \% \\
(10)\end{array}$ & $\begin{array}{c}-2.34 \% \\
(7)\end{array}$ & $\begin{array}{c}-1.68 \% \\
(3)\end{array}$ & $\begin{array}{c}-2.39 \% \\
(7)\end{array}$ \\
\hline Global & $\begin{array}{c}-1.50 \% \\
(12)\end{array}$ & $\begin{array}{c}-0.13 p p s \\
(11)\end{array}$ & $\begin{array}{c}-3.27 \% \\
(12)\end{array}$ & $\begin{array}{c}-3.23 \% \\
(12)\end{array}$ & $\begin{array}{c}-2.78 \% \\
(12)\end{array}$ & $\begin{array}{c}-3.67 \% \\
(12)\end{array}$ \\
\hline \multicolumn{7}{|l|}{ Emerging Markets } \\
\hline$\overline{\mathrm{EA}}$ & $\begin{array}{c}-0.68 \% \\
(3)\end{array}$ & $\begin{array}{c}-0.30 \mathrm{pps} \\
(9)\end{array}$ & $\begin{array}{c}-2.36 \% \\
(10)\end{array}$ & $\begin{array}{c}-1.47 \% \\
(7)\end{array}$ & $\begin{array}{c}-1.55 \% \\
(5)\end{array}$ & $\begin{array}{c}-1.99 \% \\
(3)\end{array}$ \\
\hline Global & $\begin{array}{c}-1.32 \% \\
(12)\end{array}$ & $\begin{array}{c}-0.18 \mathrm{pps} \\
(12)\end{array}$ & $\begin{array}{c}-2.97 \% \\
(12)\end{array}$ & $\begin{array}{c}-2.67 \% \\
(12)\end{array}$ & $\begin{array}{c}-2.72 \% \\
(12)\end{array}$ & $\begin{array}{c}-3.43 \% \\
(12)\end{array}$ \\
\hline
\end{tabular}

Notes: ${ }^{*}$ Numbers in parentheses represent the amount of months after a shock has taken place. As the shocks series are standardized, coefficients refer to a unit increment in the relevant shocks, which corresponds to an increase by one standard deviation.

is in line with the part of literature identifying globalization as the biggest driver of European trade after 1992 (see Corsetti et al. (2019)).

Looking at results for extra-EA economies, a euro area stress shock can trigger significant real economy effects in AEs via a compression in industrial production by $1.02 \%$ over a seven-month horizon, against a drop by $1.50 \%$ one year after a global shock (Figure 8a). In EMs, on the other hand, the negative impact on industrial production is more muted compared to AEs, as the contraction peaks at $0.68 \%$ three months after the shock (Figure 9a). Conversely, euro area stress shocks are more relevant than global shocks when it comes to assessing demand effects, since the downward pressure on RoW inflation (both AEs and EMs) is bigger than in the case of a global shock (-0.23 pps vs -0.13 pps in AEs and -0.30 pps vs -0.18 pps in EMs). However, the deflationary pressures deriving from a global shock seem more persistent than the effects stemming from euro area stress shocks.

As to international trade activity, euro area stress shocks entail a slowdown in exports and imports to and from non-EA economies, which is significant in both AEs (Figures 8e and 8f) and EMs (Figures 9e and 9f), though slightly more relevant for the former. Generally speaking, the impact of such shocks tends to be smaller compared to global risk aversion shocks. In addition, the latter seem to trigger more long-lasting slowdowns in both macroeconomic aggregates and global trade, while the repercussions of changes in euro area stress tend to fade away in a shorter 
Figure 7: Euro Area - Impulse responses to a positive one s.d.euro area stress shock (blue) and a positive one s.d. global risk aversion shock (red)

(a) Industrial production

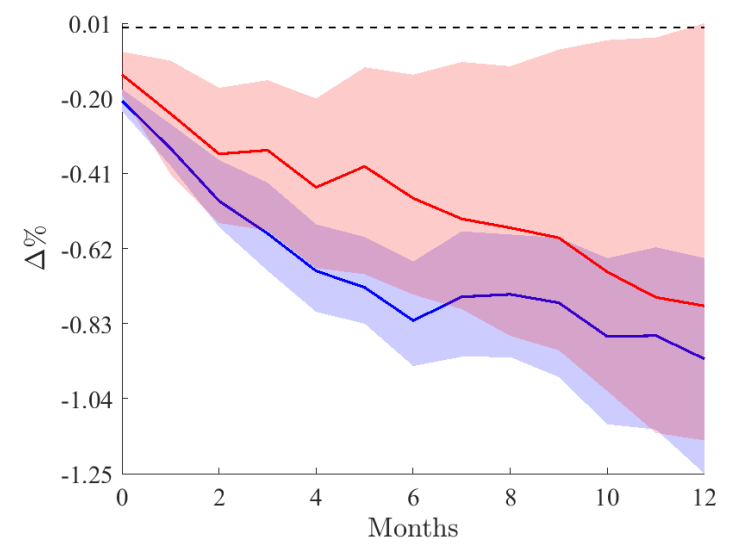

(c) Intra-euro area exports

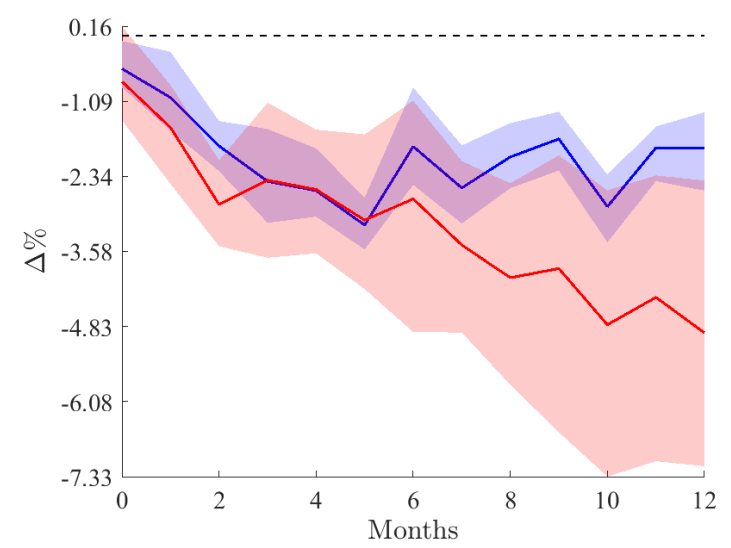

(b) Inflation

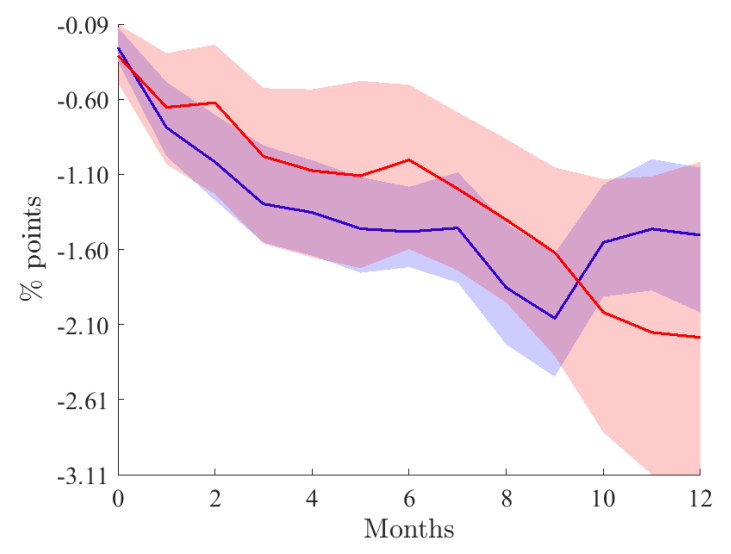

(d) Intra-euro area imports

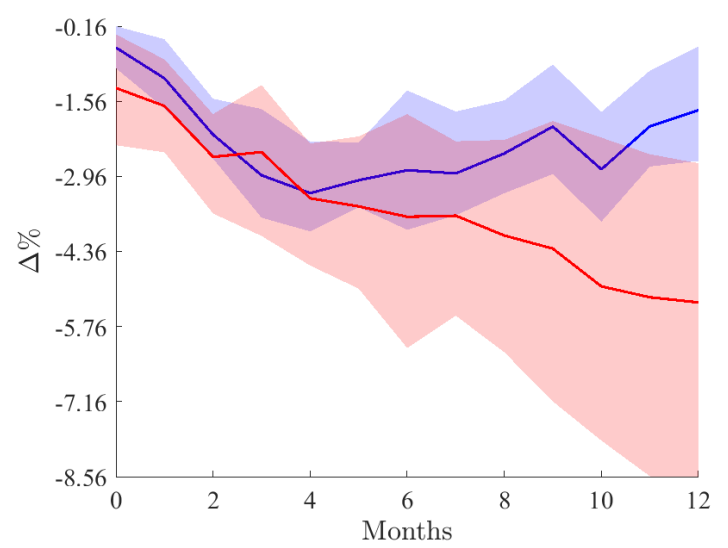

Notes: Inflation is defined as the y-o-y percentage change of the CPI. $\Delta \%$ : log-change. Shaded areas are $68 \%$ HPD credible sets.

Source: Authors' calculations.

time frame ${ }^{30}$. Ceteris paribus, a positive one-standard-deviation euro area stress shock has the following average effects over a one-year horizon: i) it decreases industrial production by $0.8 \%$ in AEs and $0.3 \%$ in EMs; ii) it pushes down yearly inflation by 0.17 pps in AEs and 0.18 pps in EMs; iii) it depresses euro area trade flows due to a decrease in both exports and imports with both AEs (-1.11\% and $-1.78 \%$ respectively) and EMs (-1.51\% and $-0.88 \%$ respectively); iv) it shrinks exports to the RoW by $1.34 \%$ in AEs and $0.8 \%$ in EMs, as well as imports from the RoW by both AEs and EMs (-1.3\% and -1\% respectively). While these estimates might look surprisingly substantial, however they correspond to a shock whose magnitude (one-standard deviation) is comparable to what observed when Spain and Cyprus requested for financial assistance. So, the results we have discussed above correspond to fairly large euro area stress shocks.

\footnotetext{
${ }^{30} \mathrm{~A}$ caveat to these findings derives from the inclusion in our sample of some (non-EA) EU members, which might bias our estimates given their particular linkages with EA members. However, our results are robust to the exclusion of these countries from the estimation sample, as shown in Section D.2.
} 
Figure 8: Advanced economies - Impulse responses to a positive one s.d.euro area stress shock (blue) and a positive one s.d. global risk aversion shock (red)

(a) Industrial production

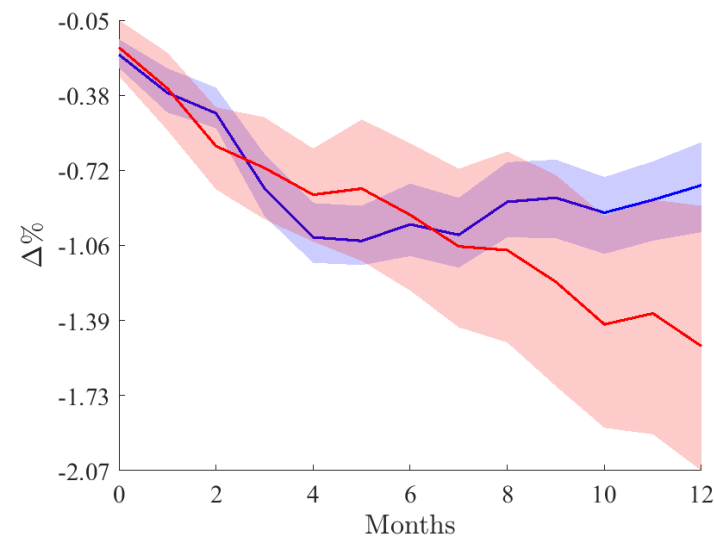

(c) Exports to euro area

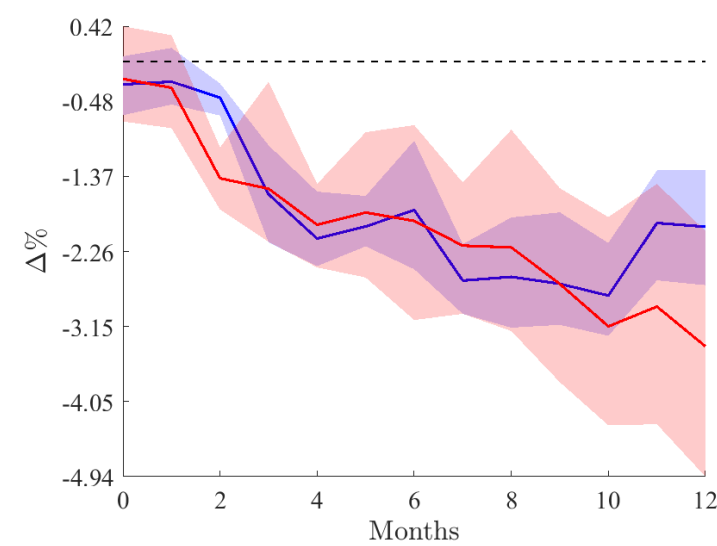

(e) Exports to RoW

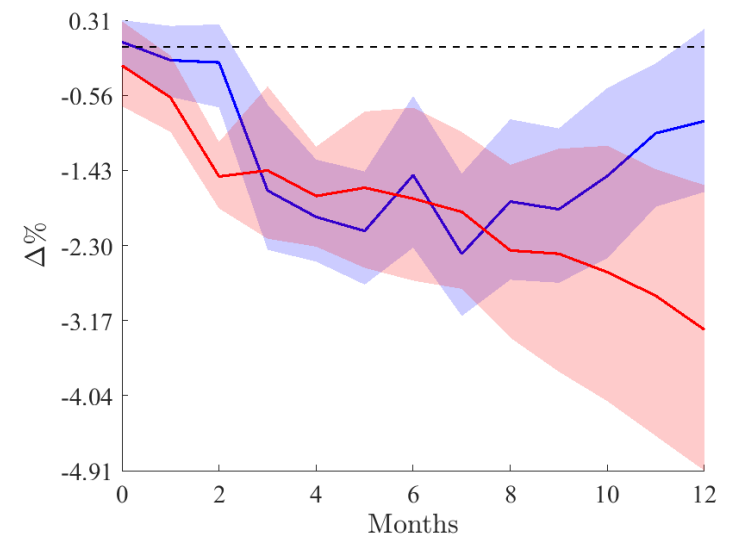

(b) Inflation

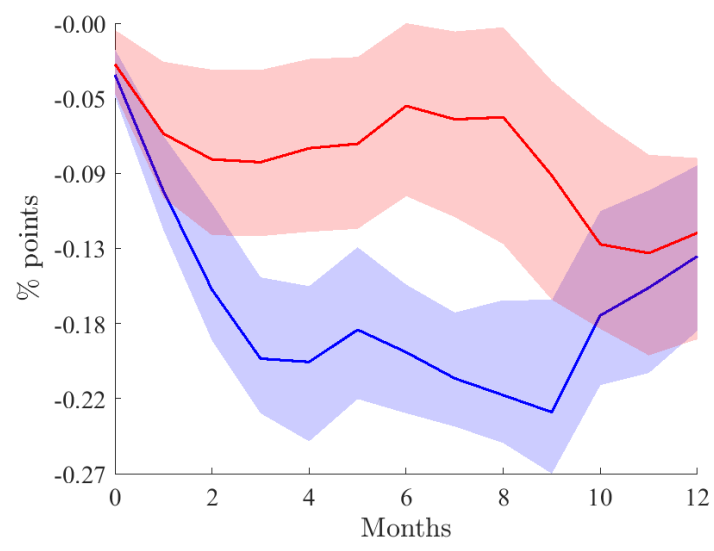

(d) Imports from euro area

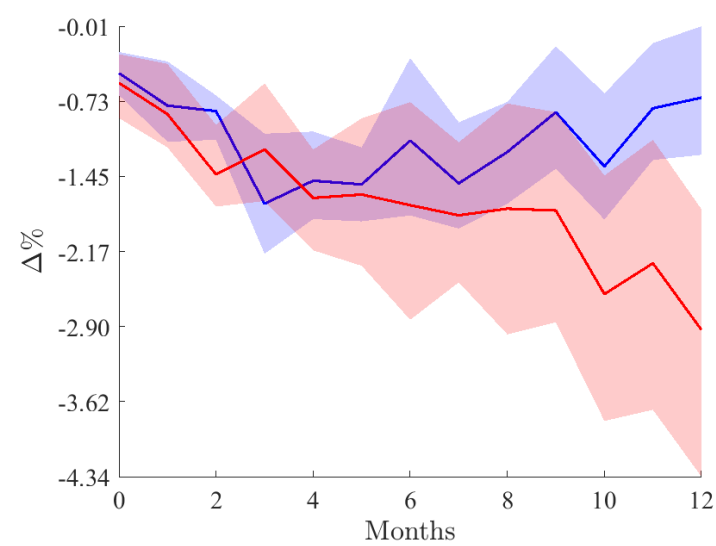

(f) Imports from RoW

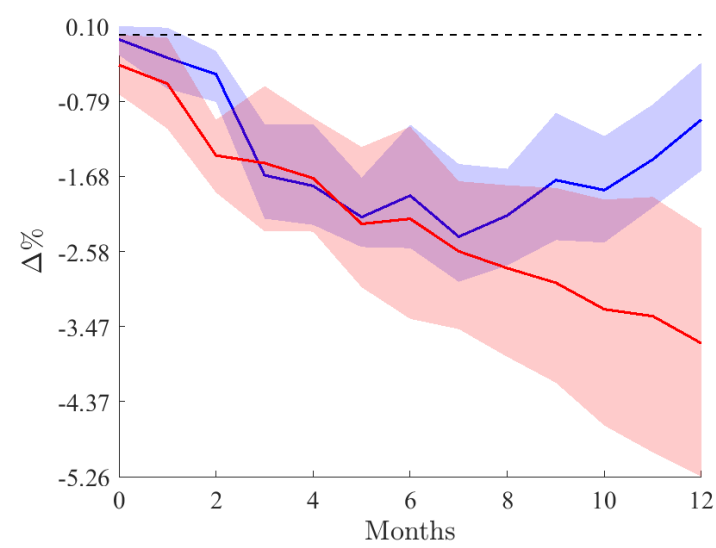

Notes: Inflation is defined as the y-o-y percentage change of the CPI. $\Delta \%$ : log-change. Shaded areas are $68 \%$ HPD credible sets.

Source: Authors' calculations. 
Figure 9: Emerging and developing economies - Impulse responses to a positive one s.d. EA stress shock (blue) and a positive one s.d. global risk aversion shock (red)

(a) Industrial production

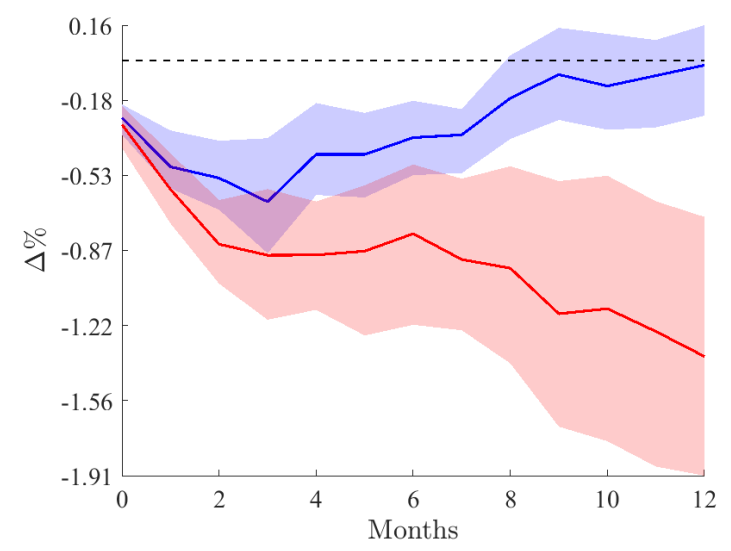

(c) Exports to euro area

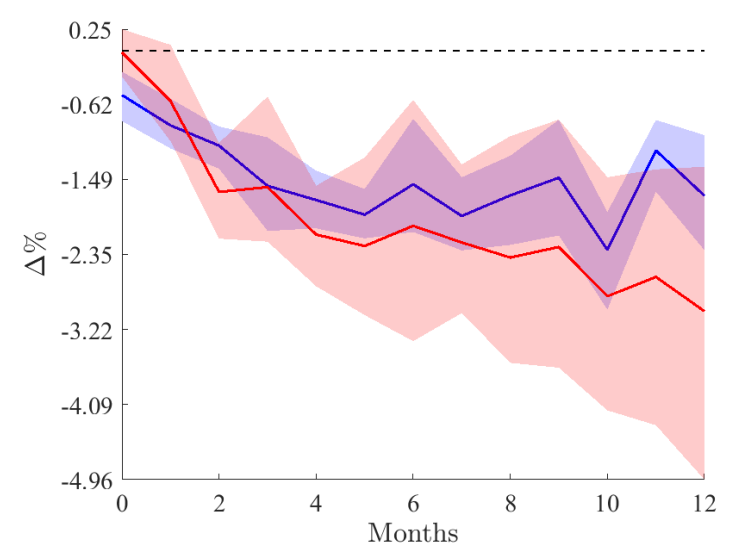

(e) Exports to RoW

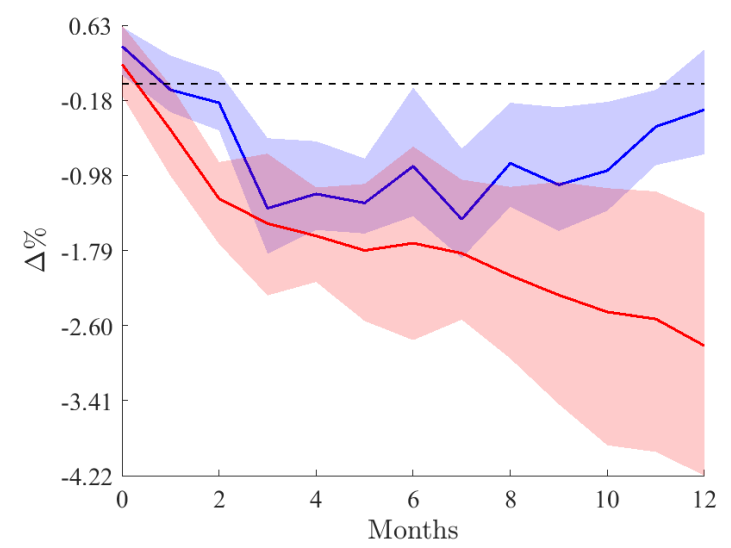

(b) Inflation

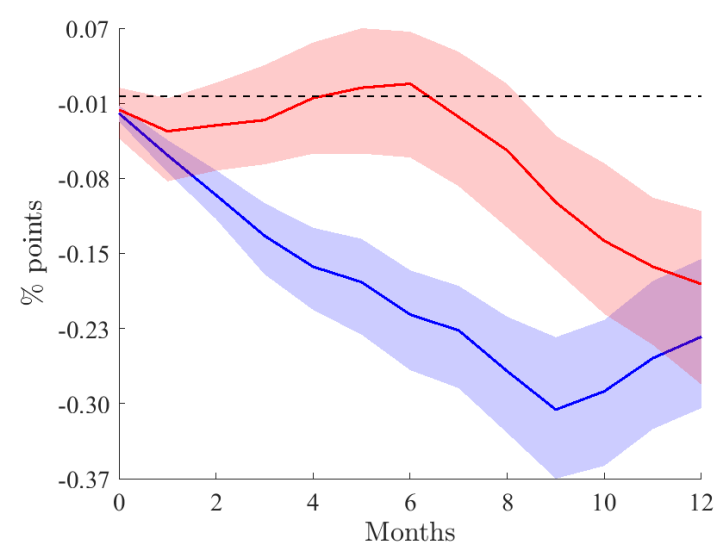

(d) Imports from euro area

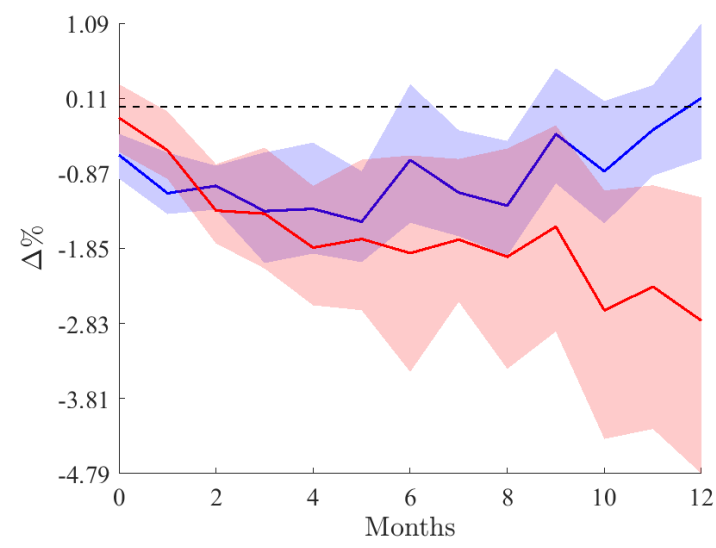

(f) Imports from RoW

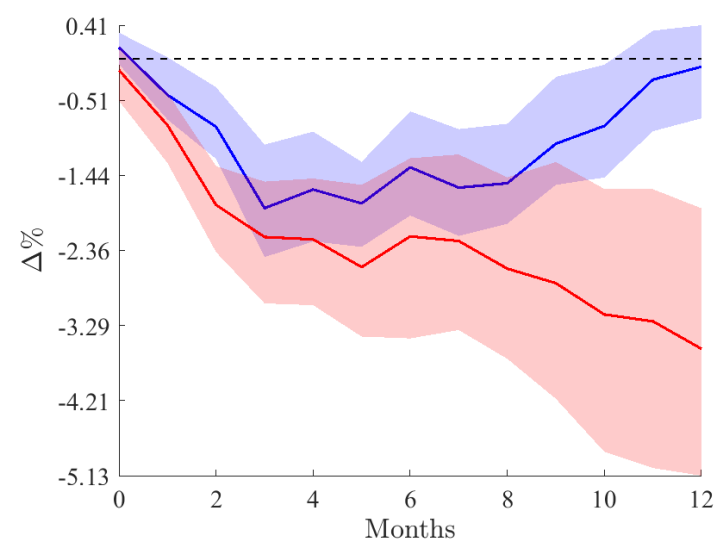

Notes: Inflation is defined as the y-o-y percentage change of the CPI. $\Delta \%$ : log-change. Shaded areas are $68 \%$ HPD credible sets.

Source: Authors' calculations. 
When disentangling between positive and negative shocks, a decrease in EMU tensions, corresponding to a negative euro area stress shock, can have more enduring positive spillovers compared to a setback (Figures 10 and 11). Though the maximum impact is roughly symmetric across positive and negative shocks, effects of negative shocks can still be significant after one year, especially in AEs (Table 7). A negative one-standard-deviation euro area stress shock, indeed, implies that, on average: i) industrial production increases by $0.73 \%$ in AEs and $0.45 \%$ in EMs: ii) yearly inflation goes up by 0.12 pps in AEs and 0.19 pps in EMs; iii) euro area imports are pushed up by 1.7\% from AEs and 1.88\% from EMs, while exports to both AEs and EMs increase by around $0.9 \%$; iv) exports of both AEs and EMs to the RoW are boosted by around $1 \%$, while imports from the RoW jump by $1.3 \%$ in AEs and $1.5 \%$ in EMs.

Table 7: Maximum impact of euro area stress shocks - positive vs negative

\begin{tabular}{l|cccccc}
\hline \hline Shock & IP & Inflation & \multicolumn{2}{c}{ Exports to } & \multicolumn{2}{c}{ Imports from } \\
& & & EA & RoW & EA & RoW \\
\hline Advanced Economies & & & & & & \\
\hline EA+ & $-1.04 \%$ & $-0.24 \%$ & $-2.64 \%$ & $-2.09 \%$ & $-1.58 \%$ & $-1.85 \%$ \\
& $(7)^{*}$ & $(9)$ & $(10)$ & $(7)$ & $(3)$ & $(5)$ \\
EA- & $0.99 \%$ & $0.20 \%$ & $2.56 \%$ & $1.51 \%$ & $1.04 \%$ & $1.01 \%$ \\
& $(11)$ & $(11)$ & $(12)$ & $(5)$ & $(12)$ & $(5)$ \\
\hline Emerging Markets & & & & & & \\
\hline EA+ & $-0.50 \%$ & $-0.38 \%$ & $-2.45 \%$ & $-1.84 \%$ & $-1.41 \%$ & $-1.31 \%$ \\
& $(3)$ & $(9)$ & $(10)$ & $(3)$ & $(5)$ & $(5)$ \\
EA- & $0.58 \%$ & $0.37 \%$ & $2.34 \%$ & $1.82 \%$ & $1.22 \%$ & $1.37 \%$ \\
& $(2)$ & $(11)$ & $(5)$ & $(2)$ & $(2)$ & $(5)$ \\
\hline \hline
\end{tabular}

Notes: ${ }^{*}$ Numbers in parentheses represent the amount of months after a shock has taken place. As the shocks series are standardized, coefficients refer to a unit increment in the relevant shocks, which corresponds to an increase by one standard deviation. 
Figure 10: Advanced economies - Impulse responses to a one s.d. negative (blue) and positive (red) euro area stress shock

(a) Industrial production

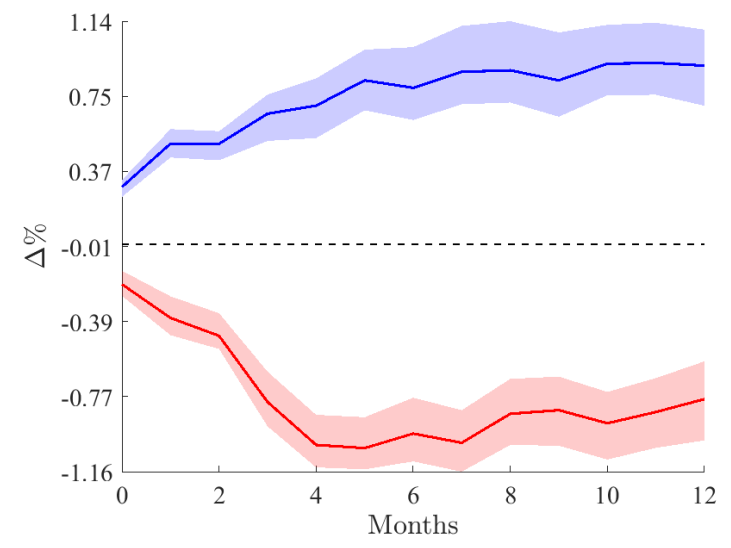

(c) Exports to euro area

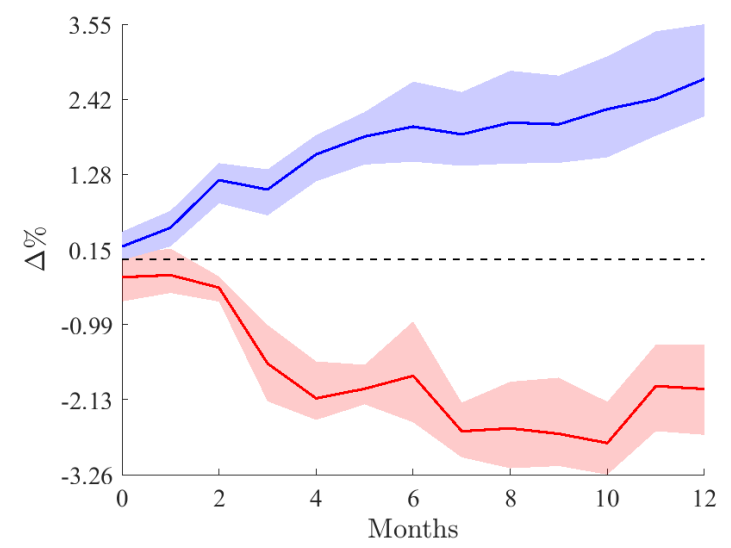

(e) Exports to RoW

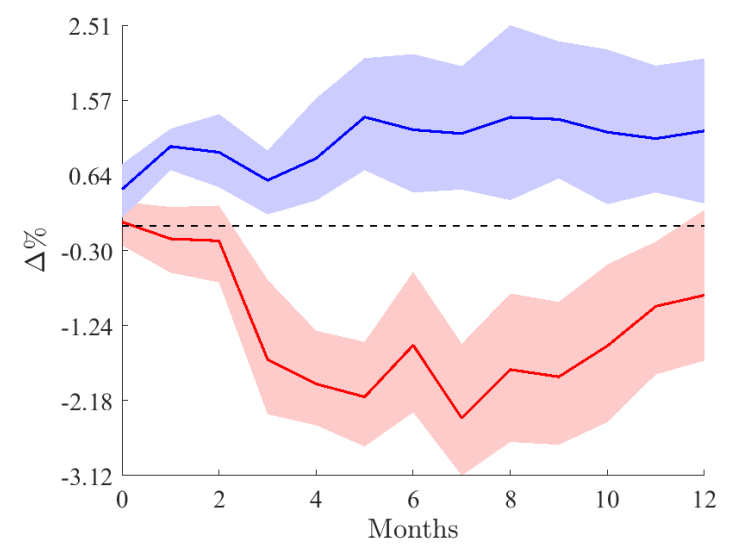

(b) Inflation

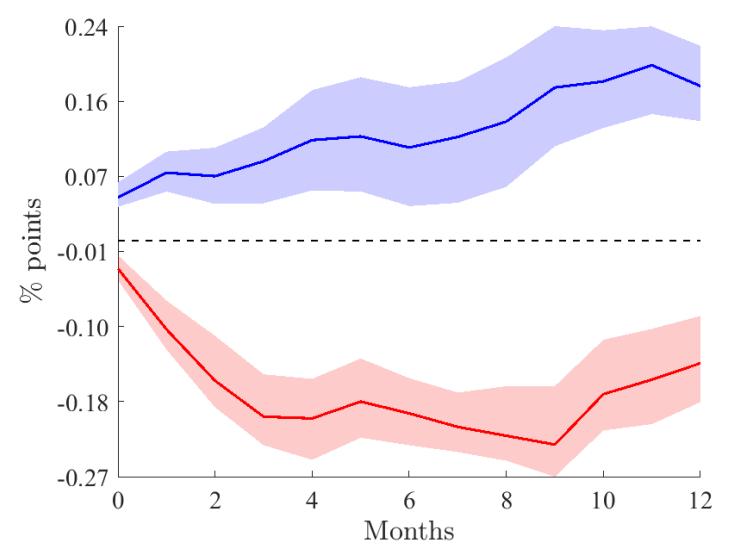

(d) Imports from euro area

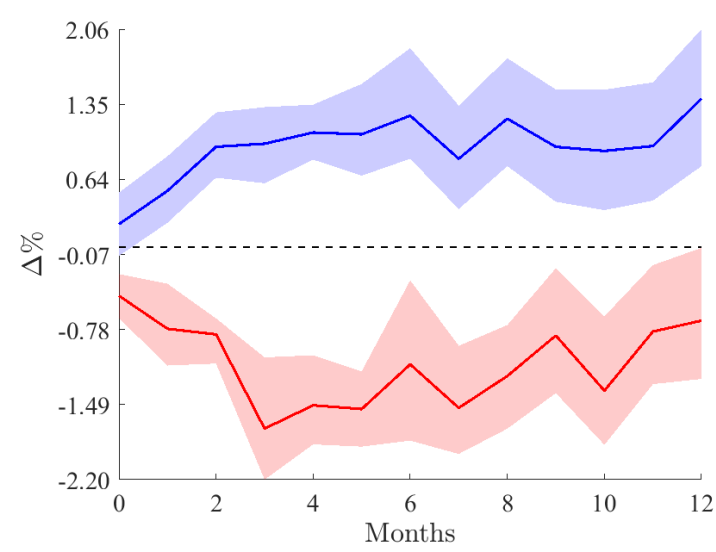

(f) Imports from RoW

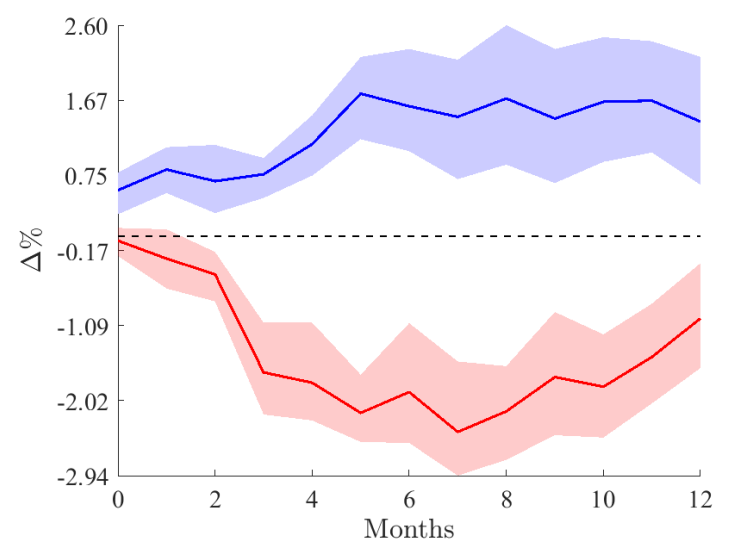

Notes: Inflation is defined as the y-o-y percentage change of the CPI. $\Delta \%$ : log-change. Shaded areas are $68 \%$ HPD credible sets.

Source: Authors' calculations. 
Figure 11: Emerging and developing economies - Impulse responses to a one s.d. negative (blue) and positive (red) euro area stress shock

(a) Industrial production

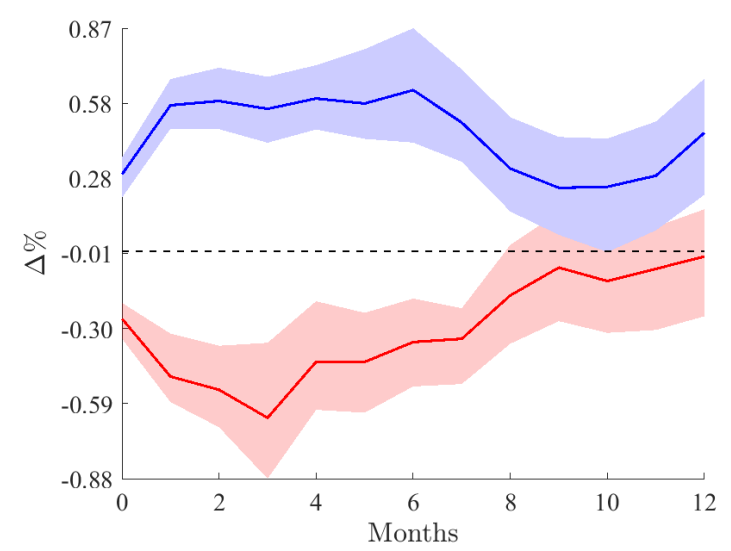

(c) Exports to euro area

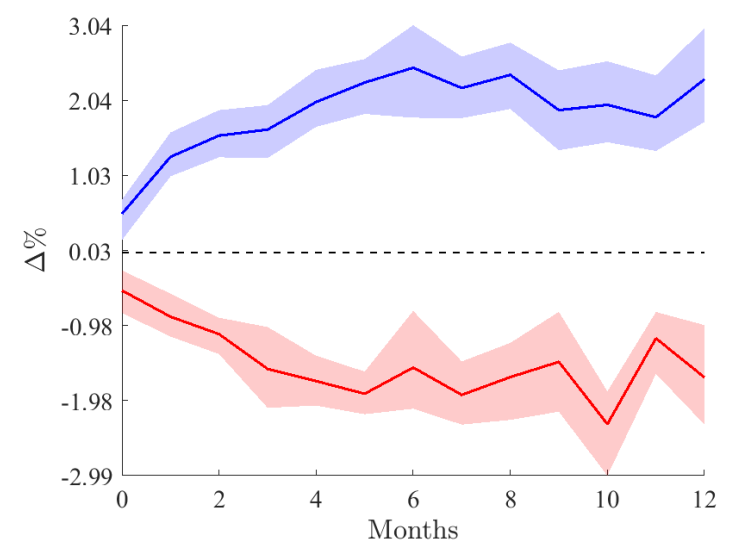

(e) Exports to RoW

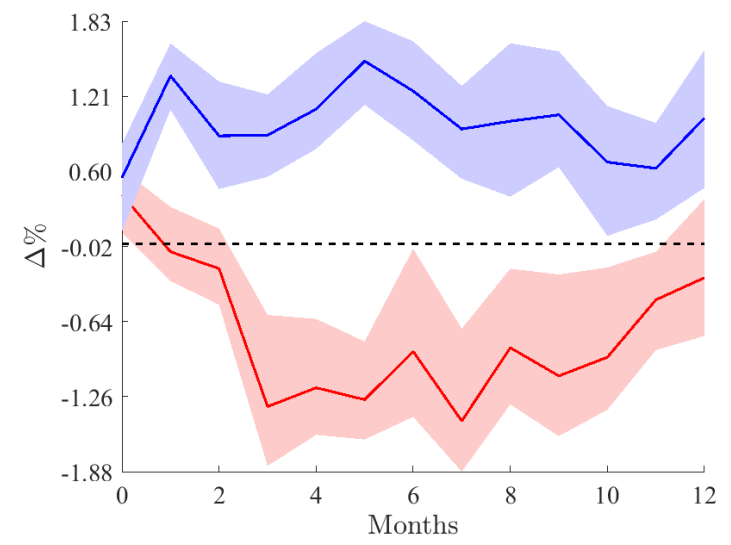

(b) Inflation

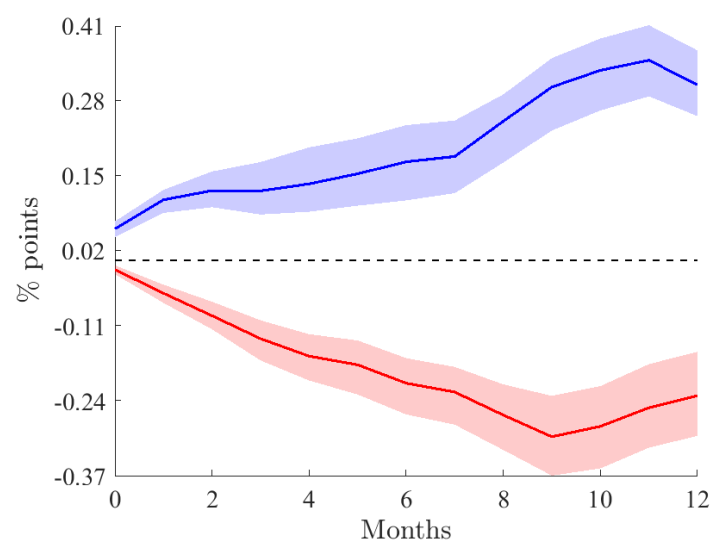

(d) Imports from euro area

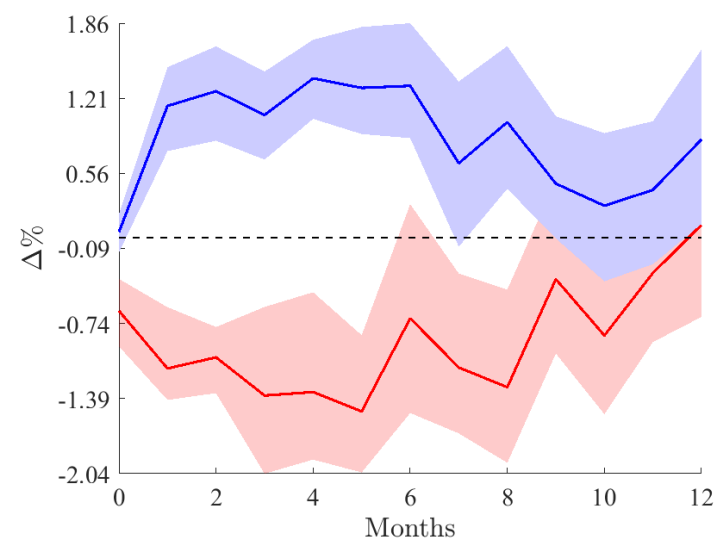

(f) Imports from RoW

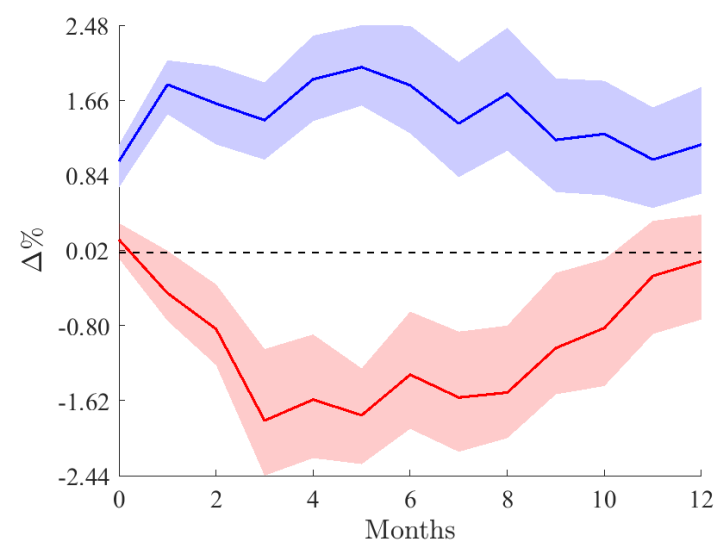

Notes: Inflation is defined as the y-o-y percentage change of the CPI. $\Delta \%$ : log-change. Shaded areas are $68 \%$ HPD credible sets.

Source: Authors' calculations. 
Local projection IRFs have shown that euro area stress shocks might have a sizeable impact on the macroeconomic performance of extra-EA AEs and EMEs, which is even bigger than what observed for a global risk aversion shock in some cases (e.g., inflation). However, our estimates relate to shocks that correspond to quite extreme events, which have the potential to become "global" from the standpoint of extra-EA economies. Moreover, as these events are quite rare, they should not systematically contribute to the volatility of macroeconomic aggregates.

We gather additional evidence on this particular aspect by carrying out a forecast error variance decomposition of the local projection IRFs. With this purpose, we adopt the methodology proposed by Gorodnichenko and Lee (2019), which is outlined in Section D.1.

As expected, global risk aversion shocks are generally more relevant in that they account for a higher share of the variance of all the variables considered, both in AEs (Figure 12) and EMEs (Figure 13). Notably, the cumulative contribution of both global and euro area stress shocks is bigger for AEs compared to EMEs. Indeed, while on the one hand the two shocks combined can explain a maximum share of variance ranging from around 11\% (industrial production) to $13 \%$ (exports to RoW) in AEs, on the other hand the range drops down to between $4.5 \%$ (inflation) to approximately 10\% (imports from RoW) for EMEs. Out of these shares, less than half is attributable to euro area shocks. 
Figure 12: Advanced economies - Forecast error variance decomposition of local projection IRFs

(a) Industrial production

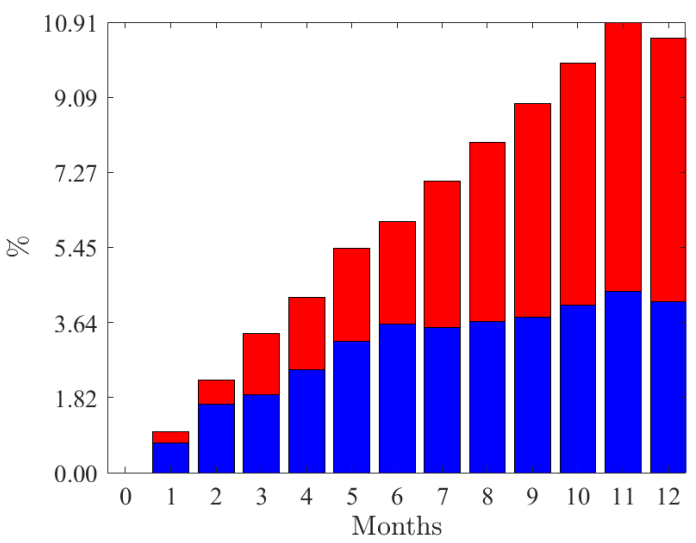

(c) Exports to euro area

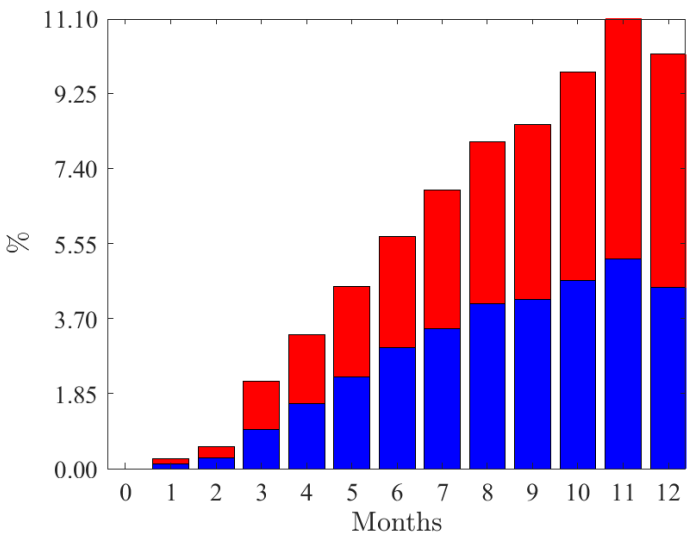

(e) Exports to RoW

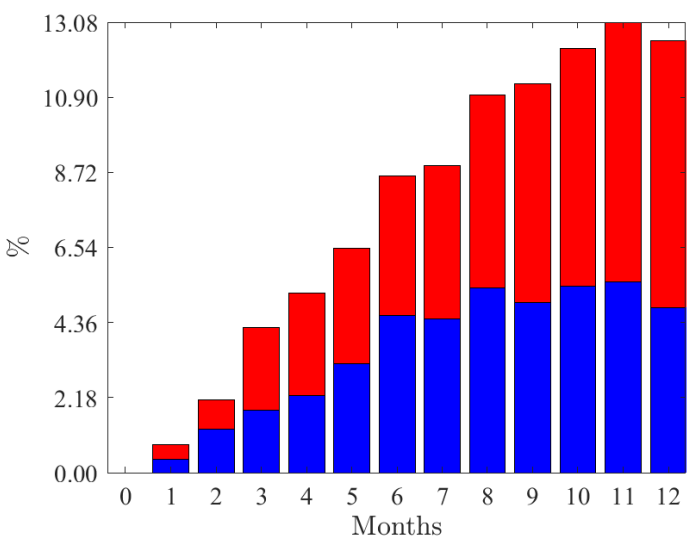

(b) Inflation

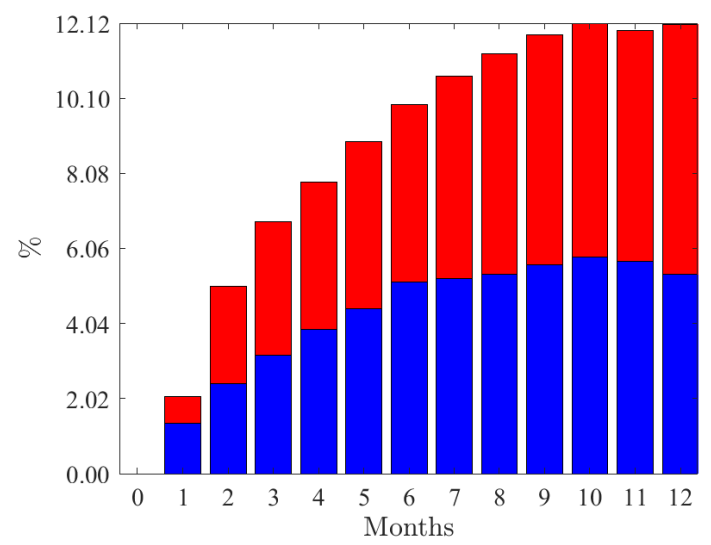

(d) Imports from euro area

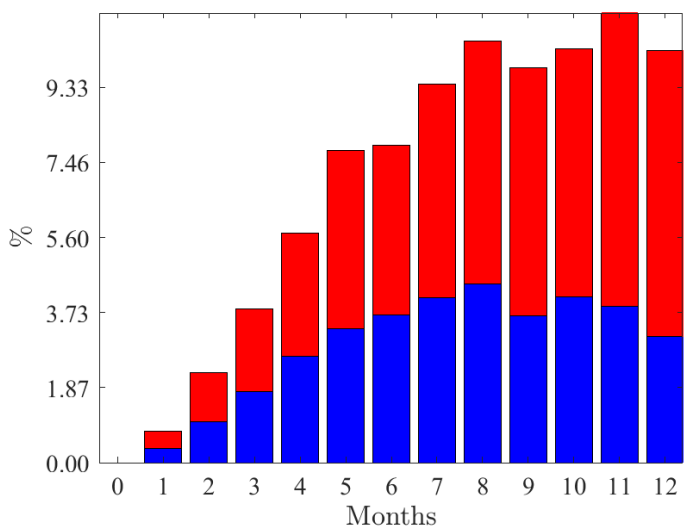

(f) Imports from RoW

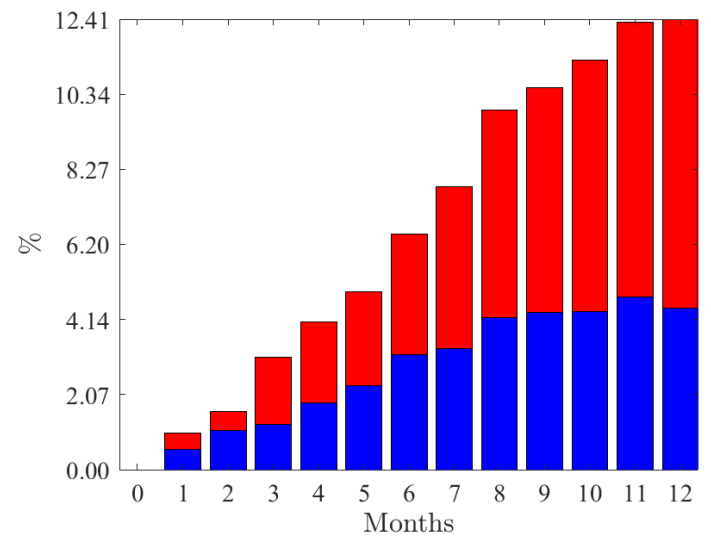

Notes: Contributions are expressed as \% share of total variance. Red bars refer to global shock contributions, blue bars to euro area stress shock contributions. Estimates are significant at the $68 \%$ confidence level. Source: Authors' calculations. 
Figure 13: Emerging and developing economies - Forecast error variance decomposition of local projection IRFs

(a) Industrial production

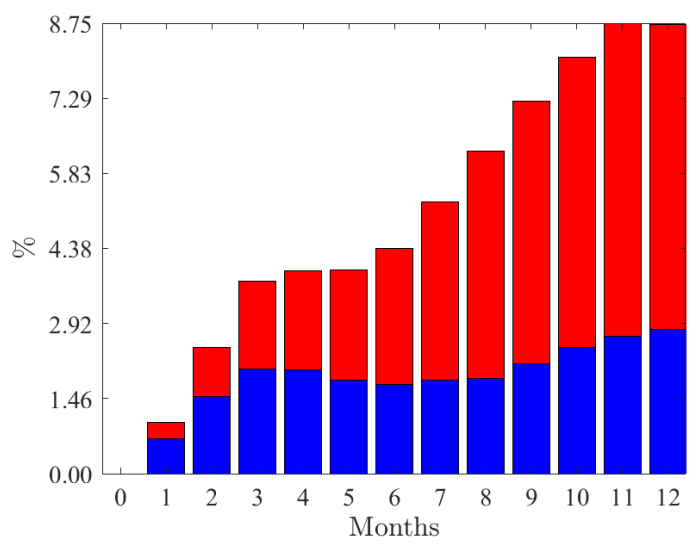

(c) Exports to euro area

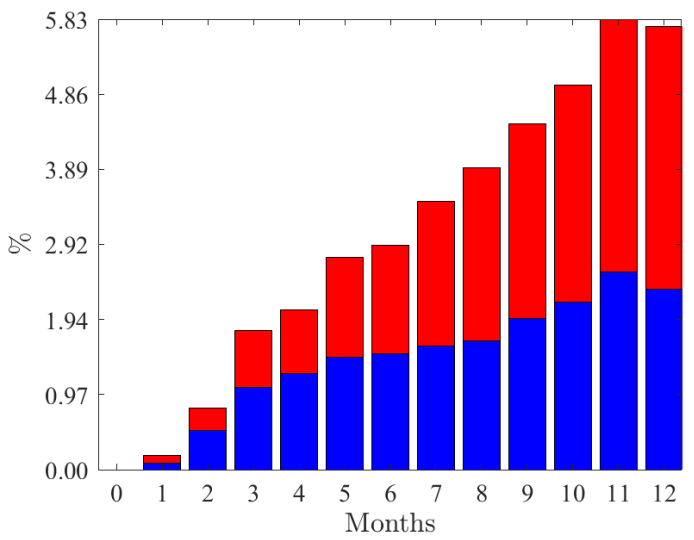

(e) Exports to RoW

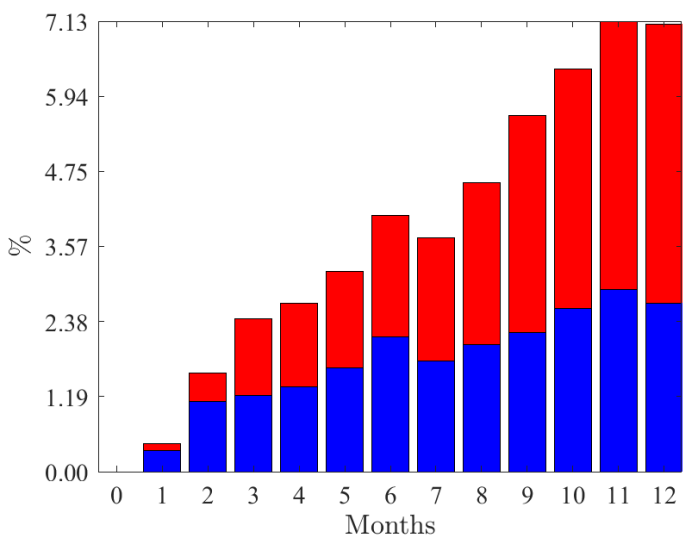

(b) Inflation

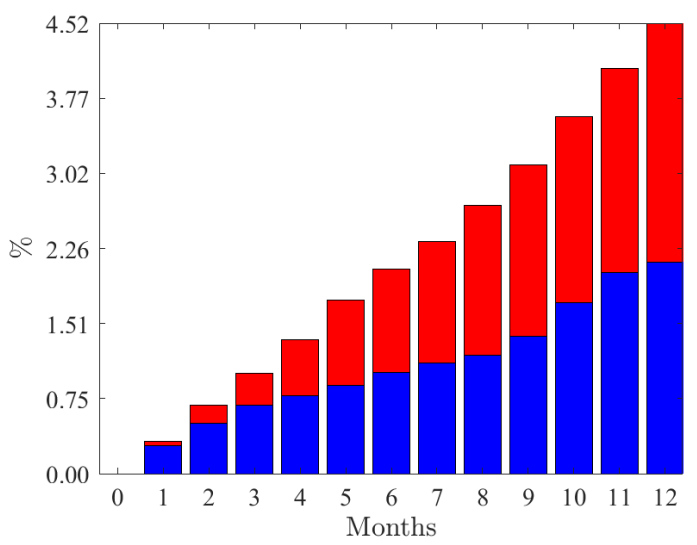

(d) Imports from euro area

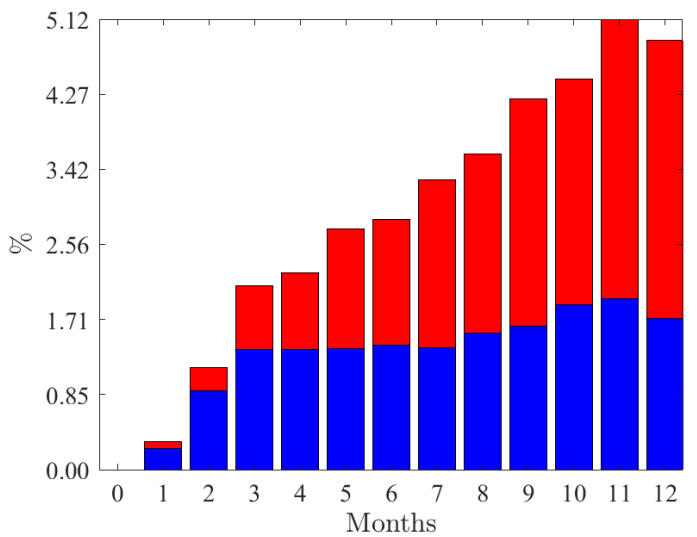

(f) Imports from RoW

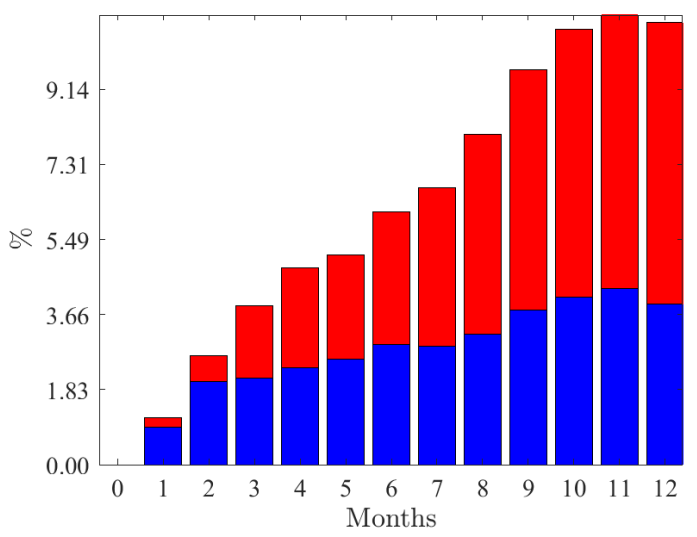

Notes: Contributions are expressed as \% share of total variance. Red bars refer to global shock contributions, blue bars to euro area stress shock contributions. Estimates are significant at the $68 \%$ confidence level. Source: Authors' calculations. 


\section{Conclusion}

This paper investigates what we call the "international dimension of an incomplete EMU" which consists of the potential effects of progress or setbacks in the completion of EMU on the global economy. In this sense, our analysis provides a contribution to the ongoing debate about the completion of the Economic and Monetary Union.

With this aim, we first construct a measure of EMU cohesion and we show that it approximates well the progress (or slowdown) in the completion of EMU. The second step of our analysis then consists of applying structural and narrative techniques to daily financial data to disentangle between "euro area stress shocks" and global risk aversion shocks. It is shown that, even if the effects of these shocks are qualitatively similar and therefore difficult to distinguish, the empirical strategy proposed in Section 2.1 is nonetheless able to tease the two out and to produce statistically different results.

Finally, in Section 3 we construct IRFs via panel local projections to estimate the effects of euro area stress shocks onto macroeconomic aggregates in the rest of the world. Our main finding is that a decrease in the cohesion of EMU has an overall negative impact on the economy of the rest of the world, both on the demand and the supply side. In addition, these shocks entail a generalized slowdown in global trade, not only because of a decrease in imports and exports from and to the euro area, but also due to a drop in trade flows outside the euro area. While these effects do not generally change across AEs and EMs and appear to be broadly symmetric, the positive impact of an increase in EMU cohesion is found to be generally more persistent over time than the drawbacks stemming from a setback in the completion of the EMU. In short, our results provide evidence that the incomplete nature of EMU is not only a problem for the euro area but also for the rest of the world. 


\section{References}

[1] Acharya, V., Drechsler, I., and Schnabl, P. "A Pyrrhic Victory? Bank Bailouts and Sovereign Credit Risk". The Journal of Finance, 69(6):2689-2739, 2014. doi: 10.1111/jofi. 12206. URL https://onlinelibrary.wiley.com/doi/abs/10.1111/jofi.12206.

[2] Afonso, A., Arghyrou, M. G., and Kontonikas, A. "PRICING SOVEREIGN BOND RISK IN THE EUROPEAN MONETARY UNION AREA: AN EMPIRICAL INVESTIGATION". International Journal of Finance E Economics, 19(1):49-56, 2014. doi: 10. 1002/ijfe.1484. URL https://onlinelibrary.wiley.com/doi/abs/10.1002/ijfe.1484.

[3] Afonso, A., Arghyrou, M. G., Bagdatoglou, G., and Kontonikas, A. "On the time-varying relationship between EMU sovereign spreads and their determinants". Economic Modelling, 44:363 - 371, 2015. ISSN 0264-9993. doi: https://doi.org/10.1016/j.econmod.2014.07.025. URL http://www.sciencedirect.com/science/article/pii/S0264999314002806.

[4] Afonso, A., Arghyrou, M. G., Gadea, M. D., and Kontonikas, A. "Whatever it takes to resolve the European sovereign debt crisis? Bond pricing regime switches and monetary policy effects". Journal of International Money and Finance, 86:1 - 30, 2018. ISSN 0261-5606. doi: https://doi.org/10.1016/j.jimonfin.2018.04.005. URL http://www.sciencedirect. com/science/article/pii/S0261560618302262.

[5] Ahmad, W., Sehgal, S., and Bhanumurthy, N. "Eurozone crisis and briicks stock markets: Contagion or market interdependence?". Economic Modelling, 33:209 - 225, 2013. ISSN 0264-9993. doi: https://doi.org/10.1016/j.econmod.2013.04.009. URL http: //www.sciencedirect.com/science/article/pii/S0264999313001405.

[6] Aizenman, J., Jinjarak, Y., Lee, M., and Park, D. "Developing countries' financial vulnerability to the euro crisis: An event study of equity and bond markets". Working Paper 18028, National Bureau of Economic Research, May 2012. URL http://www.nber.org/ papers/w18028.

[7] Allegret, J.-P., Raymond, H., and Rharrabti, H. "The impact of the european sovereign debt crisis on banks stocks. some evidence of shift contagion in europe". Journal of Banking Finance, 74:24 - 37, 2017. ISSN 0378-4266. doi: https://doi.org/10.1016/ j.jbankfin.2016.10.004. URL http://www.sciencedirect.com/science/article/pii/ S0378426616301765.

[8] Altavilla, C. and Giannone, D. "The Effectiveness of NonStandard Monetary Policy Measures: Evidence from Survey Data". Journal of Applied Econometrics, 32(5):952-964, August 2017. URL https://ideas.repec.org/a/wly/japmet/v32y2017i5p952-964.html.

[9] Altavilla, C., Giannone, D., and Lenza, M. "The Financial and Macroeconomic Effects of the OMT Announcements". International Journal of Central Banking, 12(3):29-57, September 2016. URL https://ideas.repec.org/a/ijc/ijcjou/y2016q3a1.html.

[10] Angelini, P., Grande, G., and Panetta, F. "The negative feedback loop between banks and sovereigns". Questioni di Economia e Finanza (Occasional Papers) 213, Bank of Italy, Economic Research and International Relations Area, Jan. 2014. URL https://ideas. repec.org/p/bdi/opques/qef_213_14.html.

[11] Antolín-Díaz, J. and Rubio-Ramírez, J. F. "Narrative Sign Restrictions for SVARs" . American Economic Review, 108(10):2802-29, October 2018. doi: 10.1257/aer.20161852. URL http://www . aeaweb.org/articles?id=10.1257/aer. 20161852. 
[12] Arias, J. E., Rubio-Ramírez, J. F., and Waggoner, D. F. "Inference based on structural vector autoregressions identified with sign and zero restrictions: Theory and applications". Econometrica, 86(2):685-720, 2018.

[13] Attinasi, M. G., Checherita-Westphal, C., and Nickel, C. "What explains the surge in euro area sovereign spreads during the financial crisis of 2007-09?". Working Paper Series 1131, European Central Bank, Dec. 2009. URL https://ideas.repec.org/p/ecb/ ecbwps/20091131.html.

[14] Bahaj, S. "Sovereign spreads in the euro area: Cross border transmission and macroeconomic implications". Journal of Monetary Economics, 110:116 - 135, 2020. ISSN 0304-3932. doi: https://doi.org/10.1016/j.jmoneco.2019.01.006. URL http://www.sciencedirect. com/science/article/pii/S0304393219300066.

[15] Barnichon, R. and Mesters, G. "The Phillips multiplier". Economics Working Papers 1632, Department of Economics and Business, Universitat Pompeu Fabra, Jan. 2019. URL https://ideas.repec.org/p/upf/upfgen/1632.html.

[16] Baumeister, C. and Benati, L. "Unconventional Monetary Policy and the Great Recession: Estimating the Macroeconomic Effects of a Spread Compression at the Zero Lower Bound". International Journal of Central Banking, 9(2):165-212, June 2013. URL https://ideas. repec.org/a/ijc/ijcjou/y2013q2a9.html.

[17] Bird, G., Du, W., Pentecost, E., and Willett, T. "Safe haven or contagion? the disparate effects of euro-zone crises on non-euro-zone neighbours". Applied Economics, 49 (59):5895-5904, 2017. doi: 10.1080/00036846.2017.1358445. URL https://doi.org/10. $1080 / 00036846.2017 .1358445$.

[18] Bocola, L. and Dovis, A. "Self-Fulfilling Debt Crises: A Quantitative Analysis". American Economic Review, 109(12):4343-77, December 2019. doi: 10.1257/aer.20161471. URL https://www . aeaweb.org/articles?id=10.1257/aer. 20161471.

[19] Born, B., Mller, G., Pfeifer, J., and Wellmann, S. "Different No More: Country Spreads in Advanced and Emerging Economies". Technical report, 2020.

[20] Ca' Zorzi, M., Dedola, L., Georgiadis, G., Jarociński, M., Stracca, L., and Strasser, G. "Monetary Policy and its Transmission in a Globalised World". Technical report, forthcoming 2019.

[21] Chan, J. C. C. and Eisenstat, E. "Bayesian model comparison for time-varying parameter vars with stochastic volatility". Journal of Applied Econometrics, 33(4):509-532, 2018. doi: 10.1002/jae.2617. URL https://onlinelibrary.wiley.com/doi/abs/10. $1002 / \mathrm{jae} .2617$.

[22] Chen, Q., Lombardi, M., Ross, A., and Zhu, F. "Global impact of US and euro area unconventional monetary policies: a comparison". BIS Working Papers 610, Bank for International Settlements, Jan. 2017. URL https://ideas.repec.org/p/bis/biswps/ 610.html.

[23] Claessens, S., Tong, H., and Zuccardi, I. "Did the euro crisis affect non-financial firm stock prices through a financial or trade channel?". IMF Working Papers, pages 1-40, 2011.

[24] Corsetti, G. "Roots of the Eurozone crisis: Incomplete development and imperfect credibility of institutions". In Baldwin, R. and Giavazzi, F., editors, The Eurozone Crisis: A Consensus View of the Causes and a Few Possible Remedies, chapter 4, pages 85-98. VoxEU.org eBook, 2015. URL https://voxeu.org/sites/default/files/file/reboot_upload_0. pdf. 
[25] Corsetti, G., Eichengreen, B., Hale, G., and Tallman, E. "The Euro Crisis in the Mirror of the EMS: How Tying Odysseus to the Mast Avoided the Sirens but Led Him to Charybdis". Working Paper Series 2019-4, Federal Reserve Bank of San Francisco, Feb. 2019. URL https://ideas.repec.org/p/fip/fedfwp/2019-04.html.

[26] De Bruyckere, V., Gerhardt, M., Schepens, G., and Vennet, R. V. "Bank/sovereign risk spillovers in the European debt crisis". Journal of Banking $\&$ Finance, 37(12):4793 4809, 2013. ISSN 0378-4266. doi: https://doi.org/10.1016/j.jbankfin.2013.08.012. URL http://www.sciencedirect.com/science/article/pii/S0378426613003439.

[27] De Grauwe, P. and Ji, Y. "Self-fulfilling crises in the Eurozone: An empirical test". Journal of International Money and Finance, 34:15 - 36, 2013. ISSN 0261-5606. doi: https:// doi.org/10.1016/j.jimonfin.2012.11.003. URL http://www.sciencedirect.com/science/ article/pii/S0261560612001829. The European Sovereign Debt Crisis: Background Perspective.

[28] De Santis, R. A. "The Euro area sovereign debt crisis: safe haven, credit rating agencies and the spread of the fever from Greece, Ireland and Portugal". Working Paper Series 1419, European Central Bank, Feb. 2012. URL https://ideas.repec.org/p/ecb/ ecbwps/20121419.html.

[29] De Santis, R. A. "Redenomination risk". Journal of Money, Credit and Banking, 51(8): 2173-2206, 2019. doi: 10.1111/jmcb.12582. URL https://onlinelibrary.wiley.com/ doi/abs/10.1111/jmcb.12582.

[30] Di Cesare, A., Grande, G., Manna, M., and Taboga, M. "Recent estimates of sovereign risk premia for euro-area countries". Questioni di Economia e Finanza (Occasional Papers) 128, Bank of Italy, Economic Research and International Relations Area, Sept. 2012. URL https://ideas.repec.org/p/bdi/opques/qef_128_12.html.

[31] Dorrucci, E., Mongelli, F. P., Ioannou, D., and Terzi, A. "The four unions "PIE"; on the Monetary Union "CHERRY": a new index of European Institutional Integration". Occasional Paper Series 160, European Central Bank, Feb. 2015. URL https://ideas. repec.org/p/ecb/ecbops/2015160.html.

[32] Draghi, M. "Introductory statement to the press conference, President of the ECB", April 2019. URL https://www.ecb.europa.eu/press/pressconf/2019/html/ecb. is190410 c27197866f .en.html.

[33] Dungey, M., Fry, R. A., Gonzlez-hermosillo, B., Martin, V. L., and Tang, C. Contagion and the Transmission of Financial Crises, chapter 14, pages 129-135. John Wiley Sons, Ltd, 2011. ISBN 9781118267646. doi: 10.1002/9781118267646.ch14. URL https://onlinelibrary.wiley.com/doi/abs/10.1002/9781118267646.ch14.

[34] European Central Bank. "The International Role of the Euro". Technical report, June 2020. URL https://www.ecb.europa.eu/pub/ire/html/ecb.ire202006 81495c263a. en.html.

[35] European Commission. "DG Trade Statistical guide". Technical report, July 2019. URL https://trade.ec.europa.eu/doclib/docs/2013/may/tradoc_151348.pdf.

[36] Fagan, G. and McNelis, P. "TARGET Balances and Macroeconomic Adjustment to Sudden Stops in the Euro Area". The Institute for International Integration Studies Discussion Paper Series iiisdp465, IIIS, Dec 2014. URL https://ideas.repec.org/p/iis/dispap/ iiisdp465.html. 
[37] Forbes, K. "The "Big C": Identifying Contagion". Working Paper 18465, National Bureau of Economic Research, October 2012. URL http://www.nber.org/papers/w18465.

[38] Forbes, K., Reinhardt, D., and Wieladek, T. "The spillovers, interactions, and (un)intended consequences of monetary and regulatory policies". Journal of Monetary Economics, 85:1 - 22, 2017. ISSN 0304-3932. doi: https://doi.org/10.1016/j.jmoneco.2016.10. 008. URL http://www. sciencedirect.com/science/article/pii/s0304393216301106. Carnegie-Rochester-NYU Conference Series on Public Policy Monetary Policy: Globalization in the Aftermath of the Crisis.

[39] Galí, J. and Gambetti, L. "Has the U.S. Wage Phillips Curve Flattened? A Semi-Structural Exploration". Working Paper 25476, National Bureau of Economic Research, January 2019. URL http://www.nber.org/papers/w25476.

[40] Gertler, M. and Karadi, P. "Monetary Policy Surprises, Credit Costs, and Economic Activity". American Economic Journal: Macroeconomics, 7(1):44-76, January 2015. doi: $10.1257 / \mathrm{mac} .20130329$. URL http://www . aeaweb. org/articles?id=10.1257/mac. 20130329.

[41] Gorodnichenko, Y. and Lee, B. "Forecast Error Variance Decompositions with Local Projections". Journal of Business \& Economic Statistics, 0(0):1-24, 2019. doi: 10.1080/ 07350015.2019.1610661. URL https://doi.org/10.1080/07350015.2019.1610661.

[42] IMF. "Chapter 1 - Global Prospects and Policies". World Economic Outlook. April 2019. URL https://www.imf.org/en/Publications/WEO/Issues/2019/07/18/ WEOupdateJuly2019.

[43] Jarociński, M. and Karadi, P. "Deconstructing Monetary Policy Surprises - The Role of Information Shocks". American Economic Journal: Macroeconomics, 12(2):1-43, April 2020. doi: 10.1257/mac.20180090. URL https://www.aeaweb.org/articles?id=10. $1257 / \mathrm{mac} .20180090$.

[44] Jordà, O. "Estimation and inference of impulse responses by local projections". American Economic Review, 95(1):161-182, March 2005. doi: 10.1257/0002828053828518. URL http://www . aeaweb.org/articles?id=10.1257/0002828053828518.

[45] Junker, J.-C., Tusk, D., Dijsselbloem, J., Draghi, M., and Schulz, M. "The Five President's Report: Completing Europe's Economic and Monetary Union”. Technical report, June 2015. URL https://ec.europa.eu/commission/sites/beta-political/files/ 5-presidents-report_en.pdf.

[46] Krishnamurthy, A., Nagel, S., and Vissing-Jorgensen, A. "ECB Policies Involving Government Bond Purchases: Impact and Channels*". Review of Finance, 22(1):1-44, 112017. ISSN 1572-3097. doi: 10.1093/rof/rfx053. URL https://doi.org/10.1093/rof/rfx053.

[47] Lloyd, S. P. "Unconventional Monetary Policy and the Interest Rate Channel: Signalling and Portfolio Rebalancing". Cambridge Working Papers in Economics 1735, Faculty of Economics, University of Cambridge, Sept. 2017. URL https://ideas.repec.org/p/ $\mathrm{cam} / \mathrm{camdae} / 1735 . \mathrm{html}$.

[48] Manganelli, S. and Wolswijk, G. "What drives spreads in the euro area government bond market?". Economic Policy, 24(58):191-240, 08 2014. ISSN 0266-4658. doi: 10.1111/j. 1468-0327.2009.00220.x. URL https://doi.org/10.1111/j.1468-0327.2009.00220.x. 
[49] Neri, S. and Ropele, T. "The macroeconomic effects of the sovereign debt crisis in the euro area". Temi di discussione (Economic working papers) 1007, Bank of Italy, Economic Research and International Relations Area, Mar. 2015. URL https://ideas.repec.org/ p/bdi/wptemi/td_1007_15.html.

[50] Newey, W. and West, K. "A Simple, Positive Semi-definite, Heteroskedasticity and Autocorrelation Consistent Covariance Matrix". Econometrica, 55(3):703-08, 1987. URL https://EconPapers.repec.org/RePEc:ecm:emetrp:v:55:y:1987:i:3:p:703-08.

[51] Pisani-Ferry, J. and Zettelmeyer, J., editors. Risk Sharing Plus Market Discipline: A New Paradigm for Euro Area Reform? A Debate. VoxEU ebook, June 2019. URL https://voxeu.org/content/ risk-sharing-plus-market-discipline-new-paradigm-euro-area-reform-debate.

[52] Rubio-Ramírez, J. F., Waggoner, D. F., and Zha, T. "Structural Vector Autoregressions: Theory of Identification and Algorithms for Inference". Review of Economic Studies, 77(2): 665-696, 2010. URL https://ideas.repec.org/a/oup/restud/v77y2010i2p665-696. html.

[53] Stracca, L. "Our currency, your problem? The global effects of the euro debt crisis". European Economic Review, 74:1 - 13, 2015. ISSN 0014-2921. doi: https://doi.org/10.1016/ j.euroecorev.2014.10.009. URL http://www.sciencedirect.com/science/article/pii/ S0014292114001512.

[54] Van Rompuy, H., Barroso, J. M., Junker, J. C., and Draghi, M. "TOWARDS A GENUINE ECONOMIC AND MONETARY UNION". Technical report, December 2012. URL https://ec.europa.eu/commission/sites/beta-political/files/ 5-presidents-report_en.pdf.

[55] von Hagen, J., Schuknecht, L., and Wolswijk, G. "Government bond risk premiums in the EU revisited: The impact of the financial crisis". European Journal of Political Economy, 27(1):36-43, March 2011. URL https://ideas.repec.org/a/eee/poleco/ v27y2011i1p36-43.html. 


\section{Appendices}

\section{A Data and Countries}

Table A.1 reports the variables used in our estimations, together with the sources.

Table A.1: Variables and sources

\begin{tabular}{|c|c|}
\hline & Sources \\
\hline \multicolumn{2}{|l|}{ Daily SVAR } \\
\hline EA stress variable ${ }^{1}$ & $\mathrm{ECB} \mathrm{SDW}^{+}$ \\
\hline EA equity price index ${ }^{2}$ & ECB SDW \\
\hline Euro Effective Exchange Rate ${ }^{3}$ & ECB SDW \\
\hline VIX & DataStream \\
\hline World Equity Price Index (excl. EA) ${ }^{4}$ & Bloomberg \\
\hline US 10-year govt bond yield & Bloomberg \\
\hline EMBI+ spread (excluding Europe) $)^{5}$ & Haver Analytics \\
\hline Monthly Local Projections & \\
\hline Industrial Production Index & DataStream \\
\hline Consumer Price Index & Haver Analytics \\
\hline Imports/Exports & IMF DOTS* \\
\hline \multicolumn{2}{|c|}{$\begin{array}{l}\text { Definitions: }{ }^{1} \text { Average } 10 \text {-year government bond spread of Italy and } \\
\text { Spain against Germany; }{ }^{2} \text { Dow Jones Euro Stoxx } 50 \text { EUR Price In- } \\
\text { dex; }{ }^{3} \text { Exchange rate against a basket consisting of the currencies } \\
\text { of the main } 38 \text { EA trading partners (NEER-38); an increase in the } \\
\text { €NEER implies an appreciation of the euro against other currencies; } \\
{ }^{4} \text { FTSE World Equity price index, excluding Eurobloc; }{ }^{5} \text { Spread of } \\
\text { the yields on emerging market debt over the entire US Treasury curve. } \\
\text { Sources: }{ }^{+} \text {Statistical Data Warehouse; } \\
{ }^{*} \text { Direction of Trade Statistics }\end{array}$} \\
\hline
\end{tabular}

The countries included in the panel local projections in Section 3 are reported below.

\section{Advanced Economies}

Australia, Canada, Denmark, Japan, Norway, Sweden, Switzerland, United Kingdom, United States

\section{Emerging Markets and Developing Economies}

Argentina, Brazil, Bulgaria, Chile, China, Czech Republic, Hungary, India, Indonesia, South Korea, Malaysia, Mexico, Peru, Philippines, Poland, Russia, South Africa, Thailand, Turkey

\section{B The Bayesian VAR}

The structural VAR in Equation (2.1) can be rewritten in companion form as:

$$
A_{0} Y_{t}=A_{+} \mathbf{Y}_{t-1}+\varepsilon_{t},
$$


where $A_{+}^{\prime}=\left[\mathbf{c}^{\prime}, A_{1}^{\prime}, \ldots, A_{p}^{\prime}\right]$ is an $m \times n$ matrix and $\mathbf{Y}_{t-1}^{\prime}=\left[\mathbf{1}, Y_{t-1}^{\prime}, \ldots, Y_{t-p}^{\prime}\right]$ is an $m \times 1$ vector, with $m=N p+1$. The reduced-form representation of Equation (B.2) is then:

$$
Y_{t}=B \mathbf{Y}_{t-1}+u_{t}
$$

where $B=A_{0}^{-1} A_{+}, u_{t}=A_{0}^{-1} \varepsilon_{t}$ and $E\left[u_{t} u_{t}^{\prime}\right]=\Sigma=\left(A_{0} A_{0}^{\prime}\right)^{-1}$.

\section{B.1 Impulse response functions}

Denote as $\boldsymbol{\Theta}$ the vector of structural coefficients from Equation (B.2): $\boldsymbol{\Theta} \equiv\left(A_{0}, A^{+}\right)$. Given this, the response of the $i$ th variable to the $j$ th structural shock at horizon $k$ is the $(i, j)$ th element of matrix $\mathbf{L}_{k}(\boldsymbol{\Theta})$ which is defined recursively as:

$$
\mathbf{L}_{k}(\boldsymbol{\Theta})=\left\{\begin{array}{cll}
\left(A_{0}^{-1}\right)^{\prime} & \text { if } \quad k=0 \\
\sum_{\ell=1}^{k}\left(A_{0}^{-1} A_{\ell}\right)^{\prime} \mathbf{L}_{k-\ell}(\boldsymbol{\Theta}) & \text { if } \quad 1 \leq k \leq p \\
\sum_{\ell=1}^{p}\left(A_{0}^{-1} A_{\ell}\right)^{\prime} \mathbf{L}_{k-\ell}(\boldsymbol{\Theta}) & \text { if } & p<k<\infty
\end{array}\right.
$$

\section{B.2 Structural shocks and historical decomposition}

Given $\Theta$, the structural shocks at time $t$ are:

$$
\varepsilon_{t}(\mathbf{\Theta})=A_{0} Y_{t}-A_{+} \mathbf{Y}_{\mathbf{t}-\mathbf{1}}, \quad \text { for } t=1, \ldots, T \text {. }
$$

Therefore, the cumulative contribution of the $j$ th shock to the observed changes of the $i$ th variable between $t$ and $t+h$ is given by:

$$
H_{i, j, t, t+h}\left(\boldsymbol{\Theta}, \varepsilon_{t}, \ldots, \varepsilon_{t+h}\right)=\sum_{\ell=0}^{h} \mathbf{e}_{i, n}^{\prime} \mathbf{L}_{\ell}(\Theta) \mathbf{e}_{j, n} \mathbf{L}_{\ell}(\Theta) \mathbf{e}_{j, n} \mathbf{e}_{j, n}^{\prime} \varepsilon_{t+h-\ell}, \quad \text { for } i \geq 1, j \leq N, h \geq 0,
$$

where $\mathbf{e}_{j, n}$ is the $j$ th column of the identity matrix $I_{N}$.

\section{B.3 Traditional sign restrictions}

We impose traditional sign and zero restrictions following Rubio-Ramírez et al. (2010) and Arias et al. (2018). Notably, such restrictions can be expressed in the following functional form:

$$
\Gamma(\boldsymbol{\Theta})=\left(\mathbf{e}_{1, n}^{\prime} \mathbf{F}(\boldsymbol{\Theta})^{\prime} \mathbf{S}_{1}^{\prime}, \ldots, \mathbf{e}_{n, n}^{\prime} \mathbf{F}(\boldsymbol{\Theta})^{\prime} \mathbf{S}_{n}^{\prime}\right)^{\prime}>\mathbf{0}
$$

We then impose restrictions on both $A_{0}$ and $\mathbf{L}(\boldsymbol{\Theta})$ by appropriately setting $\mathbf{S}_{j}$ and $\mathbf{F}(\boldsymbol{\Theta})$ in Equation (B.6). For instance, restrictions on the impulse response functions (IRFs) can be 
imposed by defining $\mathbf{F}(\boldsymbol{\Theta})$ as vertically stacking the IRFs at different horizons on which we want to impose restrictions and, then, $\mathbf{S}_{j}$ as a $s_{j} \times r_{j}$ matrix of $0 \mathrm{~s}, 1 \mathrm{~s}$ and $-1 \mathrm{~s}$ corresponding to the horizons and variables over which to impose the $r_{j}$ restrictions to identify shock $j$. For restrictions on $A_{0}$, on the other hand, we set $\mathbf{F}(\boldsymbol{\Theta})=\boldsymbol{\Theta}$ and we define $\mathbf{S}_{j}$ as an $s_{j} \times r_{j}$ matrix of $0 \mathrm{~s}, 1 \mathrm{~s}$ and $-1 \mathrm{~s}$ corresponding to the elements of $A_{0}$ that we want to restrict.

\section{B.4 Narrative restrictions}

We adopt the classification and formalization of narrative sign restrictions proposed by AntolínDíaz and Rubio-Ramírez (2018).

\section{B.4.1 Signs of the structural shocks}

The first type of narrative restrictions concerns the signs of the structural shocks in correspondence of particular episodes occurring at known dates. Assume, for instance, that the sign of the $j$ th shock is positive (negative) at $s_{j}$ episodes at dates $t_{1}, \ldots, t_{s_{j}}$. This can be imposed in the SVAR by setting:

$$
\mathbf{e}_{j, n}^{\prime} \varepsilon_{t_{\nu}}(\boldsymbol{\Theta})\left\{\begin{array}{c}
>0 \\
(<0)
\end{array} \text { for } 1 \leq \nu \leq s_{j} .\right.
$$

\section{B.4.2 Contributions of the structural shocks}

The second class of narrative restrictions relates to the importance that a particular structural shock has at a point in time. Notably, researchers might have additional information indicating that a certain shock has been the most important contributor to the unexpected movements of the variable of interest at well-defined dates. Such information can be incorporated in the model by imposing additional restrictions on the historical decomposition.

This can be done in two ways, by specifying either: (a) that shock $j$ was the most (least) important driver of the unexpected change in a variable during some periods; or (b) that shock $j$ was the overwhelming (negligible) driver of the unexpected change in a variable during some periods. For case (a), the restrictions can be imposed on the historical decomposition as follows:

$$
\begin{aligned}
& \left|H_{i_{\nu}, j, t_{\nu}, t_{\nu}+h_{\nu}}\left(\boldsymbol{\Theta}, \varepsilon_{t_{\nu}}(\boldsymbol{\Theta}), \ldots, \varepsilon_{t_{\nu}+h}(\boldsymbol{\Theta})\right)\right| \\
& -\max _{j^{\prime} \neq j}\left|H_{i_{\nu}, j^{\prime}, t_{\nu}, t_{\nu}+h_{\nu}}\left(\boldsymbol{\Theta}, \varepsilon_{t_{\nu}}(\boldsymbol{\Theta}), \ldots, \varepsilon_{t_{\nu}+h}(\boldsymbol{\Theta})\right)\right|
\end{aligned}\left\{\begin{array}{l}
>0 \\
(<0)
\end{array}\right.
$$


for $1 \leq \nu \leq s_{j}$. For case (b), instead, the restrictions on the historical decomposition become:

$$
\begin{aligned}
& \left|H_{i_{\nu}, j, t_{\nu}, t_{\nu}+h_{\nu}}\left(\boldsymbol{\Theta}, \varepsilon_{t_{\nu}}(\boldsymbol{\Theta}), \ldots, \varepsilon_{t_{\nu}+h}(\boldsymbol{\Theta})\right)\right| \\
& -\sum_{j^{\prime} \neq j}\left|H_{i_{\nu}, j^{\prime}, t_{\nu}, t_{\nu}+h_{\nu}}\left(\boldsymbol{\Theta}, \varepsilon_{t_{\nu}}(\boldsymbol{\Theta}), \ldots, \varepsilon_{t_{\nu}+h}(\boldsymbol{\Theta})\right)\right|\left\{\begin{array}{l}
>0 \\
(<0)
\end{array}\right.
\end{aligned}
$$

for $1 \leq \nu \leq s_{j}$.

\section{B.5 Bayesian estimation}

We adopt the algorithm proposed in Section III of Antolín-Díaz and Rubio-Ramírez (2018) to estimate the SVAR via Bayesian methods. Notably, the algorithm is an adaptation of the approach proposed by Rubio-Ramírez et al. (2010) and Arias et al. (2018) to take the narrative sign restrictions into account.

Given Equation (B.7), Equation (B.8) and Equation (B.9), narrative sign restrictions can be characterized as:

$$
\phi\left(\boldsymbol{\Theta}, \varepsilon^{\nu}\right)>\mathbf{0},
$$

where $\varepsilon^{\nu}=\left(\varepsilon_{t_{1}}, \ldots, \varepsilon_{t_{\nu}}\right)$ are the structural shocks constrained by the narrative sign restrictions. Differently from traditional sign restrictions, then, narrative sign restrictions depend on structural shocks as well. By Equation (B.4) above:

$$
\varepsilon_{t}=g_{h}\left(Y_{t}, \mathbf{Y}_{\mathbf{t}-\mathbf{1}}, \boldsymbol{\Theta}\right) \quad \text { for } 1 \leq t \leq T
$$

with $Y_{t}=g_{h}^{-1}\left(\varepsilon_{t} ; \mathbf{Y}_{\mathbf{t}-\mathbf{1}}, \boldsymbol{\Theta}\right)$ for $1 \leq t \leq T$. Combining Equation (B.11) with Equation (B.10) leads to:

$$
\tilde{\phi}\left(\boldsymbol{\Theta}, Y^{\nu}, \mathbf{Y}_{\mathbf{t}-\mathbf{1}}^{\nu}\right)=\phi\left(\boldsymbol{\Theta}, g_{h}\left(Y_{t_{1}}, \mathbf{Y}_{\mathbf{t}_{\mathbf{1}}-\mathbf{1}}, \boldsymbol{\Theta}\right), \ldots, g_{h}\left(Y_{t_{\nu}}, \mathbf{Y}_{\mathbf{t}_{\nu}-\mathbf{1}}, \boldsymbol{\Theta}\right)\right)>\mathbf{0}
$$

where $Y^{\nu}=\left(Y_{t_{1}}, \ldots, Y_{t_{\nu}}\right)$ and $\mathbf{Y}_{\mathbf{t}-\mathbf{1}}^{\nu}=\left(\mathbf{Y}_{\mathbf{t}_{1}-\mathbf{1}}, \ldots, \mathbf{Y}_{\mathbf{t}_{\nu}-\mathbf{1}}\right)$. Hence, Equation (B.12) is continuous on the parameters given the data and is continuous on the structural shocks given the parameters.

As in Arias et al. (2018), we consider the orthogonal reduced-form parameterization of Equation (B.2), which depends on $\Sigma, B$ and $Q$, where $Q \in \mathcal{O}(n)$, the set of all orthogonal $n \times n$ matrices. The mapping from $\Theta$ to $(B, \Sigma, Q)$ requires a decomposition of $\Sigma, h(\Sigma)$, satisfying: $h(\Sigma)^{\prime} h(\Sigma)=\Sigma$, where $h$ is differentiable. Usually, $h(\Sigma)$ is chosen to be the Cholesky decompo- 
sition of $\Sigma$. Therefore, the mapping between $\boldsymbol{\Theta}$ and $(B, \Sigma, Q)$ can be defined as:

$$
f_{h}(\boldsymbol{\Theta})=(\underbrace{\left(A_{+} A_{0}^{-1}\right)}_{B}, \underbrace{\left(A_{0} A_{0}^{\prime}\right)^{-1}}_{\Sigma}, \underbrace{h\left(\left(A_{0} A_{0}^{\prime}\right)^{-1} A_{0}\right)}_{Q}),
$$

where $h\left(\left(A_{0} A_{0}^{\prime}\right)^{-1} A_{0}\right)$ is an orthogonal matrix. The inverse of $f_{h}$ is then:

$$
f_{h}^{-1}(B, \Sigma, Q)=(\underbrace{h(\Sigma)^{-1} Q}_{A_{0}}, \underbrace{B h(\Sigma)^{-1} Q}_{A_{+}}) .
$$

Using Equation (B.14), Equation (B.12) can be rewritten as:

$$
\mathbf{\Phi}\left(B, \Sigma, Q, Y^{\nu}, \mathbf{Y}_{\mathbf{t}-\mathbf{1}}^{\nu}\right)=\tilde{\phi}\left(f_{h}^{-1}(B, \Sigma, Q), Y^{\nu}, \mathbf{Y}_{\mathbf{t}-\mathbf{1}}^{\nu}\right)>\mathbf{0}
$$

\section{B.5.1 Posterior with traditional sign restrictions}

The posterior of $(B, \Sigma, Q)$ subject to traditional sign restrictions is:

$$
\begin{aligned}
& \pi\left(B, \Sigma, Q \mid \mathbf{Y}^{T}, \boldsymbol{\Gamma}\left(B, \Sigma, Q, Y^{\nu}, \mathbf{Y}_{\mathbf{t}-\mathbf{1}}^{\nu}\right)\right) \\
& =\frac{\overbrace{\pi\left(\mathbf{Y}^{T} \mid B, \Sigma\right)}^{\text {Likelihood }} \overbrace{\pi\left(B, \Sigma, Q \mid \boldsymbol{\Gamma}\left(f_{h}^{-1}(B, \Sigma, Q)\right)>\mathbf{0}\right)}^{\text {Prior }}}{\int \pi\left(\mathbf{Y}^{T} \mid B, \Sigma\right) \pi\left(B, \Sigma, Q \mid \boldsymbol{\Gamma}\left(f_{h}^{-1}(B, \Sigma, Q)\right)>\mathbf{0}\right) d(B, \Sigma, Q)}
\end{aligned},
$$

where $\mathbf{Y}^{T}=\left\{Y_{1-p}, \ldots, Y_{0}, \ldots, Y_{T}\right\}$. As the likelihood function does not depend on $Q$ and the function characterizing the sign restrictions, $\boldsymbol{\Gamma}\left(f_{h}^{-1}(B, \Sigma, Q)\right)$, does not depend on the structural shocks, traditional sign restrictions simply truncate the prior of $(B, \Sigma, Q)$.

\section{B.5.2 Posterior with narrative sign restrictions}

The posterior of $(B, \Sigma, Q)$ subject to narrative sign restrictions is:

$$
\begin{aligned}
& \pi\left(B, \Sigma, Q \mid \mathbf{Y}^{T}, \mathbf{\Phi}\left(B, \Sigma, Q, Y^{\nu}, \mathbf{Y}_{\mathbf{t}-\mathbf{1}}^{\nu}\right)\right) \\
& =\frac{\overbrace{\left.\pi\left(\mathbf{Y}^{T} \mid B, \Sigma, Q, \mathbf{\Phi}\left(B, \Sigma, Q, Y^{\nu}, \mathbf{Y}_{\mathbf{t}-\mathbf{1}}^{\nu}\right)>\mathbf{0}\right)\right)}^{\text {Likelihood }} \overbrace{\pi(B, \Sigma, Q)}^{\text {Prior }}}{\int \pi\left(\mathbf{Y}^{T} \mid B, \Sigma, Q, \mathbf{\Phi}\left(B, \Sigma, Q, Y^{\nu}, \mathbf{Y}_{\mathbf{t}-\mathbf{1}}^{\nu}\right)>\mathbf{0}\right) \pi(B, \Sigma, Q) d(B, \Sigma, Q)}
\end{aligned} .
$$

In this case, the function characterizing the narrative restrictions, $\left.\mathbf{\Phi}\left(B, \Sigma, Q, Y^{\nu}, \mathbf{Y}_{\mathbf{t}-\mathbf{1}}^{\nu}\right)\right)$, depends on the structural shocks, thus implying that narrative sign restrictions truncate the likelihood function. 
The truncated likelihood can be rewritten as:

$$
\begin{aligned}
& \left.\pi\left(\mathbf{Y}^{T} \mid B, \Sigma, Q, \mathbf{\Phi}\left(B, \Sigma, Q, Y^{\nu}, \mathbf{Y}_{\mathbf{t}-\mathbf{1}}^{\nu}\right)>\mathbf{0}\right)\right) \\
& =\frac{\left[\mathbf{\Phi}\left(B, \Sigma, Q, Y^{\nu}, \mathbf{Y}_{\mathbf{t}-\mathbf{1}}^{\nu}\right)>\mathbf{0}\right] \pi\left(\mathbf{Y}^{T} \mid B, \Sigma\right)}{\int\left[\mathbf{\Phi}\left(B, \Sigma, Q, Y^{\nu}, \mathbf{Y}_{\mathbf{t}-\mathbf{1}}^{\nu}\right)>\mathbf{0}\right] \pi\left(\mathbf{Y}^{T} \mid B, \Sigma\right) d \mathbf{Y}^{T}}
\end{aligned}
$$

In addition, the denominator of Equation (B.17) is:

$$
\begin{aligned}
& \int\left[\mathbf{\Phi}\left(B, \Sigma, Q, Y^{\nu}, \mathbf{Y}_{\mathbf{t}-\mathbf{1}}^{\nu}\right)>\mathbf{0}\right] \pi\left(\mathbf{Y}^{T} \mid B, \Sigma\right) d \mathbf{Y}^{T} \\
& =\int\left[\mathbf{\Phi}\left(B, \Sigma, Q, Y^{\nu}, \mathbf{Y}_{\mathbf{t}-\mathbf{1}}^{\nu}\right)>\mathbf{0}\right]\left(\prod_{t=1}^{T} \pi\left(Y_{t} \mid \mathbf{Y}_{\mathbf{t}-\mathbf{1}}, B, \Sigma\right)\right) d\left(Y_{1}, \ldots, Y_{T}\right) \\
& =\int\left[\tilde{\mathbf{\Phi}}\left(B, \Sigma, Q, \varepsilon^{\nu}\right)>\mathbf{0}\right]\left(\prod_{t=1}^{T} \frac{\pi\left(g_{h}^{-1}\left(\varepsilon_{t} ; \mathbf{Y}_{\mathbf{t}-\mathbf{1}}, f_{h}^{-1}(B, \Sigma, Q)\right) \mid \mathbf{Y}_{\mathbf{t}-\mathbf{1}}, B, \Sigma\right)}{v_{g_{h}}\left(g_{h}^{-1}\left(\varepsilon_{t} ; \mathbf{Y}_{\mathbf{t}-\mathbf{1}}, f_{h}^{-1}(B, \Sigma, Q)\right)\right)}\right) d\left(\varepsilon_{1}, \ldots, \varepsilon_{T}\right)
\end{aligned}
$$

where $\tilde{\boldsymbol{\Phi}}\left(B, \Sigma, Q, \varepsilon^{\nu}\right)=\phi\left(f_{h}^{-1}\left(B, \Sigma, Q, \varepsilon^{\nu}\right)\right.$ and $v_{g_{h}}$ is the volume of function $g_{h}$ evaluated at $g_{h}^{-1}\left(\varepsilon_{t} ; \mathbf{Y}_{\mathbf{t}-\mathbf{1}}, f_{h}^{-1}(B, \Sigma, Q)\right)$. By Equation (B.11):

$$
v_{g_{h}}\left(g_{h}^{-1}\left(\varepsilon_{t} ; \mathbf{Y}_{\mathbf{t}-\mathbf{1}}, f_{h}^{-1}(B, \Sigma, Q)\right)\right)=|\Sigma|^{-1 / 2} \quad \text { for } 1 \leq t \leq T
$$

It follows that:

$$
\begin{aligned}
& \int\left[\tilde{\mathbf{\Phi}}\left(B, \Sigma, Q, \varepsilon^{\nu}\right)>\mathbf{0}\right]\left(\prod_{t=1}^{T} \frac{\pi\left(g_{h}^{-1}\left(\varepsilon_{t} ; \mathbf{Y}_{\mathbf{t}-\mathbf{1}}, f_{h}^{-1}(B, \Sigma, Q)\right) \mid \mathbf{Y}_{\mathbf{t}-\mathbf{1}}, B, \Sigma\right)}{v_{g_{h}}\left(g_{h}^{-1}\left(\varepsilon_{t} ; \mathbf{Y}_{\mathbf{t}-\mathbf{1}}, f_{h}^{-1}(B, \Sigma, Q)\right)\right)}\right) d\left(\varepsilon_{1}, \ldots, \varepsilon_{T}\right) \\
& =\int\left[\tilde{\mathbf{\Phi}}\left(B, \Sigma, Q, \varepsilon^{\nu}\right)>\mathbf{0}\right]\left(\prod_{t=1}^{T}\left(\varepsilon_{t}\right) d\left(\varepsilon_{1}, \ldots, \varepsilon_{T}\right)\right. \\
& =\int\left[\tilde{\mathbf{\Phi}}\left(B, \Sigma, Q, \varepsilon^{\nu}\right)>\mathbf{0}\right]\left(\prod_{s=1}^{\nu}\left(\varepsilon_{t_{s}}\right) d\left(\varepsilon_{t_{1}}, \ldots, \varepsilon_{t_{\nu}}\right) .\right.
\end{aligned}
$$

By using Equation (B.18), Equation (B.17) can be rearranged as:

$$
\begin{aligned}
& \left.\pi\left(\mathbf{Y}^{T} \mid B, \Sigma, Q, \mathbf{\Phi}\left(B, \Sigma, Q, Y^{\nu}, \mathbf{Y}_{\mathbf{t}-\mathbf{1}}^{\nu}\right)>\mathbf{0}\right)\right) \\
& =\frac{\left[\mathbf{\Phi}\left(B, \Sigma, Q, Y^{\nu}, \mathbf{Y}_{\mathbf{t}-\mathbf{1}}^{\nu}\right)>\mathbf{0}\right] \pi\left(\mathbf{Y}^{T} \mid B, \Sigma\right)}{\omega(B, \Sigma, Q)},
\end{aligned}
$$

where $\omega(B, \Sigma, Q)=\int\left[\tilde{\mathbf{\Phi}}\left(B, \Sigma, Q, \varepsilon^{\nu}\right)>\mathbf{0}\right]\left(\prod_{s=1}^{\nu}\left(\varepsilon_{t_{s}}\right)\right) d\left(\varepsilon_{t_{1}}, \ldots, \varepsilon_{t_{\nu}}\right)$.

Therefore, the truncated likelihood can be simply formulated as a weighted likelihood, with weights that are inversely proportional to the probability of satisfying the narrative restriction. 


\section{B.5.3 Posterior with both traditional and narrative sign restrictions}

By assuming a normal-inverse-Wishart-uniform prior for $(B, \Sigma, Q)$, it follows that $\pi(B, \Sigma, Q)=$ $\pi(B, \Sigma)$. Therefore, the posterior subject to, respectively, traditional and narrative sign restrictions becomes:

\section{Traditional sign restrictions}

$\pi\left(B, \Sigma, Q \mid \boldsymbol{\Gamma}\left(f_{h}^{-1}(B, \Sigma, Q)\right)>\mathbf{0}\right) \propto\left[\boldsymbol{\Gamma}\left(f_{h}^{-1}(B, \Sigma, Q)\right)>\mathbf{0}\right] \pi\left(\mathbf{Y}^{\mathbf{T}} \mid B, \Sigma\right) \pi(B, \Sigma)$

\section{Narrative sign restrictions}

$$
\pi\left(B, \Sigma, Q \mid \mathbf{Y}^{\mathbf{T}}, \mathbf{\Phi}\left(B, \Sigma, Q, Y^{\nu}, \mathbf{Y}_{\mathbf{t}-\mathbf{1}}^{\nu}\right)>\mathbf{0}\right) \propto \frac{\left[\mathbf{\Phi}\left(B, \Sigma, Q, Y^{\nu}, \mathbf{Y}_{\mathbf{t}-\mathbf{1}}^{\nu}\right)>\mathbf{0}\right] \pi\left(\mathbf{Y}^{T} \mid B, \Sigma\right)}{\omega(B, \Sigma, Q)} \pi(B, \Sigma) .
$$

Consequently, the posterior of $(B, \Sigma, Q)$, subject to both traditional and narrative sign restrictions, is:

$$
\begin{aligned}
& \pi\left(B, \Sigma, Q \mid \boldsymbol{\Gamma}\left(f_{h}^{-1}(B, \Sigma, Q)\right)>\mathbf{0}, \mathbf{\Phi}\left(B, \Sigma, Q, Y^{\nu}, \mathbf{Y}_{\mathbf{t}-\mathbf{1}}^{\nu}\right)>\mathbf{0}\right) \\
& \propto\left[\boldsymbol{\Gamma}\left(f_{h}^{-1}(B, \Sigma, Q)\right)>\mathbf{0}\right] \frac{\left[\mathbf{\Phi}\left(B, \Sigma, Q, Y^{\nu}, \mathbf{Y}_{\mathbf{t}-\mathbf{1}}^{\nu}\right)>\mathbf{0}\right] \pi\left(\mathbf{Y}^{T} \mid B, \Sigma\right)}{\omega(B, \Sigma, Q)} \pi(B, \Sigma) .
\end{aligned}
$$

\section{B.5.4 Algorithm to draw from the posterior}

Given the normal-inverse-Wishart-uniform priors and posteriors for $(B, \Sigma, Q)$, the algorithm used to independently draw from the posterior under both traditional and narrative sign restrictions consists of the following steps:

1. Independently draw $(B, \Sigma)$ from the normal-inverse-Wishart posterior of the reduced-form parameters and $Q$ from the uniform distribution over $\mathcal{O}(n)$.

2. Check whether $\boldsymbol{\Gamma}\left(f_{h}^{-1}(B, \Sigma, Q)\right)>\mathbf{0}$ and $\mathbf{\Phi}\left(B, \Sigma, Q, Y^{\nu}, \mathbf{Y}_{\mathbf{t}-\mathbf{1}}^{\nu}\right)>\mathbf{0}$ are satisfied.

3. If not, discard the draw. Otherwise set the importance weight of $(B, \Sigma, Q)$ as follows:

(a) Take $N$ independent draws of $\varepsilon^{\nu}$ from the standard normal distribution.

(b) Approximate $\omega(B, \Sigma, Q)$ as the proportion of $N$ satisfying $\tilde{\boldsymbol{\Phi}}\left(B, \Sigma, Q, \varepsilon^{\nu}\right)>\mathbf{0}$ and set the importance weight to $1 / \omega(B, \Sigma, Q)$.

4. Return to step 1 until the required number of draws has been reached.

5. Draw with replacement from the set of $(B, \Sigma, Q)$ using the importance weights computed in step $3 b$. 


\section{BVAR robustness checks}

This section reports several robustness checks performed on the specification of Equation (2.1) above. Notably, we check the validity of the baseline setup's working assumptions concerning: i) the need for additional variables to exactly qualify the relationship between EASTR and EMBI+ and, thus, get a complete identification of shocks; ii) the addition of narrative restrictions on top of the traditional sign and magnitude restrictions; iii) the appropriateness of the lag choice $(p=2)$.

\section{C.1 Simplified setup}

In this section we estimate a three-variable SVAR and we use simple sign restrictions to identify the euro area and global risk aversion shocks.

Specifically, given Equation (2.1), we set $\mathrm{Y}_{t}=\left\{E A S T R_{t}, E M B I_{t}, \Delta_{t}\right\}$, with $\Delta_{t}=E A S T R_{t}-$ $E M B I_{t}$. The identification scheme is based on the assumption that a euro area stress shock positively impacts the EASTR variable to a larger extent than the EMBI+ spread, thus leading to an increase in $\Delta_{t}$. On the other hand, a global risk aversion shock impacts the EMBI+ spread more than the EASTR variable, thus leading to a decrease in $\Delta_{t}$ (see Table C.2).

Table C.2: Simplified sign restrictions

\begin{tabular}{|c|c|c|}
\hline $\begin{array}{ll}\text { Variables } & \text { Shocks } \\
\end{array}$ & EA stress & Global \\
\hline $\begin{array}{l}\text { EASTR }_{t} \\
\mathrm{EMBI}_{t}\end{array}$ & $>0$ & $\begin{array}{l}\geq 0 \\
>0\end{array}$ \\
\hline$\Delta_{t}$ & $>0$ & $<0$ \\
\hline
\end{tabular}

Figure C.1 depicts the IRFs to an increase by $10 \mathrm{bps}$ in, respectively, the EASTR variable (positive euro area stress shock) and the EMBI+ spread (positive global risk aversion shock). The most striking difference compared to the baseline setup is given by the IRFs of the EASTR variable, in that they are not statistically different across the two shocks. This simpler setup, though appealing given the much reduced computational burden, is not suitable for the purpose of our exercise, as we are also interested into the dynamics concerning other financial indicators. Including the VIX, equity prices, the NEER and the US 10 year yield indeed allows us to characterize some of the most interesting qualitative features of the two shocks. As shown in Section 2.2, a global risk aversion shock triggers a flight-to-safety reaction, while a euro area stress shock does not. These mechanisms cannot be detected without including additional variables and restrictions.

Further insights are provided by the comparison across the structural shocks series that are 
Figure C.1: IRFs - euro area stress (blue) and global risk aversion (red)
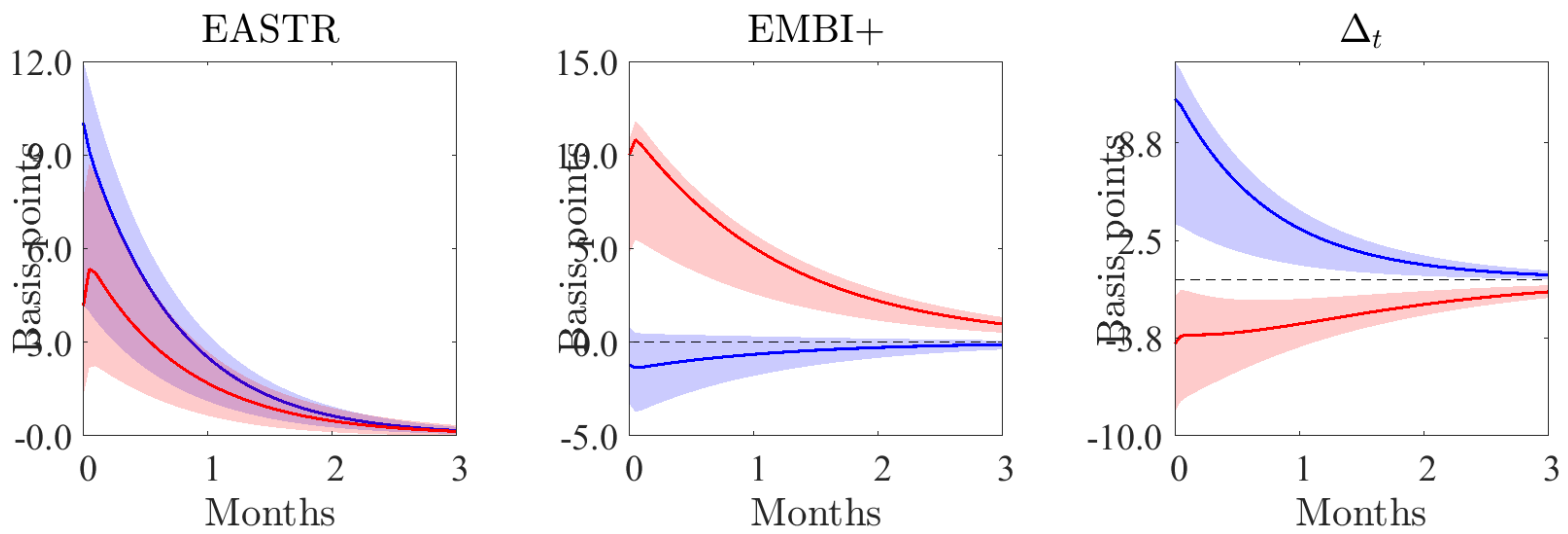

Notes: Shaded areas represent 68\% HPD credible sets. In this setup, euro area stress shocks are represented by increases in the EASTR variable, while global risk aversion shocks are given by increases in the EMBI+. Source: Authors' calculations.

Figure C.2: Daily shock series in the simplified model (red), in the model with traditional restrictions (green) and in the model with narrative restrictions (blue).

(a) Euro area stress

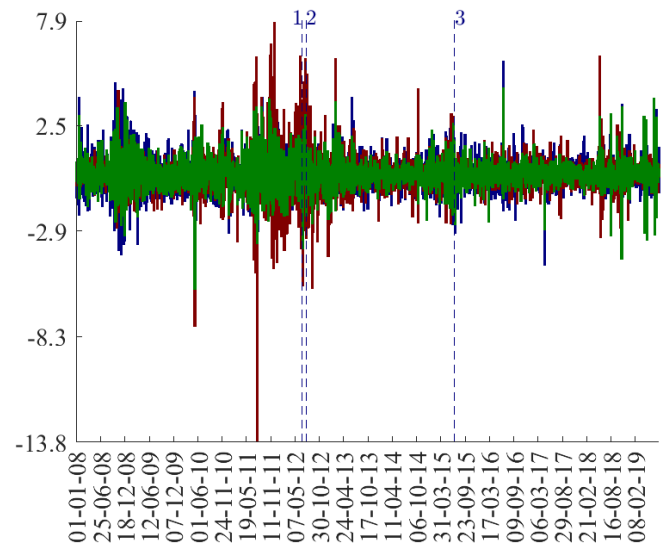

(b) Global risk aversion

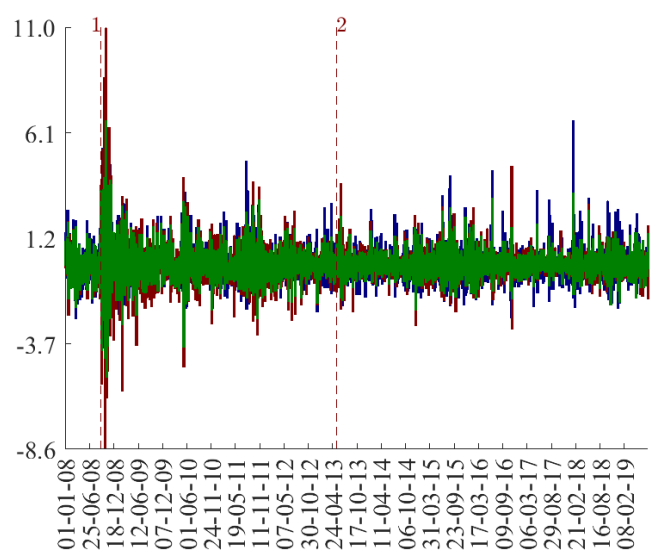

Notes: Blue dashed lines in the left panel mark the following relevant events: 1. Spain and Cyprus request for programme; 2. London speech; 3. EG agrees on Greek $3^{\text {rd }}$ programme. Red dashed lines in the right panel correspond to the following events: 1. Lehman Brothers collapse; 2. Fed's "Taper tantrum."

Source: Authors' calculations.

obtained in three different frameworks: the simplified setup, the SVAR with traditional restrictions and the SVAR with narrative restrictions (red, green and blue bars in Figure C.2). Figure C.2a shows that the series of euro area stress shocks as estimated in the baseline model is much more volatile compared to the estimates produced by the seven-variable models with traditional sign restrictions (green bars) and narrative restrictions (blue bars, our baseline). This is particularly evident over the period 2011-2012 and, to a lesser extent, towards the end of the sample. In addition, we also find that the correlation coefficients across the euro area shock series estimated in the three models are generally high (Table C.3). 
Table C.3: Estimated correlation coefficients across shock series

\begin{tabular}{c|cccc}
\hline \hline Shocks & \multicolumn{2}{|c}{ EA stress } & \multicolumn{2}{c}{ Global risk aversion } \\
& Model II & Model III & Model II & Model III \\
\hline Model I & 0.61 & 0.51 & 0.88 & 0.61 \\
& $(0.00)$ & $(0.00)$ & $(0.00)$ & $(0.00)$ \\
Model II & & 0.75 & & 0.88 \\
& & $(0.00)$ & & $(0.00)$ \\
\hline \hline
\end{tabular}

Notes: Model I: three-variable SVAR; Model II: seven-variable SVAR with sign + magnitude restrictions; Model III: seven-variable SVAR with narrative restrictions (baseline). P-values in parentheses.

\section{C.2 Comparing sign, magnitude and narrative restrictions}

Figures C.3 and C.4 display the impulse response functions (IRFs) with traditional (sign and sign + magnitude) and narrative restrictions, for a 10-basis-point increase in the EASTR variable and a $1 \%$ increase in the VIX respectively, which, in our framework, correspond to a positive euro area stress shock and a positive shock to global risk aversion. Generally speaking, the imposition of the narrative restrictions makes the point estimates more precise than in the frameworks with only sign and magnitude restrictions ("traditional" settings henceforth). The difference in the results is particularly evident in Figure C.3, which shows that narrative restrictions allow for a much sharper identification of the euro area stress shock as well as of the impact on the other endogenous variables. In particular, in the traditional settings, an increase in the EASTR variable does not have any significant impact on either the US 10-year yield or the EMBI+ spread. By adding the narrative restrictions, the former increases on impact by around $6 \mathrm{bps}$, while the latter is significantly impacted by an average of +1.76 bps over a three-month horizon. Such dynamics could not be captured by relying on sign and magnitude restrictions only. On top of that, a quick comparison with the IRFs to a global risk aversion shocks shows how a relatively narrow set of narrative restrictions is able to unveil the inherent different nature of the two shocks, in particular when considering the effects on the US 10-year yield (Figure C.4).

In this regard, the traditional settings tend to overestimate the impact that a $1 \%$ increase in the VIX exerts on the EASTR variable, the US 10-year yield and the EMBI+ spread (Figure C.4). In these cases, indeed, the absolute average difference among the IRFs is in the order of 3.7, 2.1 and 3.5 basis points respectively. 
Figure C.3: IRFs for a EA stress shock (10-basis points increase in EASTR) - sign (black), magnitude (blue) and narrative (red) restrictions
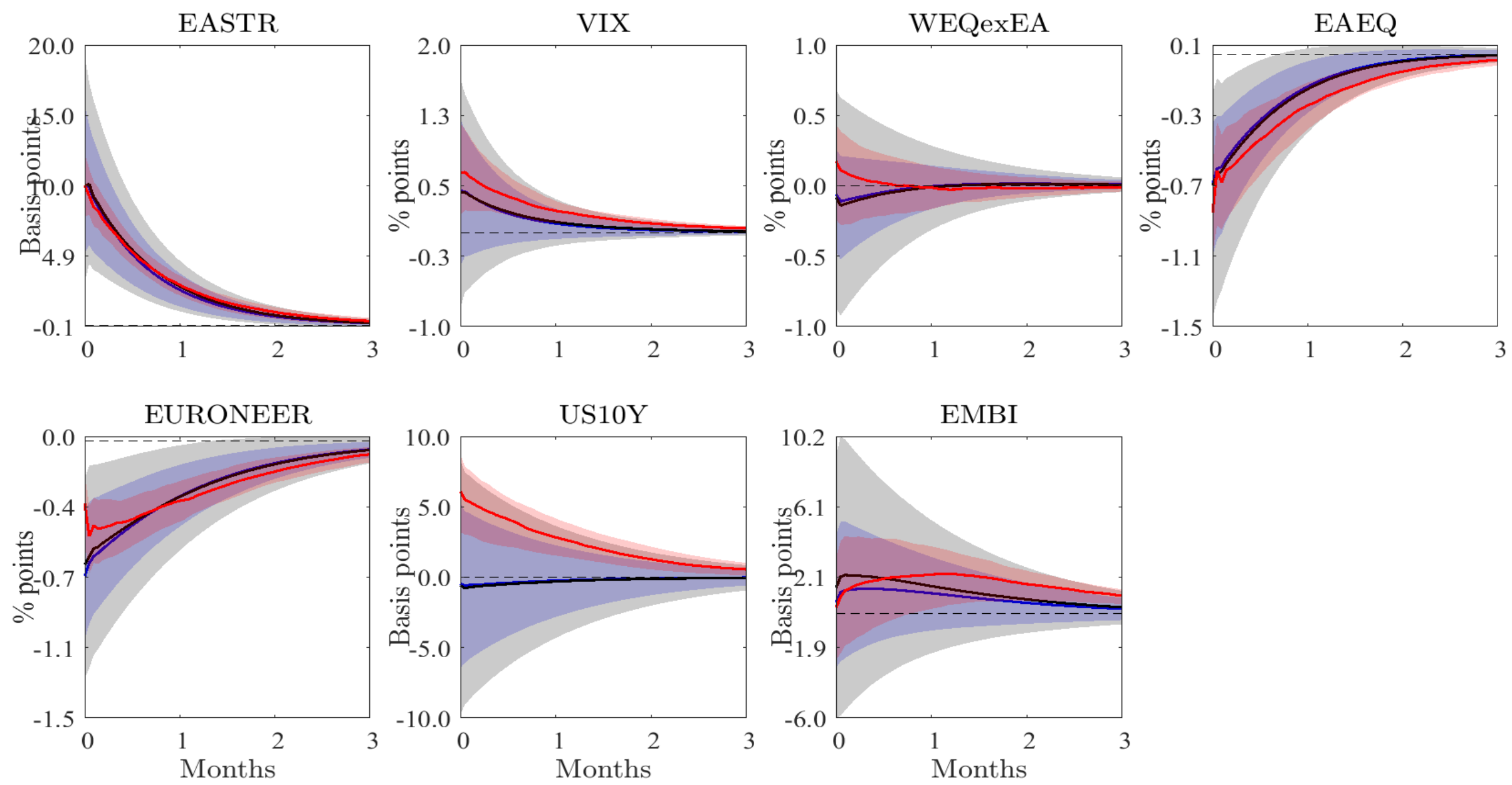

Notes: Shaded areas represent $68 \%$ HPD credible sets.

Source: Authors' calculations. 
Figure C.4: IRFs for a global risk aversion shock (1\% increase in VIX) - sign (black), magnitude (blue) and narrative (red) restrictions
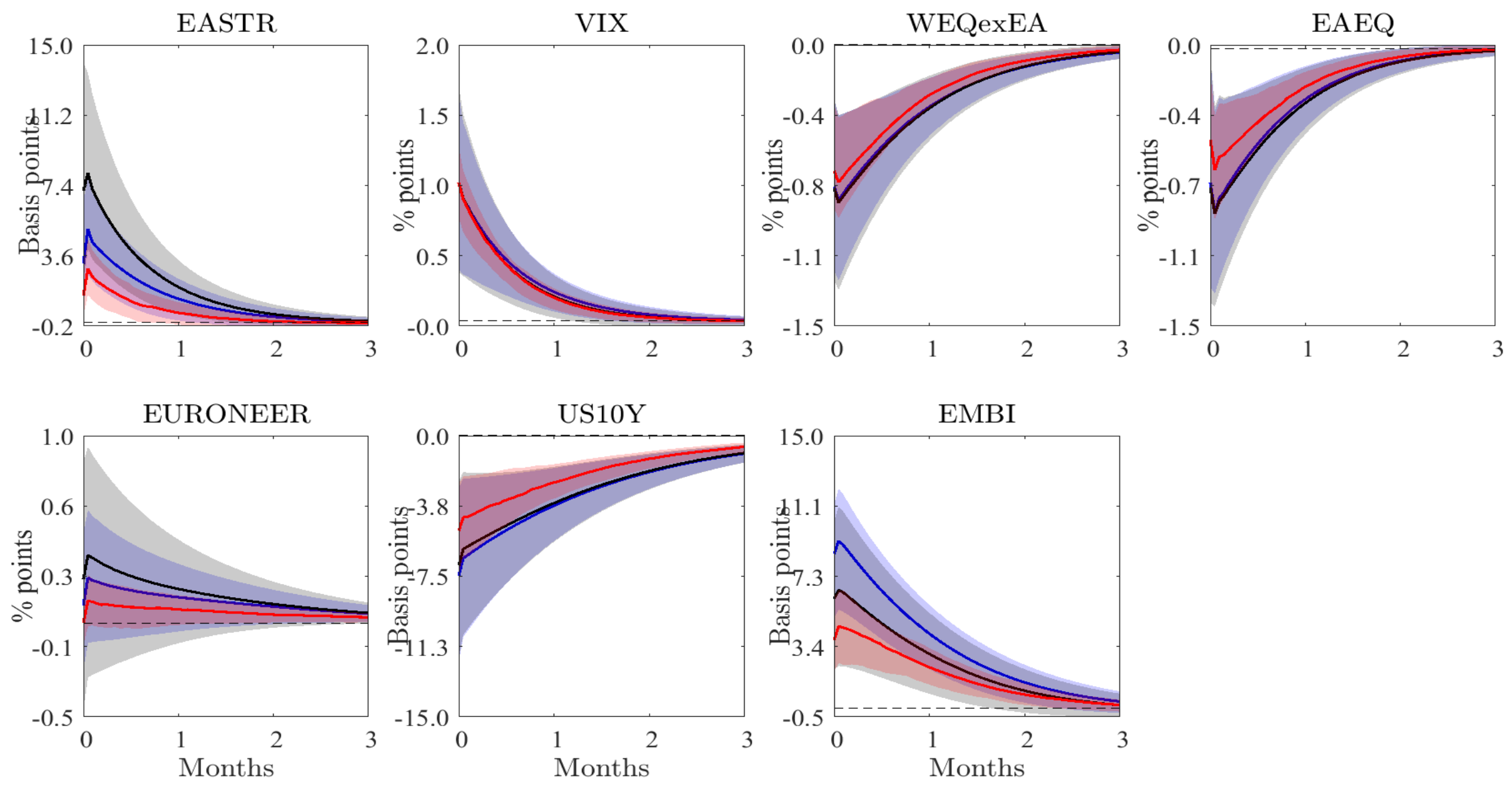

Notes: Shaded areas represent $68 \%$ HPD credible sets.

Source: Authors' calculations. 


\section{C.3 Lag length}

In this section we discuss the choice of the lag length made in the baseline setting $(p=2)$. Notably, we take into consideration one of the most popular Bayesian model comparison criteria, which is based on posterior marginal likelihood. This particular approach is generally found more suitable compared to standard information criteria, which might provide contrasting indications ${ }^{31}$. In this context, we compute the marginal likelihood by making use of the methodology proposed by Chan and Eisenstat (2018), which is based on integrated likelihood, for $p=1, \ldots, 4$ (Table C.4). Results suggest the the $\operatorname{VAR}(2)$ specification is the one delivering the maximum (log-)likelihood value.

Table C.4: Estimated posterior marginal likelihood

\begin{tabular}{c|cccc}
\hline \hline Lag length & $p=1$ & $p=2$ & $p=3$ & $p=4$ \\
\hline Marginal likelihood & -2997 & $\mathbf{- 2 4 0 4 . 6}$ & -2581.5 & -2775.9 \\
& $(0.00)$ & $(0.00)$ & $(0.01)$ & $(0.01)$ \\
\hline \hline
\end{tabular}

Notes: Standard errors in parentheses. Refer to Chan and Eisenstat (2018) for technical details.

We then check whether this specification is able to fully grasp the dynamics of the data. Notably, we test for the normality and autocorrelation of reduced-form residuals (i.e., $\mathrm{u}_{t}=A_{0}^{-1} \varepsilon_{t}$ ) after estimating the baseline setting of Equation (2.1). Figure C.5 and Figure C.6 show that the residuals follow a standard normal distribution. A quick look at Figure C.7 also shows no autocorrelation in the estimated residuals, which is also confirmed by the Ljung-Box Q test.

\footnotetext{
${ }^{31}$ In our case, the lag length suggested by the Schwartz information criterion would be $p=1$, while Akaike and Hannan-Quinn criteria would deliver $p=4$, thus suggesting a fairly different specification.
} 
Figure C.5: QQ-plots for residuals of $\operatorname{SVAR}(2)$
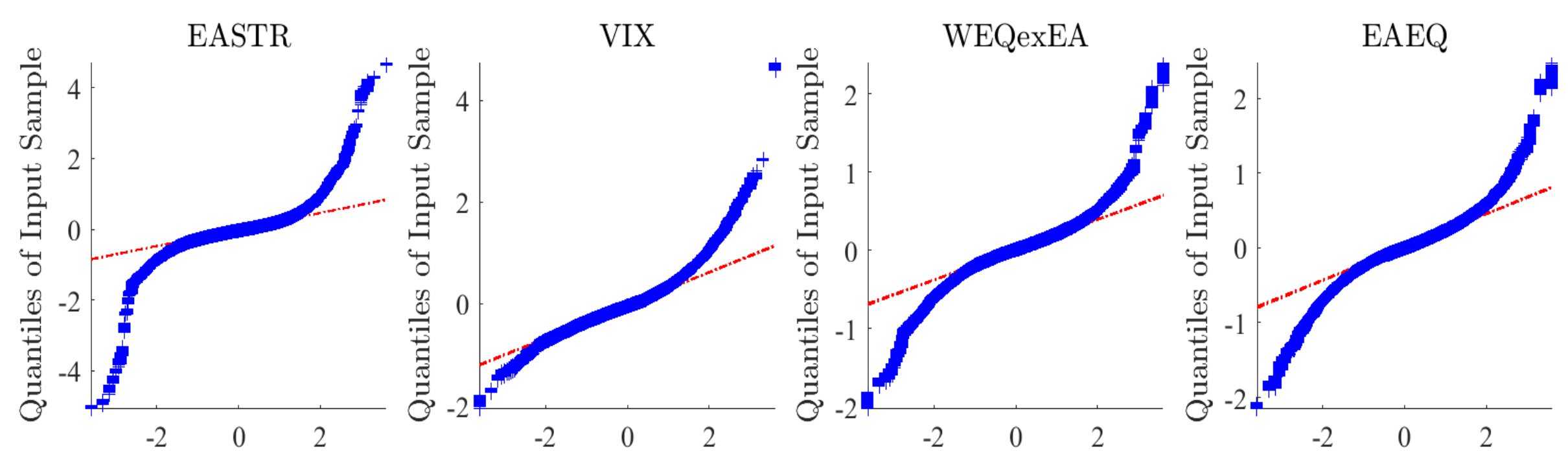

Standard Normal Quantiles Standard Normal Quantiles Standard Normal Quantiles Standard Normal Quantiles
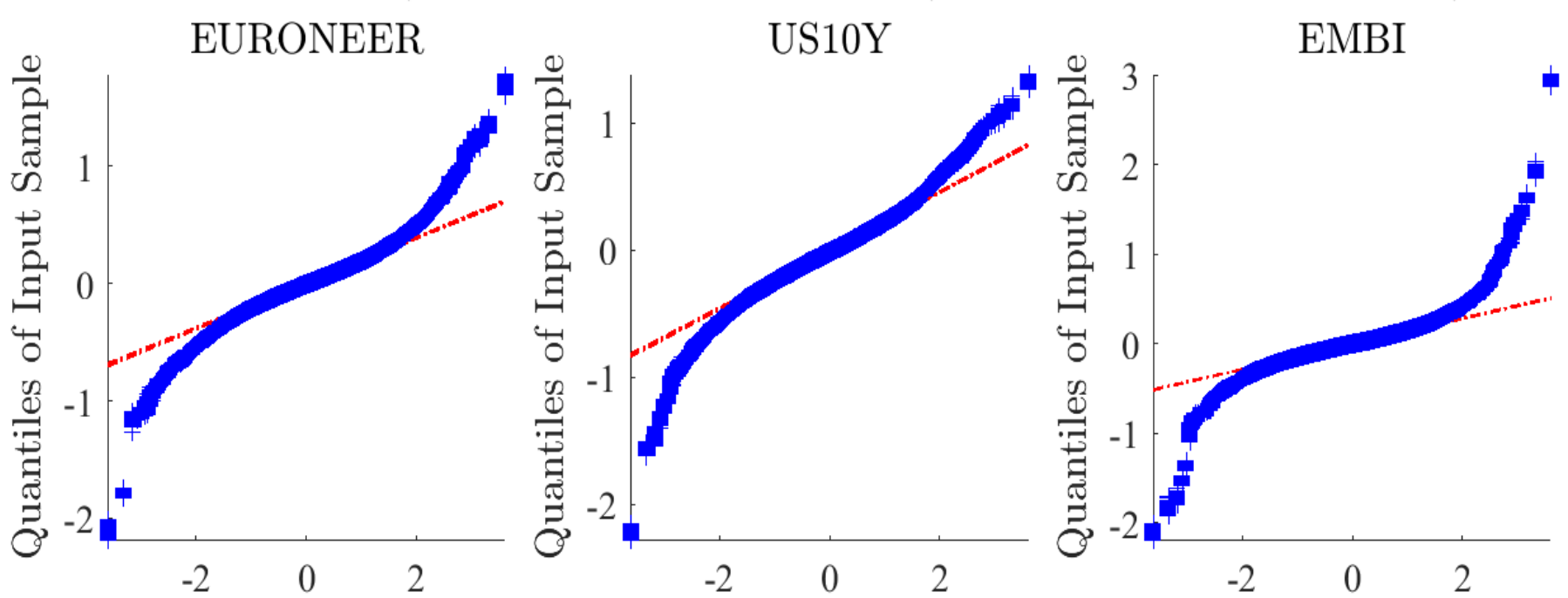

Standard Normal Quantiles Standard Normal Quantiles Standard Normal Quantiles 
Figure C.6: Posterior densities for residuals from Equation (2.1)
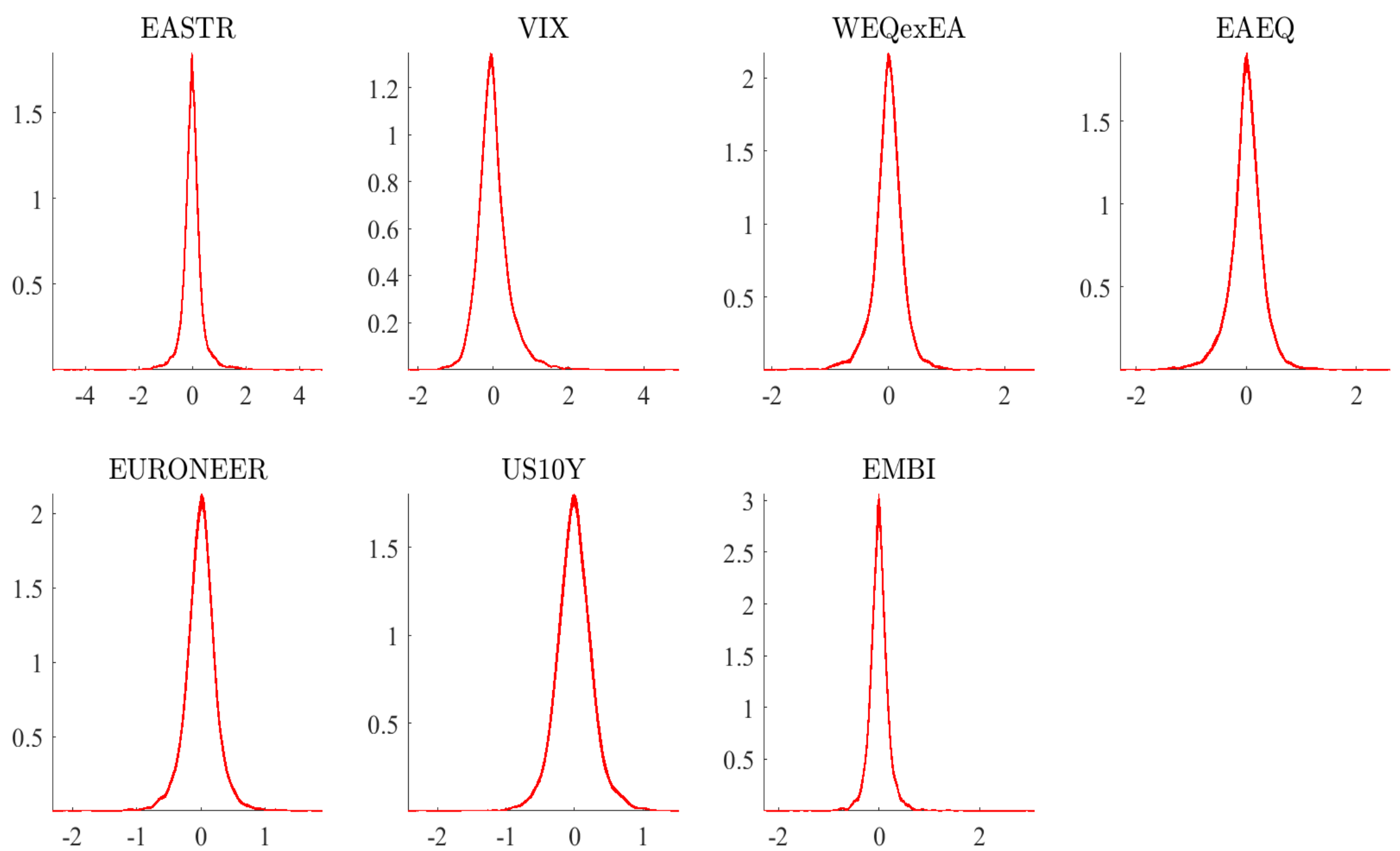

Notes: These charts plot the posterior densities of the vectors in $\mathrm{u}_{t}=A_{0}^{-1} \varepsilon_{t}$. Source: Authors' calculations. 
Figure C.7: Autocorrelation functions for residuals of SVAR(2)
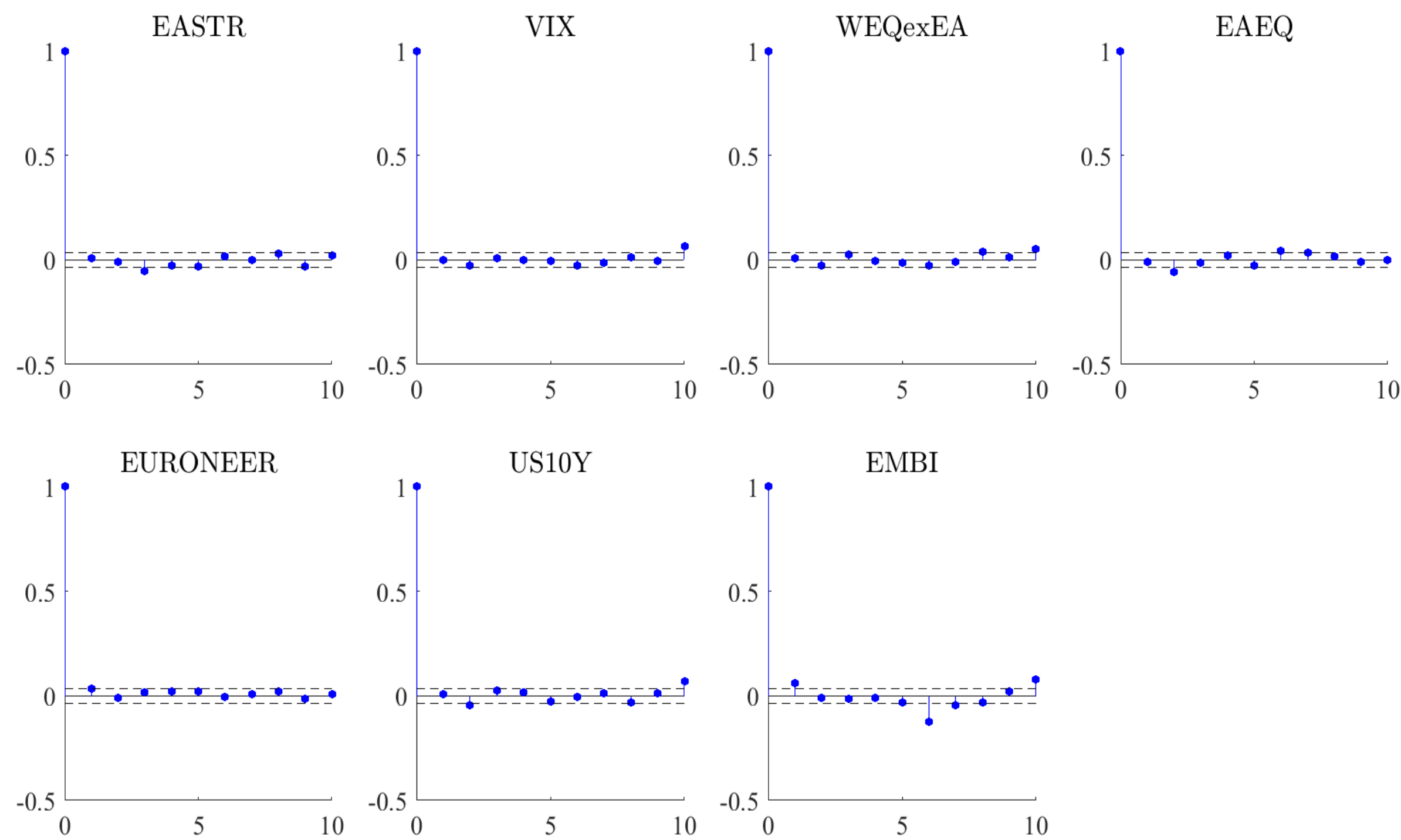

Notes: Dashed lines represent $90 \%$ confidence bands. 


\section{Local projections}

\section{D.1 Variance decomposition}

This section explains the methodology adopted to estimate the forecast error variance decomposition of panel local projections in Section 3. In particular, we extend the approach devised by Gorodnichenko and Lee (2019) to a panel setting.

Notably, the estimated residuals of Equation (3.1), $\hat{\nu}_{i, h, t+h}$, are considered as the estimate of the forecast error, $\hat{f}_{i, t+h \mid t-1}$, where $\left.f_{i, t+h \mid t-1}=\left(y_{i, t+h}-y_{i, t-1}\right)-P\left[y_{i, t+h}-y_{i, t-1} \mid \Omega_{i, t-1}\right]\right)$, and $\left.P\left[y_{i, t+h}-y_{i, t-1} \mid \boldsymbol{\Omega}_{i, t-1}\right]\right)$ is the projection of $y_{i, t+h}-y_{i, t-1}$ onto $\boldsymbol{\Omega}_{i, t-1}=\left[\varepsilon_{t}^{z}, x_{i, t-1}, \ldots, x_{i, t-p}, \boldsymbol{Z}_{t-1}\right]$. Consequently, the forecast error can be decomposed as variations of $\varepsilon_{t}^{z}$ as follows:

$$
f_{i, t+h \mid t-1}=\psi_{z, 0} \varepsilon_{t+h}^{z}+\cdots+\psi_{z, h} \varepsilon_{t}^{z}+\eta_{t+h \mid t-1}
$$

Specifically, the share of variance explained by $\varepsilon_{t}^{z}$ at horizon $h$ is:

$$
s_{h}=\frac{\operatorname{var}\left(\psi_{z, 0} \varepsilon_{t+h}^{z}+\cdots+\psi_{z, h} \varepsilon_{t}^{z}\right)}{\operatorname{var}\left(f_{i, t+h \mid t-1}\right)}
$$

which can be rewritten as:

$$
s_{h}=\frac{\operatorname{covar}\left(f_{i, t+h \mid t-1}, Z_{t}^{h}\right)\left[\operatorname{var}\left(Z_{t}^{h}\right)\right]^{-1} \operatorname{covar}\left(Z_{t}^{h}, f_{i, t+h \mid t-1}\right)}{\operatorname{var}\left(f_{i, t+h \mid t-1}\right)},
$$

where $\left.\boldsymbol{Z}_{t}^{h}=\left[\varepsilon_{t+h}^{z}, \ldots, \varepsilon_{t}^{z}\right)\right]$. At each horizon $h$ we run the following regression:

$$
\hat{f}_{i, t+h \mid t-1}=\alpha_{z, 0} \varepsilon_{t+h}^{z}+\cdots+\alpha_{z, h} \varepsilon_{t}^{z}+v_{i, t+h \mid t-1} .
$$

The estimator of the forecast error variance decomposition at horizon $h, \hat{s}_{h}^{R^{2}}$, is then given by the $R^{2}$ of Equation (D.2).

\section{D.2 Different sample coverage}

In this section we re-estimate Equation (3.1) over a panel of countries that excludes (non-EA) EU members as of July 2019. Results, reported in Table D.5 and displayed in Figures D.8 and D.9 below, are not statistically different from what already discussed in Section 3.1. Our analysis is then found robust to the presence of these countries in the sample. 
Figure D.8: Extra-EU Advanced economies - Impulse responses to a positive one s.d. euro stress shock (blue) and a positive one s.d. global risk aversion shock (red)

(a) Industrial production

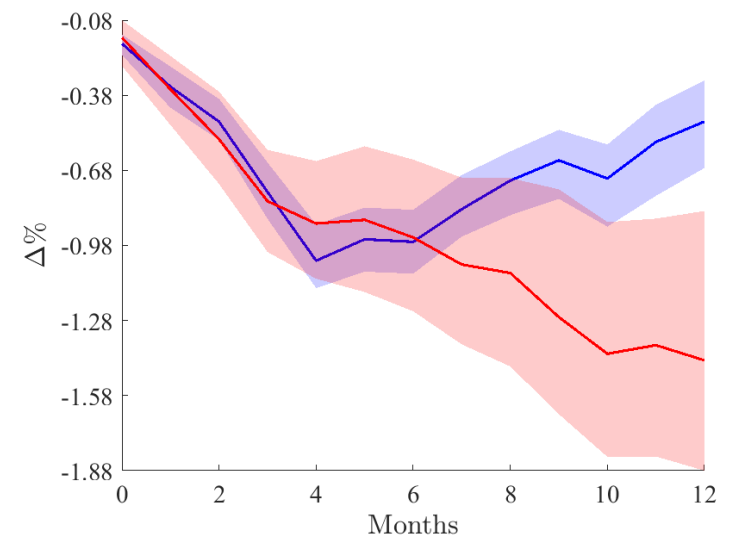

(c) Exports to euro area

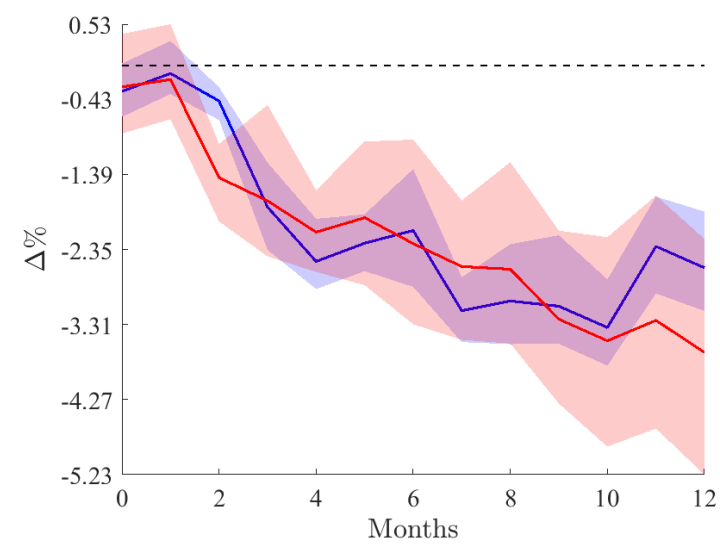

(e) Exports to RoW

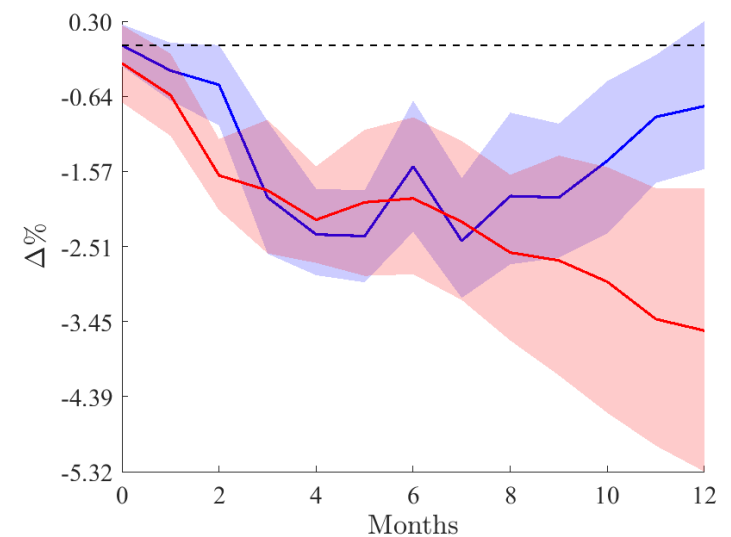

(b) Inflation

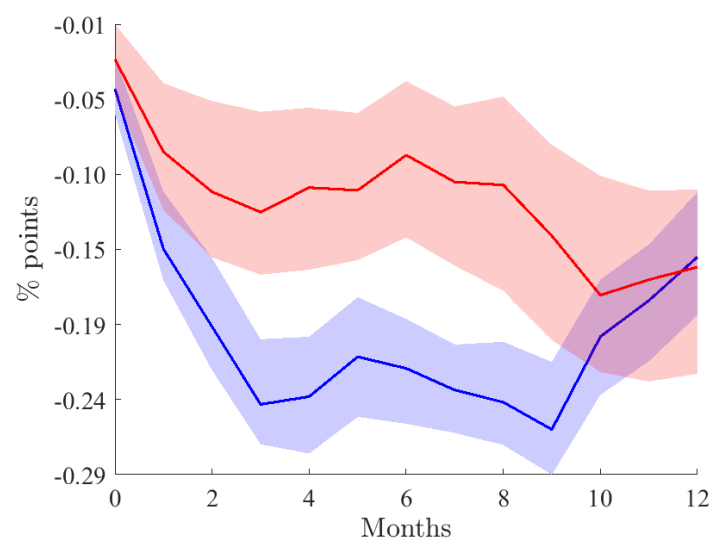

(d) Imports from euro area

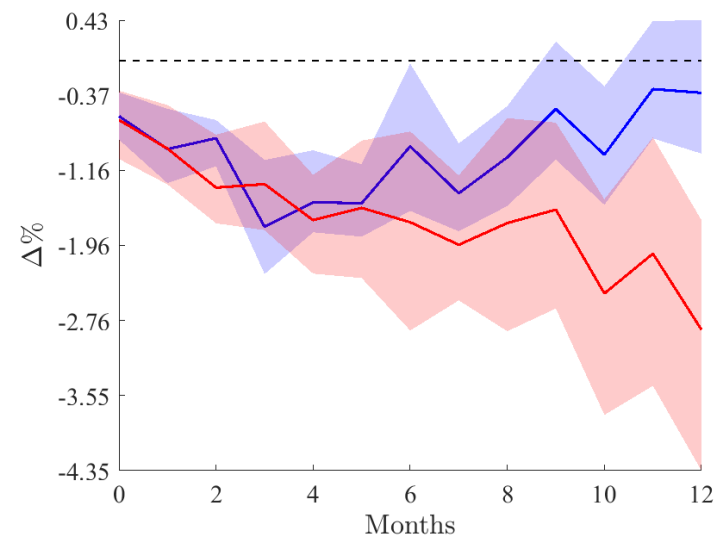

(f) Imports from RoW

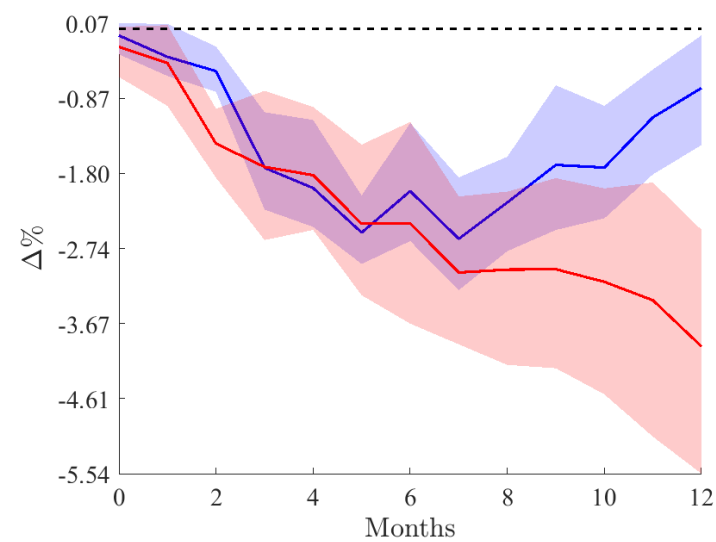

Notes: Inflation is defined as the y-o-y percentage change of the CPI. $\Delta \%$ : log-change. Shaded areas are $68 \%$ HPD credible sets.

Source: Authors' calculations. 
Figure D.9: Extra-EU Emerging and developing economies - Impulse responses to a positive one s.d.euro area stress shock (blue) and a positive one s.d. global risk aversion shock (red)

(a) Industrial production

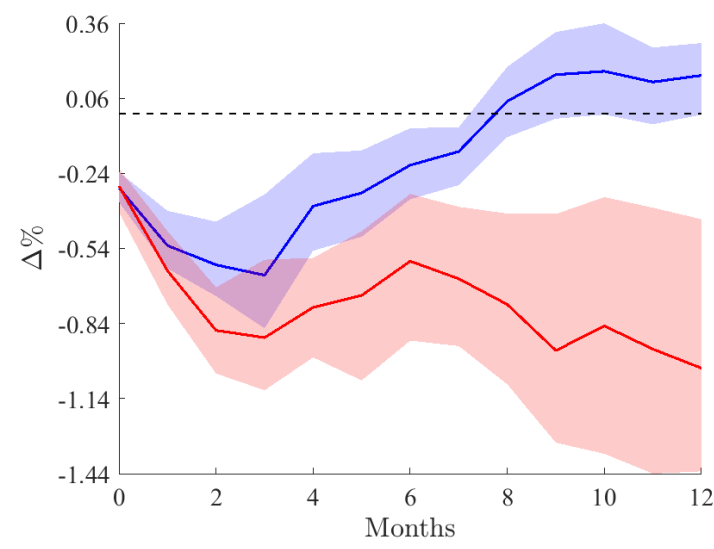

(c) Exports to euro area

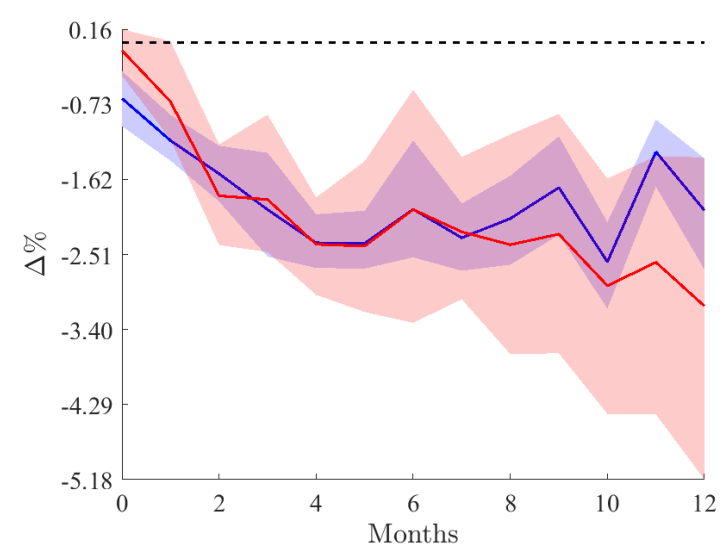

(e) Exports to RoW

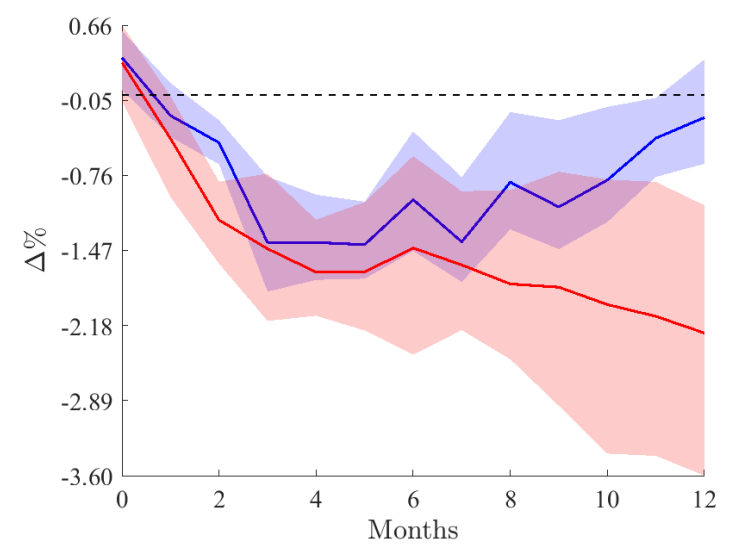

(b) Inflation

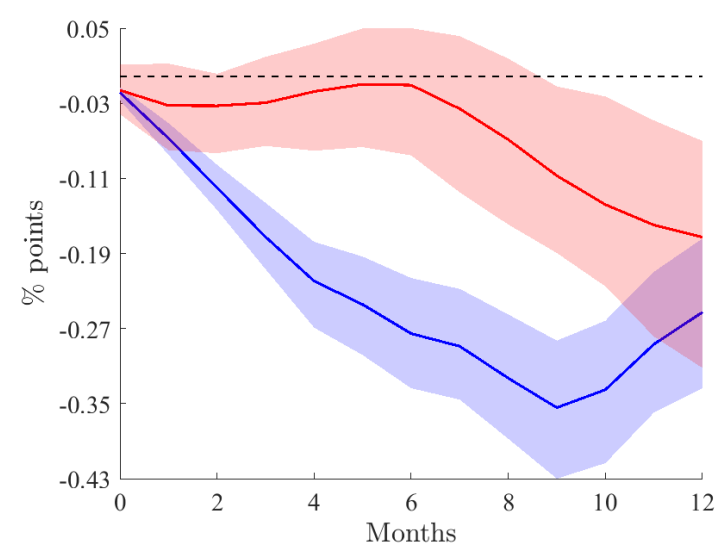

(d) Imports from euro area

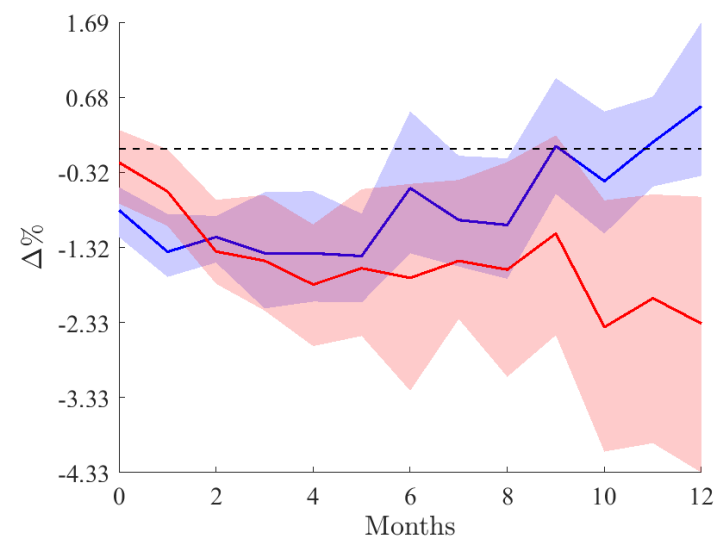

(f) Imports from RoW

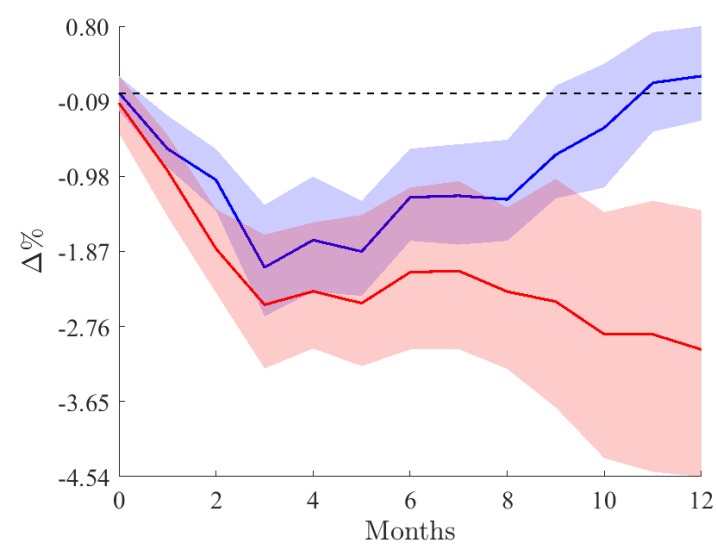

Notes: Inflation is defined as the y-o-y percentage change of the CPI. $\Delta \%$ : log-change. Shaded areas are $68 \%$ HPD credible sets.

Source: Authors' calculations. 
Table D.5: Maximum impact of euro area stress and global risk aversion shocks

\begin{tabular}{|c|c|c|c|c|c|c|}
\hline \multirow{2}{*}{ Shock $\quad$ Variable } & \multirow[t]{2}{*}{ IP } & \multirow[t]{2}{*}{ Inflation } & \multicolumn{2}{|c|}{ Exports to } & \multicolumn{2}{|c|}{ Imports from } \\
\hline & & & EA & RoW & EA & RoW \\
\hline \multicolumn{7}{|c|}{ Extra-EU Advanced Economies } \\
\hline $\mathrm{EA}$ & $\begin{array}{c}-1.02 \% \\
(6)^{*}\end{array}$ & $\begin{array}{c}-0.27 \mathrm{pps} \\
(9)\end{array}$ & $\begin{array}{c}-3.29 \% \\
(10)\end{array}$ & $\begin{array}{c}-2.28 \% \\
(7)\end{array}$ & $\begin{array}{c}-1.57 \% \\
(3)\end{array}$ & $\begin{array}{c}-1.94 \% \\
(5)\end{array}$ \\
\hline Global & $\begin{array}{c}-1.46 \% \\
(12)\end{array}$ & $\begin{array}{c}-0.16 \mathrm{pps} \\
(10)\end{array}$ & $\begin{array}{c}-4.14 \% \\
(12)\end{array}$ & $\begin{array}{c}-3.78 \% \\
(12)\end{array}$ & $\begin{array}{c}-2.76 \% \\
(12)\end{array}$ & $\begin{array}{c}-3.81 \% \\
(11)\end{array}$ \\
\hline \multicolumn{7}{|c|}{ Extra-EU Emerging Markets } \\
\hline EA & $\begin{array}{c}-0.48 \% \\
(2)\end{array}$ & $\begin{array}{c}-0.45 \mathrm{pps} \\
(9)\end{array}$ & $\begin{array}{c}-2.79 \% \\
(10)\end{array}$ & $\begin{array}{c}-2.01 \% \\
(3)\end{array}$ & $\begin{array}{c}-1.35 \% \\
(3)\end{array}$ & $\begin{array}{c}-1.28 \% \\
(5)\end{array}$ \\
\hline Global & $\begin{array}{c}-1.06 \% \\
(12)\end{array}$ & $\begin{array}{c}-0.16 \mathrm{pps} \\
(12)\end{array}$ & $\begin{array}{c}-3.04 \% \\
(12)\end{array}$ & $\begin{array}{c}-2.91 \% \\
(12)\end{array}$ & $\begin{array}{c}-2.50 \% \\
(12)\end{array}$ & $\begin{array}{c}-2.38 \% \\
(12)\end{array}$ \\
\hline
\end{tabular}

Notes: ${ }^{*}$ Numbers in parentheses represent the amount of months after a shock has taken place. 